\title{
The Hybrid Monumental Symbols of Canada's Warrior Nation Moment
}

\author{
by \\ Ian Alexander Mortimer
}

A thesis submitted to the Faculty of Graduate and Postdoctoral Affairs

In partial fulfillment of the requirements for the degree of

\author{
Master of Arts \\ In \\ Canadian Studies
Carleton University
Ottawa, Ontario

(C) 2014

Ian Alexander Mortimer 


\section{Abstract}

Since its majority re-election in 2011, the Harper government has led a project of re-branding of Canadian identity. This study focuses on three militaristic symbols from this project as important cultural texts unto themselves. All three share a Hybrid Monumental form, articulating a narrative of Canada as a Warrior Nation. They communicate a monumental vision of Canada as being defined by war and sacrifice for the nation. However, they are all polysemic symbols, hybridized through the layering of established symbols of Canadian identity within their representation, tempering their monumental messaging. These Hybrid Monumental symbols are the product of a mutual commitment amongst the Harper Government and key stakeholders to market themselves as iconic brands, in an attempt to forge a connection with a shared target audience. These symbols serve as markers of the reality of the adoption of iconic branding and marketing as a primary political strategy. This reality has created an environment where not even Canadian soldiers' deaths are immune from being co-opted and collapsed into brand marks, used to target certain customers and hopefully secure their votes, while remaining ambiguous enough to allow the brand's image to shift and move on when the market conditions change. 


\section{Acknowledgment}

Thank you to professors, Peter Hodgins, for your guidance, humor and confidence in me, Peter Thompson, for your encouragement and enthusiasm, Richard Nimijean, for inviting me to share my ideas with your students, and Aleksandra Bennett, for showing me I could do this in the first place.

Thank you to my parents, Elizabeth Elton and Brian Mortimer, for your continuing example of how to live thoughtfully, and your unwavering support.

Thank you to my wife, Jenna Contestabile, for everything.

This thesis is dedicated to my grandmother, Mary Mortimer, and her father Jack Robertson, who fought at Vimy Ridge, but could never speak of the horror of his war. 


\section{Table of Contents}

ABSTRACT II

ACKNOWLEDGMENT III

TABLE OF CONTENTS IV

LIST OF ILLUSTRATIONS V V

PREFACE 1

INTRODUCTION

CHAPTER 1: MONUMENTAL 29

CHAPTER 2: HYBRID $\quad 66$

CHAPTER 3: JUST ANOTHER BRAND $\quad 102$

\begin{tabular}{lr} 
CONCLUSION & 130 \\
\hline
\end{tabular}

$\begin{array}{lr}\text { BIBLIOGRAPHY } & 138\end{array}$ 


\section{List of Illustrations}

Figure 1 - Winnipeg Jet's New Logo ................................................................................. 30

Figure 2 - Canadian Fallen Firefighers Memorial................................................................. 32

Figure 3 - Vimy Ridge Twenty Dollar Bill .......................................................................... 34

Figure 4 - Jets Logo Breakdown Sources: Jets Logo ……………………………………... 42

Figure 5- Jets Logo's Past and Present................................................................................... 44

Figure 6 - Winnipeg Jets Brand Identity Slide Show, Slides 2 and 3 …………………... 45

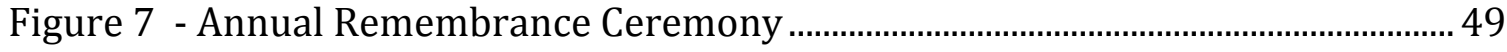

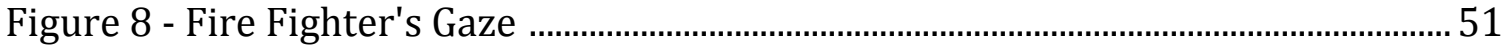

Figure 9 -Canadian National Vimy Memorial Details -.....................................................55

Figure 10 - The Crop Twenty Dollar Bill ............................................................................ 56

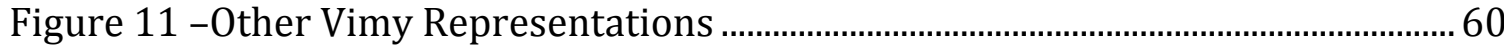

Figure 12 - Design of Canadian Fallen Firefighters Memorial - ........................................ 77

Figure 13 - Canadian Fallen Firefighters Foundation Logo ………….......................... 91

Figure 14 - Vimy Twenty Dollar Bill Launch, Novmber 7, 2011 ................................... 114 


\section{Preface}

Like most hockey fans across Canada, I was excited to hear the news in May 2011 that after a 15 year break, the National Hockey League (NHL) would be returning to Winnipeg. News video spread images of excited fans gathering at the corner of Portage and Main in Winnipeg, decked out in their old Winnipeg Jets gear, chanting 'Go Jets Go' and stopping traffic with impromptu games of street hockey. ${ }^{1}$ These chants at Winnipeg's iconic downtown intersection were an immediate indication of the popular choice among fans of Jets for the name of the new NHL franchise. Speculation mounted through the month of June over what nickname the ownership would choose. Through these weeks the nostalgic choice of the Jets persisted as the front-runner, with fans petitioning the new owners with a flood of emails supporting a return of the Jets name, ${ }^{2}$ and an informal poll by the local CBC news showing a strong majority supported the old names' return. ${ }^{3}$ Team chairman and co-owner Mark Chipman finally ended the speculation at the 2011 NHL Draft on June $24^{\text {th }}$, announcing that the team would re-adopt the former

\footnotetext{
${ }^{1}$ CBC Sports. 'Winnipeg Cheers Return of Jets.' CBC Sports cbc.ca, May 31, 2011. http://www.cbc.ca/news/canada/manitoba/winnipeg-cheers-return-of-nhl1.1062589

2 Ibid.

${ }^{3}$ CBC News."Hockey: What should Winnipeg's NHL team be called?" CBC NEWS: Community Blog, June 21, 2011.

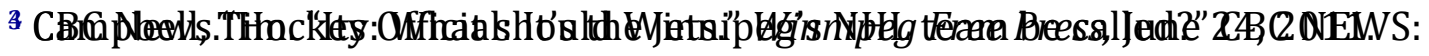

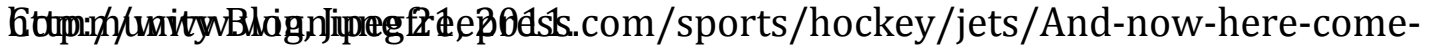


franchises' nickname of the Jets. ${ }^{4}$ This readopting of the Jets name was possible because the NHL itself had retained the rights to the name, and the league's leadership was willing to offer its use to the new owners of the franchise. When the now officially named Jets announced their draft picks, the young men selected by the team were handed on stage, not a new jets logo, but instead a generic NHL hockey sweater; the name was settled but the logo and jersey were still a mystery. Not surprisingly, for what do sport media pundits and fans alike do better than speculate, the discussion around NHL hockey's return to Manitoba quickly shifted to the subject of what the team's hockey sweater and logo would look like. The Jets were coming home, and the re-adoption of this name immediately created a connection to pro hockey's history in the city. But, the question now shifted to the team's visual identity; would the owners look to the team's history to recreate imagery used by the former franchise, or were they looking to move the visual representation of the team's identity in a new direction? It was the answering of this question, with the release of the Jets logo on July 22, 2011, which sparked this project.

My first sight of the logo was in an article in The Globe and Mail the day of its release. The logo's direct use of both the RCAF roundel, and the silhouette of a CF-18 in its design immediately took me aback. From my perspective the logo was crafting an entirely new definition of the nickname the Jets, centered on Canada's military present and past. Reading commentary on the release of the logo, I saw I

${ }^{4}$ Campbell, Tim. “Its Official: It's the Jets.” Winnipeg Free Press, June 24, 2011. http://www.winnipegfreepress.com/sports/hockey/jets/And-now-here-comeThe-Jets--124498414.html 
was not alone in taking note of the militaristic theme of the logo. The comments of Mark Chipman, reinforced at the unveiling of the logo that the connection I was reading in the logo was completely intended. "We wanted to make it authentic, bring authenticity to the old Jets name, " Chipman declared after showing off the new design; "we believe the new logo does that through its connection to our country's remarkable Air Force heritage." ${ }^{\prime 5}$ It was this statement that really made me begin to see this logo as holding a wider significance. In adopting this logo, the owners of the team clearly had confidence that the consumers of hockey in Winnipeg and the diaspora of Winnipeggers across the country, the potential buyers of all the merchandise with this logo on it, would not just be comfortable with its militaristic symbolism and its unabashed jingoism, but would indeed find it "really authentic". Reading commentary after the Jets logo's unveiling, I came across an article written by Winnipeg singer and songwriter John K. Samson, reflecting on his own reaction to the release of the Jets logo titled, The New Jets Logo, a Boardroom, and a Bargain. Samson strongly articulated the feeling that had been nagging me since I first saw the logo. Speaking of the image of the CF-18 fighter jet as the focus of the logo Samson asserted that, "at the very least, putting such a weapon on a logo that every hockey-loving Winnipegger should feel enthusiastic to wear, both here at home and while traveling outside our city, a logo that children will draw and redraw with crayons innumerable times, is a decision

${ }^{5}$ Mirtle, James. "Winnipeg Jets Unveil Logo," The Globe and Mail, July 22, 2001. http://www.theglobeandmail.com/sports/hockey/globe-on-hockey/winnipegjets-unveil-logo/article616579/ 
we should ask some serious questions about."6 This thesis is an attempt to do exactly what Samson suggests; it asks serious questions of the Jets logo, and other contemporary jingoistic symbols presenting Canada as a Warrior Nation.

${ }^{6}$ Samson, John K. "The New Jets Logo, a Boardroom, and a Bargain," The Winnipeg Review, August 2, 2011. http://www.winnipegreview.com/wp/2011/08/the-newjets-logo-a-boardroom-and-a-bargain/ 


\section{Introduction}

When the results of Canada's 41 ${ }^{\text {st }}$ Federal election held on May 2, 2011 were tabulated, it became clear that after three tries Stephen Harper had led the Conservative Party of Canada to a coveted majority government. Part of the postelection policy adopted by the Harper Government from its new, secure political position, was a program of creating and promoting new symbols of Canadian identity. Jane Taber noted the impetus for this focus on identity production and representation in her syndicated column in The Globe and Mail. Taber sharply declared that, "Stephen Harper is working to recast the Canadian identity, undoing 40 years of a Liberal narrative and instead creating a new patriotism viewed through a conservative lens." ${ }^{7}$ She argued that the Tories were encouraging this new patriotism by "pursuing symbols and areas" such as "monarchy, the arctic, the military, and national sports." ${ }^{8}$ These symbols and cultural areas were specifically being promoted as replacements for those favoured by previous Liberal Governments such as, "multiculturalism, the Canadian Charter of Rights and Freedoms and peacekeeping." 9 The motivations for this process of re-branding the nation on the part of a sitting government are deeply political. In presenting a new narrative of Canadian Identity, specifically focused on certain areas and symbols, an alternative way to understand both Canada's past, present and future is offered.

7 Taber, Jane. "Harper spins a new brand of patriotism," The Globe and Mail, August 19, 2011. http://www.theglobeandmail.com/news/politics/ottawanotebook/harper-spins-a-new-brand-ofpatriotism/article618385/\#dashboard/follows/ ${ }^{8}$ Ibid.

${ }^{9}$ Ibid. 
By promoting their own alternative narrative, the Harper conservatives are looking to promote themselves in turn as the new 'natural governing party', placing themselves as the true champions of Canadian identity. The hope in this strategy is that by creating a branding strategy, which harmonizes the image of the Prime Minister, The Conservative Party and the entire nation, voters will identify and essentially 'buy' this cultural product, by voting for the Conservatives in elections to come. Richard Nimijean described the importance of a government's branding of the nation's identity in their own image, while they hold the reins of power in his article, Articulating the 'Canadian Way': Canada(TM) and the Political Manipulation of the Canadian Identity. Nimijean argues that branding of the nation, the constant manipulation, and focus on "[i]mage and reputation are [...] becoming essential parts of the state's strategic equity." 10 This commitment to branding as a political strategy imagines the identity of the nation as a product, packaged and sold to potential costumers. Nimijean points this out asserting that, "like branded products, branded states depend on trust and customer satisfaction."11

A string of militaristic symbols appeared within the sphere of influence of the Harper Government after their electoral triumph in 2011 and into the following year. It began with the announcement by the Minister of Defence in August 2011, that the Royal pre-fix would be returned to the official name of the

\footnotetext{
${ }^{10}$ Nimijean, Richard. "Articulating the 'Canadian Way': Canada(TM) and the Political Manipulation of the Canadian Identity." British Journal of Canadian Studies, 18.1 (2005): 26,52,206. ProQuest. Web. 27 Feb. 2014.

11 Ibid.
} 
Canadian Naval and Air Forces, undoing a change that was enacted in $1968 .{ }^{12}$ The name change was paired with a return in prominence of old symbols of the military, including the RCAF roundel which had been chosen as the inspiration of the Winnipeg Jets logo less than a month earlier. ${ }^{13}$ Later, on October $9^{\text {th }}$, Prime Minister Harper flew to Winnipeg for the Jets' first home game. While there he posed for a photo-op with a specially minted coin featuring the Jets' new logo. On

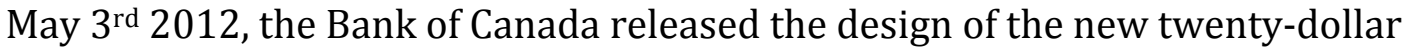
bank note with a representation of the Canadian National Vimy Memorial as the focus of its artwork. ${ }^{14}$ Then during the London Olympic Games in July and August, a government-sponsored television commercial titled "The Fight For Canada” was aired which dramatized the War of 1812 and promoted the two-year celebration of the conflict, funded by the Federal Government. ${ }^{15}$ In September 2012, a massive golden firefighter statue was unveiled as the centerpiece of the thoroughly military-inspired Canadian Fallen Firefighters Memorial in Ottawa. ${ }^{16}$ Finally, at the end of October 2012, a new Canadian passport was unveiled containing a visual history of Canada through its pages; the narrative represented puts considerable

${ }^{12}$ CTV News. "McKay: Renming military corrects 'historical mistake," CTV News, August 16, 2011. http://www.ctvnews.ca/mackay-renaming-military-correctshistorical-mistake-1.684081

13 Ibid.

14 Vimy Foundation."The Bank of Canada Launches New Vimy-Themed \$20 Bill," Vimy Foundation. Accessed May 17, 2014. https://www.vimyfoundation.ca/node/212 15 Government of Canada."The Fight For Canada - War of 1812 Advertisement," YouTube Video, July 3, 2012. https://www.youtube.com/watch?v=s4i_qe9W6Dk. 16 Royal Canadian Legion. "Memorial Unveiled For Fallen Firefighters," Legion Magazine, November 24, 2012. http://legionmagazine.com/en/index.php/2012/11/memorial-unveiled-forfallen-firefighters/ 
focus on the military and a sanitized representation of war. ${ }^{17}$ All of these examples focus on narratives of Canada as being an essentially militarized space. They were all partially funded, approved or directly created by the Harper Government. This string of prominent symbols, illustrate that the brand of Canada that the Harper Government felt their target costumers would trust and be satisfied with, was a militarized one.

Looking at the recent history of Canada, it is not surprising that the relationship of the nation with war would be something that the government felt it needed to address in its communications strategy. Though it is has not always been readily perceptible, the Afghanistan War has had an important impact on the collective experience of Canadians. This prolonged engagement for the Canadian Forces, and the heavy human cost of 162 Canadian's losing their lives in the war, has been a defining element of the Canadian national experience in the $21^{\text {st }}$ century..$^{18} \mathrm{~A}$ generation has come of age in a nation at war, not with an easily defined enemy, but as part of the larger paradigm of the War on Terror. Although there has often not been a clear idea in this conflict of who the 'enemy' is, and what the true objectives of war in this paradigm are, the losses are concrete, human and painful to the nation. In Canada, the Afghanistan War has provided a particularly sharp contradiction in the national identity construction. Because the myth of

17 Raj, Althia. "New Canadian Passports: Tories Pushed Design in a Historical Direction," The Huffington Post, October 10, 2012. http://www.huffingtonpost.ca/2012/10/25/new-canadian-passportsepassports_n_2016055.html\#slide=1690113 18 The Canadian Press. "Canadian Involvment in Afghanistan Formally End," The Canadian Press, March 12, 2014. http://www.cbc.ca/news/world/canadianmilitary-involvement-in-afghanistan-formally-ends-1.2569162 
Canada as being a peaceful nation, only engaging in martial operations in the context of peacekeeping, had been a longstanding and popular narrative of Canadian identity, the fact that Canadians were fighting overseas for a decade presented a challenge, and essentially destroyed this peacekeeper myth. In his text, Yellow Ribbons: The Militarization of National Identity in Canada, A.L McCready argues that cultural texts, such as the string of representations listed above, need to be understood as being shaped by this cultural climate. He argues that war has shaped the cultural landscape more than Canadians may be actively conscious of. Because of this, "cultural texts produced under the War on Terror form one important lens through which to study the shift in military values currently underway in Canada, and to discuss the cultural production of that shift."19

With a self-imposed deadline set by the Harper Government for the withdrawal of active troops in July 2011, the need to brand the conflict as both justified and as having achieved some measure of success came to a head. As had been shown by the American experience in Iraq, and specifically by George W. Bush and his infamous 'Mission Accomplished' banner, declaring an orthodox victory in warfare within the War on Terror paradigm can be a foolhardy move. With internal conflict still raging in Afghanistan, and with the threat of terrorist attacks still looming in North America, it was easy to argue in 2011 that no clear success had been gained after the Canadian Forces' decade at war. This tough fact made the move to present the military and war as inherently part of the Canadian

${ }^{19}$ McCready, A.L. Yellow Ribbons: The Militarization of National Identity in Canada. (Halifax: Fenwood Publishing, 2013). P. 64 
identity as part of the Harper Government branding strategy as the Afghanistan conflict wound down a solid tactic. This strategy looked to pull the focus away from the Afghanistan conflict, or any conflict specifically, and instead present Canada as being defined by its military and its role as a warrior. The questions of why we were fighting in Afghanistan and if it was either justified or successful are then not as relevant; Canadians were doing what Canadians have always done, according to this narrative, fighting wars. With the deadline for Canada's withdrawal from fighting in Afghanistan set as a election year commitment, the Harper Government entered the general election campaign of spring 2011, with the political legacy of this war still up for discussion and the need for a way to understand the conflict pressing. With the election of 2011 looming and a chance to overturn the Liberal-inspired myths of Canadian Identity, the Harper Government ramped up its own brand as being a supporter of the military, and it began to actively encourage a vision of Canada as being essentially a nation naturally disposed to war.

This process did not go unnoticed in academic circles. Queen's University historian Ian McKay was one of the earliest and most vocal critics of the Harper Government program of promotion of the military in the period leading up to the general election of May 2011, and the Afghanistan withdrawal. His observations on this program were first presented in his keynote address titled, The Empire Strikes Back: Militarism, Imperial Nostalgia, and the Right-Wing Reconceptualization of Canada, delivered at the $15^{\text {th }}$ annual New Frontiers Graduate History Conference at York University. McKay argued that there was underway a, "concerted effort on the 
part of the Conservative government and it supporters, to promote the military and forge a new reading of Canadian identity that put the military and war as central to understanding being Canadian."20 Ian McKay describes this promotion of a new heroic, jingoistic rhetoric around the Canadian military as a, "growing marginalization of peacekeeping as a Canadian ideal, and its replacement by a very different, very aggressive warrior ethos." ${ }^{21}$ In this lecture, MacKay labeled this new narrative of Canadian identity Warrior Nation, which would serve as the title for a subsequent book co-authored with Jamie Swift. Howard Fremeth also captured the genesis of McKay's concept of the myth of Warrior Nation in his Ph.D. thesis, Memory, Militarism and Citizenship: Tracking the Dominion Institute in Canada's Military Cultural Network. Fremeth describes a concerted effort between Conservative politicians and their circle of influence to spark a cultural shift to move Canada from, "a society that once preferred only to speak about its military in an unmilitaristic way, if at all, to a warrior culture."22 In their text, McKay and Swift provide a more detailed explanation of the Warrior Nation myth first described by McKay, Fremeth and the larger project pointed out by Taber;

“Canada's new myth-symbol complex entails an aggressive campaign to substitute the Warrior Nation for the peaceable kingdom - including a

\footnotetext{
${ }^{20}$ McKay, Ian. "Empire Strikes Back: Militarism, Imperial Nostalgia, and the RightWing Reconceptualization of Canada," Lecture at the New Frontiers Graduate Conference, March 15, 2011. http://activehistory.ca/2011/03/podcast-ian-mckayon-the-right-wing-reconceptualization-of-canada/

21 Ibid.

${ }^{22}$ Fremeth, Howard D. Memory, Militarism and Citizenship: Tracking the Dominion Institute in Canada's Military Cultural Network. PhD. Thesis. (Ottawa: Carleton University, 2011) p. 8
} 
no-holds barred attack on the "myth" of peacekeeping as a key component of the Canadian Identity... New warriors have targeted what they take to be the most pernicious myths and symbols of post-1960's Canada: the Charter of Rights and Freedoms, bilingualism, multicultural relativism, gender equality, and peacekeeping. In their place they promote religious fundamentalism, the military, manly sports, the special relationship with the Untied States and Britain, and the British monarchy - all now described as core attributes of Canada."23

The string of symbols that appeared in the period after the 2011 General Election, fit McKay and Swifts description. They are articulations of the mythsymbol complex described as Warrior Nation, a term adopted in this study. They represent an important component of the Government-lead nation branding described by Nimijean and Taber. These symbols are essentially propaganda, recounting a new narrative of Canadian identity.

In July 2011 a few months after Harper won his majority and at the same time as Canadian troops were officially wrapping up the official mission to Afghanistan, the latest incarnation of the Winnipeg Jets of the NHL unveiled their logo. At the logo's unveiling, Mark Chipman co-owner of the team, described the organizations' goal in the designing of the new symbols as a desire, "to authenticate the name and make it as meaningful as we possibly could." 24 The logo which they decided fulfilled this goal, can best be described as an adaptation of the Royal Canadian Air force's historical Roundel, with a CF-18 layered onto the central maple leaf. The logo is a striking example of a visual articulation of the Warrior Nation myth of Canadian identity. However, the Jet's logo did not, at first

${ }^{23}$ McKay, Ian and Jamie Swift. Warrior Nation: Rebranding Canada in an Age of Anxiety. (Toronto: Between The Lines Publishing, 2013). p270

${ }^{24}$ CBC News. "Winnipeg Jets Unveil New Logo" CBC News - CBC.CA, July 22, 2011. http://www.cbc.ca/sports/hockey/winnipeg-jets-unveil-new-logo-1.1041454 
appearance, seem to fit in with the other examples listed above; there did not seem to be a direct connection to the Harper government and its nation-branding program. As a hockey team, privately owned and looking to turn a profit, was it a stretch to read this symbol as part of a larger shift in Canadian culture? Did the logo fit into the program of government endorsed and created symbols promoting the military, or was it proof that the Warrior Nation project was being effective in shifting popular conceptions of Canadian identity? As the weeks passed leading up to puck drop in the new era of the Winnipeg Jets, the support for the logo by the military and the Harper Government began to hint that there was a deeper connection than coincidence, or even indirect influence. The connection between the team and the then newly renamed Royal Canadian Air force was heavily promoted at the launch of the team's jerseys, on September $6^{\text {th }}, 2011.25$ The launch was held, not at the MTS Arena where the Jets play their home games, but at the Royal Canadian Air Force base in Winnipeg. ${ }^{26}$ At the unveiling, four of the team's players emerged from the back of a Royal Canadian Air Force Hercules aircraft, with pump up music blaring and lights flashing, to be photographed in the new jerseys. ${ }^{27}$ The setting and cheesy entrance out of a combat support aircraft, reinforced the visual linkage made in the logo itself. The team was clearly using a partnership with the Department of Defense to create a break with past

25 CBC News. "Winnipeg Jets Unveil New Jerseys" CBC News Manitoba, September 6, 2011. http://www.cbc.ca/news/canada/manitoba/winnipeg-jets-unveil-newjerseys-1.1051695

26 Ibid.

27 Ibid. 
associations with the Jets nickname and brand, building a new militarized definition for the 'Jets' name.

The endorsement of the Jets logo was taken to a national, and much more directly political level the weekend of the team's first home game in October 2012 . During the broadcast of the Jets' home opener versus the Montreal Canadiens on Hockey Night in Canada, Scott Oake conducted an interview with Prime Minister Stephen Harper himself in his seat during a stop in play. Oake asked Harper specifically about the Jets new logo:

"(I) want to get your take on the logo which the Jets have specifically designed to reflect the heritage of Winnipeg and its relationship with the Canadian Air Force." 28

To which Stephen Harper replied:

"Look, I think it's a really attractive logo. As you say it's a great tribute to the men and women of the RCAF. It combines the heritage of the Jets franchise from the good old days, but it also updates it with something that I think is really striking and it's really good for the country."29

Coming from the Prime Minister himself, whose comments to the media are notoriously both scripted, and carefully strategized, this statement amounted to a rousing endorsement of the logo. There seemed to be more to the story than a

${ }^{28}$ CBC Sports. 'Hockey Night in Canada Broadcast, Winnipeg Jets vs. Montreal Canadiens' CBC Sports, October 9th, 2011.

29 Ibid. 
happy coincidence and shared interest in the military's past and present between team ownership and Harper.

This suspicion was proven correct when the results of an access to information came to light in late November 2011. The results of the request were published in The Globe and Mail in an article written by Steve Rennie. His piece titled, Canadian military has final say on Jets logo described a 5-page contract signed by the Department of Defense the previous summer during the rapid design phase of the logo, which spells out how Canada's newest NHL team can and cannot use its new, RCAF Roundel-based emblem. ${ }^{30}$ The agreement outlines the conditions that the Jets need to meet in the use of their own new logo, because of its use of a registered Department of Defense trademark:

"The club agrees to use the Winnipeg Jets logos solely in accordance with the terms and conditions of this agreement, and in such manner as to protect and preserve the reputation and integrity of Her Majesty the Queen in Right of Canada, as represented by the Minister of National Defence, and the Canadian Forces."

Exactly what this vague agreement specifically covers is not clear. However, it does outline that the cost of the 'authenticity' that Mark Chipman stated that the Jets looked for in their logo, and found in the use of Canadian militaristic symbols, was a loss of total control over their own team's symbols and brand. The Jets logo is then not simply a symbol of the Jets hockey team, but a Canadian Forces symbol,

${ }^{30}$ Rennie, Steve. "Canadian military has final say on Jets logo," The Globe and Mail, November 19, 2011. http://www.theglobeandmail.com/sports/hockey/canadianmilitary-has-final-say-on-jets-logo/article4183945/\#dashboard/follows/ 
and a symbol who's design was firmly in the sphere of influence of the Harper Government, and a part of project of Warrior Nation promotion described above.

Though there was an undeniable link between the Jets, the Department of National Defence, and by extension the Harper Government, in the logo's design, however as is the case with many of the examples, the direct influence of the government remains difficult to assess. In trying to draw links between the representations of the Warrior Nation branding project, linkages of authorship and motivation are difficult to establish. When the Mint releases a new bank note, when the National Capital Commission agrees to the design of a new memorial, or when the Jets enter into a vague agreement with the Department of National Defense, it is very hard to judge the extent of involvement of the highest levels of political strategists and politicians. It can be guessed, especially in an era when the PMO is famously powerful in the decision making of the government as a whole, that these designs and decisions went forward with a nod from the central nervous system of the government, but it is difficult, if not impossible to know for sure. This murkiness shifted the focus of this research of these symbols away from the authors of these symbols and the motivation of those who designed and sponsored these symbols, and instead became centered on the visual symbols themselves. What ultimately led this project down this path was the words of the Prime Minister himself, and his final line of the interview on Hockey Night in Canada when he declared that the Jets logo, " is something that is really striking, and it's good for the country." The Prime Minister is right, the logo is striking, but it was the puzzling second point he made which inspired the direction of looking at these 
symbols themselves as important cultural texts. The logo itself, not the referencing that the logo makes to the military past and present in Canada, nor it relation to the sport of hockey, but the logo itself, which Harper declared, 'good for the country'.

Two of the works mentioned above, Warrior Nation, by MacKay and Swift, as well as McCready's Yellow Ribbons, inform a great deal of the argument made in this research. Both of these works provide a solid description of the project of constructing a new narrative of Canadian identity based on the military, militarism and war that has been championed by the Harper Government. MacKay and Swift's work takes a historiographical approach, tracking the way that the historical narrative of Canada is being brashly altered and revised, with once archaic seeming conceptions of Canadian nationhood and militarism being brought back into the public discourse in an attempt to fit a militarized Canadian present into a congruent history of Canada as being thoroughly militaristic. McCready's text is based around contemporary cultural case studies focused on varied examples including Yellow 'Support the Troops' Ribbons, the Highway of Heroes, the Red Friday phenomenon, as well as CBC's Afghanada program and Canadian Forces recruitment advertisements. McCready uses these case studies to illustrate the breadth, character and pervasiveness of the Warrior Nation narrative of Canadian identity. It is important to note that both of these texts take a clear stance from the left, criticizing the government and its network of supporters, in the promotion of Canada as a Warrior Nation as part of a largely conservative, right-wing project. Both of these texts, used as a jumping off point for this work, and indeed this thesis 
itself, have a strong polemic element, critical of the Warrior Nation project as a negative, top down effort to shape Canadian cultural history. It would be remiss not to point out that there is a significant amount of writing and public discussion on the opposite side of the debate. David Bercuson, director of the Center for Military and Strategic Studies at the University of Calgary, is perhaps most vocal on the opposite side of the debate. In July 2011, the same month that the Jets logo was released, he had an editorial published in The Globe and Mail under the title, "The Military is a Central Actor in Canada's Story," which well sums up the argument for the Warrior Nation project. Bercuson argues that Canada's military belongs front and center in public life, asserting that, "it is entirely appropriate that the Canadian military play an important role [...] in all manner of public celebrations in Canada from the welcome of foreign leaders, to major national sports celebrations, and even to provincial and civic ceremonious occasions." ${ }^{31} \mathrm{He}$ argues that the Warrior Nation imagining of Canada is an overdue movement, highlighting the fact that, "since the 18th century, Canada's soldiers have played a central part in shaping the nation we are today." 32 For Bercuson, the military, its history and its place in popular culture has long been overlooked, and the "Harper government is entirely right in restoring the Canadian military as a central actor in the Canadian story." 33

\footnotetext{
${ }^{31}$ Bercuson, David. "The military is a central actor in Canada's story," The Globe and Mail, July 12, 2014. http://www.theglobeandmail.com/globe-debate/themilitary-is-a-central-actor-in-canadas-story/article586788/\#dashboard/follows/ 32 Ibid.

33 Ibid.
} 
This research sides with McKay and his critique of the Warrior Nation project. This thesis is critical, not specifically of the position Bercuson takes, but of the implications of the celebrating of war that he calls for. There is no doubt that the history of Canadians fighting in two World Wars, and conflicts since, have had a great effect on Canadian society, and led to some degree to the overwhelmingly peaceful lives most Canadians live day-to-day. Where the argument in support of the Warrior Nation project falls apart, is precisely where this thesis makes its focus, at the level of simplified representation and communication of Canada and its relationship with war and violence. Representing, remembering and commemorating a nation's involvement in war is a difficult business. The danger for those promoting the Warrior Nation project is to be able to promote the narrative of Canada as Warrior, without in fact promoting and glorifying war and death in the name of the nation. For, any time there is an earnest, jingoistic celebration of war, where the glory and honour of armed conflict is promoted and violence is celebrated as being noble, the 'old lie', described by Wilfred Owen in his World War One poem Dolce and Decorum Est, is being repeated once more:

To children ardent for some desperate glory, The old Lie: Dulce and Decorum est Pro patria mori. ${ }^{34}$

34 Owen, Wilfred. "Dolce and Decorum Est," The War Poetry Website. Written 19171918. Accessed on September 12, 2014 http://www.warpoetry.co.uk/owen1.html 
Where this thesis diverges in its methodology from the other two key works critical of the Warrior Nation project by Mckay and McReady, is through the inspiration taken from the Prime Minister's comment at the Jets home opener that the logo of the team was, itself, "good for the country," and how symbols of the Warrior Nation are designed and constructed to walk this line between commemoration and monumental jingoism. Inspired and intrigued by this concept, this research strives to look at the representations of Canada and war in the contemporary moment as texts unto themselves. Simply asking what it is about the Jets logo and these other symbols being used for the promotion of a militarized myth-symbol system, that could make the Prime Minister confidently assert that they are in and of themselves important cultural entities. This approach is first informed by the framework for critical analysis of visual texts laid out by Gillian Rose in her book, Visual Methodologies: An Introduction to the Interpretation of Visual Materials. ${ }^{35}$ Rose insists that in order to "take images seriously, it is necessary to look carefully at visual images, because they are not entirely reducible to their context". ${ }^{36}$ Following Rose's lead, this research accepts her "insistence that images themselves have their own agency."37 The first two chapters of this study make what Rose describes as a, "detailed account of the exact ways the meaning of the image is produced," 38 in order to understand what these texts are doing. This semiotic approach allows Roland Barthes' account of the

35 Rose, Gillian. Visual Methodologies: An Introduction to the Interpretation of Visual Materials (London: Sage Publishing, 2001) p.12

36 Ibid. p. 12

37 Ibid. p. 11

38 Ibid. p. 75 
role of myth in visual texts, laid out in Mythologies to serve as an important inspiration. ${ }^{39}$ For Barthes, texts such as the Jets logo, the Canadian Fallen Firefighters Memorial and the Vimy twenty-dollar bill, work on a level beyond their own specific signification or meaning. The meanings associated with the constitutive parts of these texts, the different elements of these representations and the varied narratives of nationalism that are drawn on through their inclusion, is actually pushed away as they are layered into a new symbol. These codes of representation and the narratives they reference, which some viewers arrive at the moment of encountering the image comfortable and accustomed too, become according to Barthes, "a kind of ideal servant" when they are hybridized into a new myth's visual construction. In their layering into a new symbol, the history of these other, sometime contradictory symbols, "silently disappears: all that is left for one to do is to enjoy this beautiful object without wondering where it comes from." 40 The master of these now empty signs, "what bridges this gap in meaning is another layer of signification," this wider cultural construction, is what Barthes calls myth. ${ }^{41}$ The texts in question will be analyzed through this approach to understand the way that the myth of Canada as a Warrior Nation is being created and communicated through the use of these ideal servants, the older codes of nationalism and identity. With this approach of focusing on the image itself as a powerful cultural force as an articulator of myth, this study looks at three examples of visual articulations of Canadian identity, which appeared in 2011 and

${ }^{39}$ Barthes, Roland. Mythologies. (London: J Cape. 1972) p. 117

40 Ibid.

${ }^{41}$ Ibid. 
2012; the Vimy Ridge Bank Note, the Canadian Fallen Firefighters Memorial and the Winnipeg Jets logo. A particular effort has been made to approach these symbols as stand alone texts, to approach them as a viewer first looking down at the new twenty dollar bank note, a visitor to Ottawa walking up to the Firefighter Memorial on Lebreton Flats, and a casual fan of hockey first seeing a Jets logo on a t-shirt on the street.

These three examples all present a narrative of Canadian identity, which would seem to be in complete contrast to the previous myth of Canada as a peacekeeping, peace-loving nation. Ian McKay dramatically described this conflict that the project of pushing the myth of the Warrior Nation presents, saying a, "War has been declared on the former Pearsonian, Peaceable Kingdom of Canada, it has been replaced with Warrior Nation." 42 The symbols focused on in this study at length, are quite effective in representing the Warrior Nation myth, and signaling this complete shift in Canadian identity production as it relates to war. It might be excepted that the appearance of this wave of monumental, heroic and militaristic representations of Canada as a Warrior Nation listed above, would lead to what Chris Prendergast describes in his text The Triangle of Representation as, "a diversified agon of representation, dominated by no single voice but in which multiple voices speak and clash." 43 Yet this agon, a great competition and struggle

42 McKay, Ian. "Empire Strikes Back: Militarism, Imperial Nostalgia, and the RightWing Reconceptualization of Canada," Lecture at the New Frontiers Graduate Conference, March 15, 2011. http://activehistory.ca/2011/03/podcast-ian-mckayon-the-right-wing-reconceptualization-of-canada/

43 Prendergast, Chris. "Introduction" The Triangle of Representation (New York: Columbia University Press, 2000) p. 71 
over the representation of Canadian identity, has not shaken Canadian public life. The appearance of the Warrior Nation myth in popular culture, as is exemplified in the three examples documented here, has not been particularly perceptible to a casual observer. There are few signs of the 'war' McKay described between competing narratives of Canada's relationship with militarism. This absence of a clash over symbols of Canada is not because Taber, Fremeth, Swift and McKay are wrong. This research accepts that there has been a concerted effort from the Harper Government to promote its own brand of Canadian identity with the Warrior Nation myth as an important component of this process.

This thesis focuses itself squarely on the images, for the clues as to why these symbols have been able to present this conflicting narrative of Canadian identity in a largely non-disruptive manner, lies in the structure of the visual texts themselves. This research argues that the mode of representation employed by these symbols articulating the Warrior Nation narrative of Canadian Identity, promoted by the Harper Government, have all adopted a certain genre of representation, which has been named here Hybrid Monumentalism. This genre, described for the first time in this thesis, is defined by its ability to hybridize multiple codes and narratives, symbolic tropes, even those which would seemingly contradict each other, within a single visual text. Hybrid Monumental symbols also have the ability to straddle traditional dichotomies of sacred vs. profane space in nationalistic representation, bringing revered symbols into the profane space of the everyday lives of citizens of the nation. Hybrid Monumental representations are nimble, they can incorporate different elements of competing symbols making 
them feel less disruptive than their core monumental expression may in fact be. They are also structurally able to withstand criticism, with critical arguments deflected to one side of the sacred/profane division or the other. Hybrid Monumental symbols are at the same time a marker of the sacredness of the nation, and a 'no big deal', element of the day-to-day visual landscape of the nation. The genre of Hybrid Monumentalism is distinguishable in these examples, through each text's main thematic thrust of supporting and promoting Canada as a warrior and, war-faring nation. At their core, these symbols are pro-war and jingoistic and monumental. However, all of these symbols, in different ways, have been tempered. Their strikingly pro-military messaging has been insulated through the visual co-opting and referencing of other established narratives of identity and genres of representation. These symbolic tropes and codes, and the cultural narratives they reference, bring certain viewers closer to these texts, while at the same time allow other viewers to miss or at least feel comfortable with the jingoistic messaging. The strong underlying message of these texts is muted and made less jarringly monumental through this layering of other symbols and narratives. This thesis argues that these examples of Warrior Nation promotion mark the particular genre of representation of Hybrid Monumentalism. These representations are Hybrids because of their defining characteristic of layering and combining multiple symbols and tropes, drawing from different narratives of national identity production into a single text. Yet the core message that these symbols articulate through this layering is a monumental, orthodox nationalistic message. 
The three Hybrid Monumental symbols focused on in this research have been created, not directly by the Harper Government, but through partnerships between the Government and different entities. For the three examples of this thesis this partners have been; the arms-length, yet Government funded and mandated organization, the Bank of Canada, the fully independent, non-profit organization of Canadian Fire Fighting leaders from across the county, the Canadian Fallen Firefighters Foundation, and True North Sports and Entertainment, the private ownership company of the Winnipeg Jets. The Harper Government influenced all of these organizations in different ways; formal, but not publicized agreements in the case of the Jets, required approval in the case of the Vimy Twenty and direct funding in the case of the CFF Memorial. However, the details and nature of these relationships and connections is murky. The outsourcing of the production of these symbols of the Warrior Nation seems like a coup on the part of the Harper Government, in essentially getting others to help in its branding and political promotion. However, this thesis argues that it is not political ideology and obedience to the Harper Government that offers the only, or even best explanation for these groups collaborating in the production of these symbols. Instead, it is the shared commitment to the branding process, to the building of iconic brands for their respective products, and a shared target audience, which united the stakeholders in the process of creating these symbols. This argument was largely inspired by Douglas B. Holt and his instructive text, How Brands Become Icons, in which he argues that, "iconic brands provide extraordinary identity value because they address the collective anxieties and 
desires of a nation. "44 Looking at these texts from this perspective of Holt's theory of iconic branding, all of the stakeholders in these symbols creation were looking to promote and solidify their own respective brand, by marketing themselves through these symbols, towards a certain group of Canadian society, and their specific anxieties and desires. In the examples of this thesis, White males, most likely from a family in its second, third or more generation in Canada, were the target constituency of these symbols. This group is the key target audience for, and the vast majority of the membership of; professional hockey teams, the Canadian Armed Forces past and present and firefighting departments in Canada. The Warrior Nation myth and its placing of contemporary conflicts within a heroic narrative of Canadian history which casts other generations of most often white, male Canadians as the heroes, presented itself as useful for all of the stakeholders involved in these symbols' creation, because of its powerful ability to play to the anxieties and nostalgia within this group. The core, monumental messaging of the heroism of the military, and the sacred nature of death for the nation is targeted at this audience, and used to create connection with each stakeholder's respective product, be it the profession of firefighting or military service, a certain hockey team or the government's political brand. This jingoistic messaging has the potential to offend other Canadian's and potentially harm these brands, so these symbols have been hybridized to not strike other casual viewers, who may be turned off or offended by this messaging as not being overly jingoistic, or even un-

${ }^{44}$ Holt, Douglas B. How Brands Become Icons: The Principles of Cultural Branding. (Boston: Harvard Business School Press, 2004) P, 6 
Canadian. The hybridization of these symbols is then best understood as the way they address the inherent rhetorical challenge of bold, iconic branding geared toward the composite audience of the general public. In their text, The New Rhetoric: A Treatise On Argumentation, Chaïm Pearlman and Lucie OlbrechtsTyteca, describe this challenge as a, "danger that is apparent in the case of a composite audience", because those making an argument, or in this case marketing a product, "must resolve," this diverse and large composite audience, "into its constituent parts," to craft an effective message and gain support. ${ }^{45}$ However, Pearlman and Olbrechts-Tyteca point out that this sort of targeted marketing and, "argumentation aimed exclusively at a particular audience has the drawback that the speaker, by the very fact of adapting to the views of his listeners, might rely on arguments foreign or even directly opposed to what is acceptable to persons other that those he is presently addressing." 46 The symbols looked at in this study, take a Hybrid Monumental form to address this rhetorical challenge of a composite audience, they make a strong case to the target audience with monumental messaging of Canada as Warrior Nation, while their hybrid form clouds and obscures this messaging. This form allows these symbols to walk the line between reaching and gaining traction with the important target audience, while not offending and creating negative reaction with too many of the other constituents of the composite audience.

\footnotetext{
${ }^{45}$ Pearlman, Chaïm and Lucie Olbrechts-Tyteca. The New Rhetoric: A Treatise on Argumentation, Translated by: John Wilkinson and Purcell Weaver. (Notre Dame: University of Notre Dame Press, 1969). p. 31

${ }^{46}$ Ibid. p. 31
} 
These symbols are not best understood as wholly, or even chiefly political propaganda, but instead can be understood as signs of the dominance within the realm of political branding and national propaganda of a paradigm of iconic branding. In looking to build culturally significant brands aimed at a certain target population in Canadian society, all of these stakeholders responded to similar conditions in the market for these myth-building products. The results were iconic brands, which share the same thematic focus, and Hybrid Monumental form.

The first two chapters of this thesis outline the characteristics of the genre of Hybrid Monumentalism that has proven popular and successful in the visual articulation of a militarized Canadian identity, focusing on the three examples of the Jets logo, the Vimy Ridge twenty-dollar bill and the Canadian Fallen Firefighters Memorial. The final chapter argues that it is the shared, deep commitment to iconic branding strategy on the part of all the key stakeholders of these symbols' creation that firmly united them in purpose with the Harper Government and led in large part to their creation. Understood as iconic brands of Canada as a Warrior Nation, these texts ultimately do not symbolize a solemn, sacred respect for those who die in the name of the nation of Canada, as there monumental messaging would suggest. Instead they are markers of the extent to which a commitment to an iconic branding mentality can take any subject mater, even the deaths of Canadian forces members and turn them into slick, nonobtrusive marketing campaign. 


\section{Chapter 1: Monumental}

To explain the genre of Hybrid Monumental nationalistic symbols, well exemplified by the texts which depict Canada as a Warrior Nation, the first Chapter will look at the three examples of the Jets Logo, the Vimy Ridge Twenty-Dollar Bill and the Canadian Fallen Firefighters Memorial and first examine their core, monumental and militarist messaging. The first step in breaking down these symbols is to briefly describe each of these representations.

The logo of the newly reincarnated Winnipeg Jets is best described as an altered version of the Roundel, which serves as the official emblem of the Royal Canadian Air Force (See Figure 1). The air force of Canada, known originally as the RCAF, then amalgamated into the single administrative unit of the Canadian Forces in 1968, before finally being separated and redubbed the RCAF in August 2011, has used the roundel in slightly altered forms as an identifying mark on its aircraft throughout this history. ${ }^{47}$ In the Jets new logo, the maple leaf of the roundel has had the grey silhouette of a CF-18 fighter jet layered on top of it; with the jet's nose and tail-wings completing the shape of the maple leaf. The dark blue circular band of the roundel is

47 Hooper, Tristan. "Royal returns for Canadian Forces." The National Post, August 15, 2011. http://news.nationalpost.com/2011/08/15/royal-returns-for-canadasarmed-forces/ 


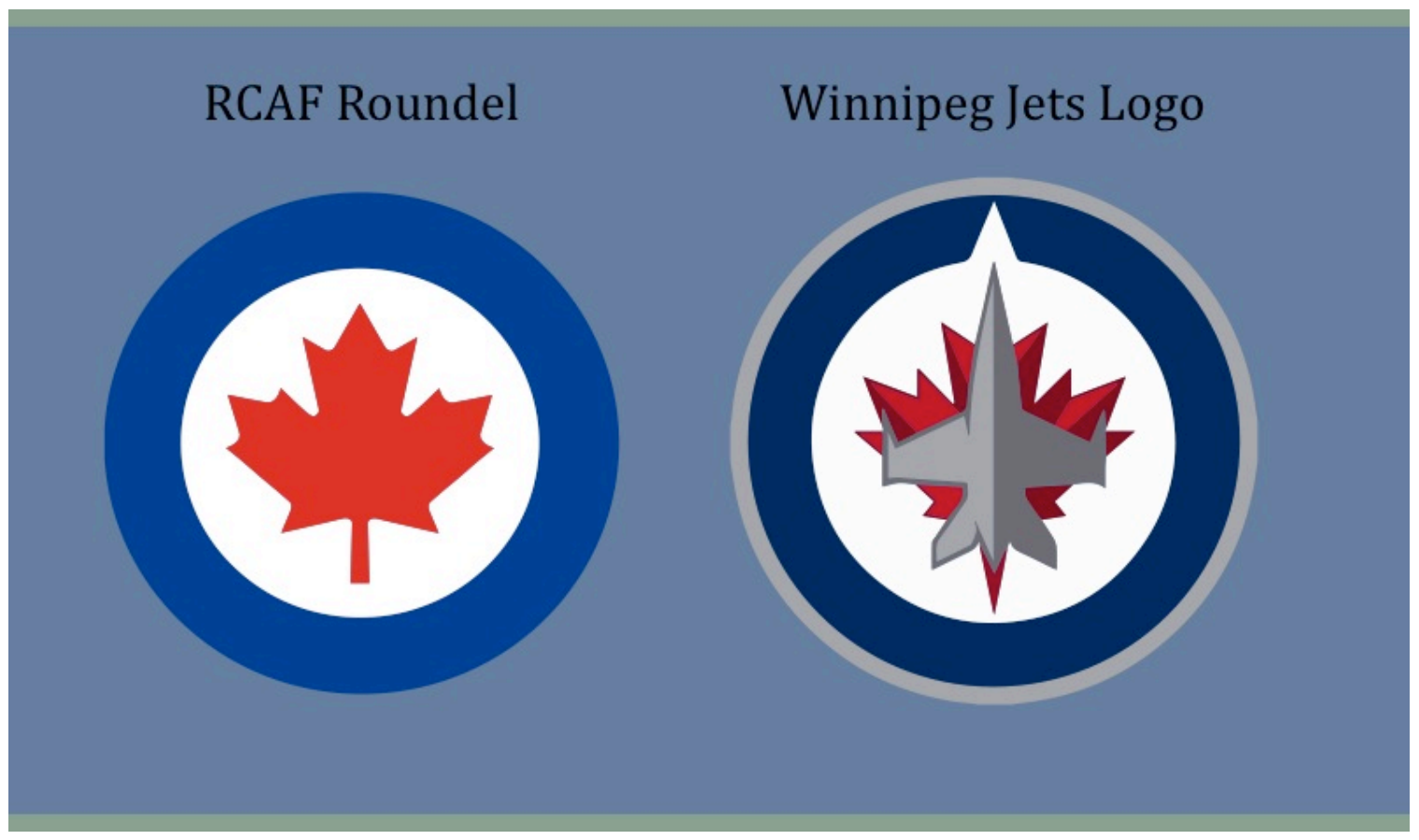

Figure 1 - Winnipeg Jet's New Logo

Winipeg Jets Website: http:http://jets.nhl.com/club/gallery.htm?id=23491

cut away at its top with a white chevron, cutting a path for the nose of the jet below. The effect of this cut allows the entire logo to be viewed as a compass with the fighter jet pointing north, a nod to the ownership company of the team, True North Sports and Entertainment. A grey outside ring has been added to the original roundel, which mimics the fuselage paint of Canadian military aircraft.

The Canadian Fallen Fire Fighters Memorial, dedicated in September 2011, is a memorial landscape located on the eastern edge of the Lebreton Flats in downtown Ottawa, kitty-corner to the intersection of Booth Street and the John A. MacDonald Parkway, across from the National War Museum. The memorial, designed through a collaboration between Canadian artist Douglas Coupland and 
PLANT Architect, is an official National Monument dedicated to Canadian firefighters who have died in the line of duty, including those who died as a result of an incident on the job, as well as those who have died as a result of work-related illness. ${ }^{48}$ The landscape of the memorial is dominated by a 20 -foot tall golden statue of a male firefighter (See Figure 2). This figure stands in the role of wayfinder beside a tall golden fire poll, gesturing with an outstretched arm and finger towards a memorial Name Wall that encloses the north side of the memorial. This Name Wall of polished granite is engraved with the names of firefighters who have died in the line of duty from pre-confederation to the present. A pathway interrupts the Name Wall, leading north out of the memorial, with the isolated section of granite beyond this path dubbed the White Pine Tree Rock. ${ }^{49}$ This rock's face is also polished, with the words Never Forgotten/Grave dans nous memorie engraved into it. As the name suggest, this rock is filled with earth, and is planted with a single pine tree. The interior of the landscape is bounded on its east and south sides by planted trees and a raised mound of grass, enclosing an interior sanctuary space used for annual memorial services.

The new Canadian twenty-dollar bill was unveiled by the Governor of the Bank of Canada, Mark Carney, and Minister of Finance, Jim Flaherty, in May 2012,

48 PLANT Architect. Canadian Firefighters Memorial, PLANT Architect Website. Accessed May 12, 2014. http://www.branchplant.com/landscape/cfm.html 49 Ibid. 


\section{Canadian Fallen Firefighters Memorial}

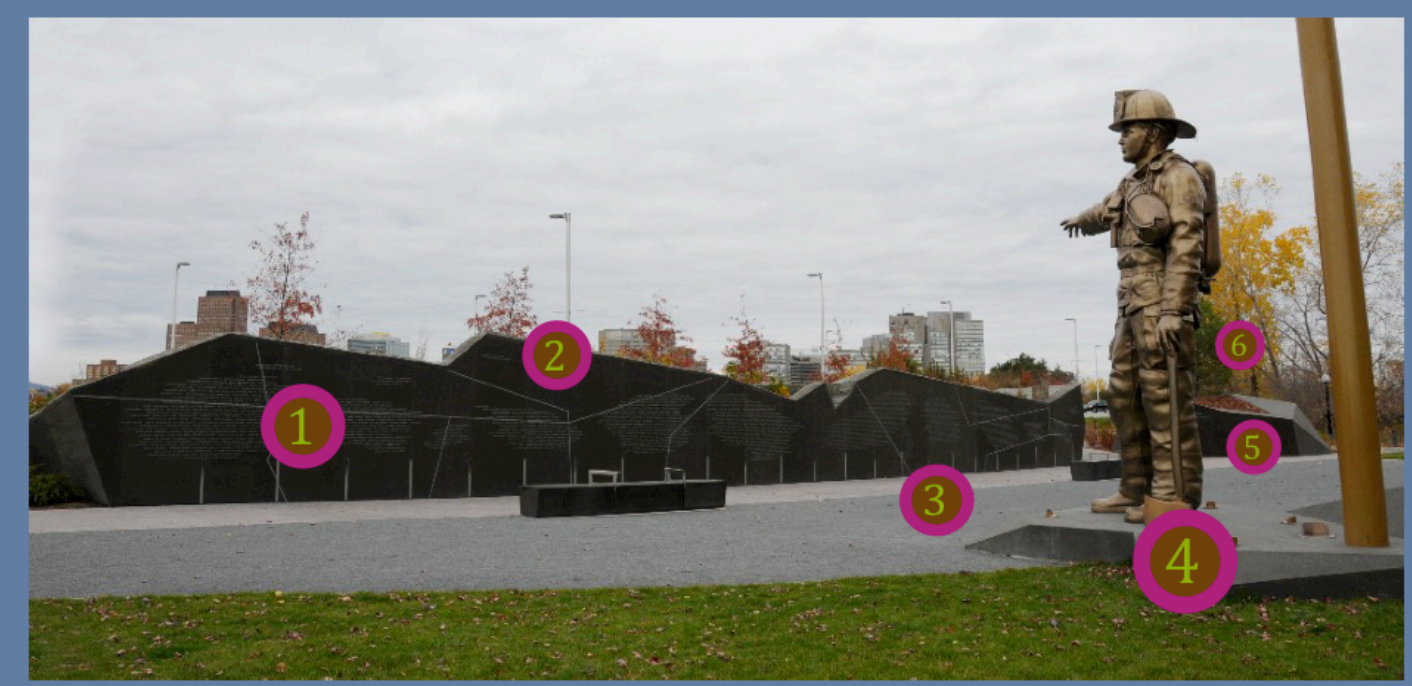

(1) Name Wall

2 Unknown Firefighters Inscription

3 Sanctuary Space

4. Firefighter Statue

5 White Pine Tree Rock

6 Lone Pine

Figure 2 - Canadian Fallen Firefighers Memorial

Source: CFFF Web Site: htp://efff.ca/media/files/upload/CFM1_vbn.jog 
and put into circulation in November of the same year. ${ }^{50}$ The bill was notable because it was among the first Canadian bank notes to be made from plastic polymers in place of paper fiber, in an attempt to increase the lifetime of the bills..$^{51}$ The new Canadian twenty is specifically important to this project because of its new graphic design, with the reverse of the note featuring a representation of the Canadian National Vimy Memorial (See Figure 3). The image is a close-up of the massive twin pylons of the memorial, designed by Francis Seymore Allward and dedicated in Vimy, France in 1936,52 with a faint image of a Canadian Flag emerging behind. Maple leaves and two groupings of red poppies frame the memorial. The front side of the bill features a portrait of Queen Elizabeth II.

These three examples, quite different in form and function, hold key similarities, which allow them to be understood as all exhibiting a Hybrid Monumentalism. To begin describing this genre, the core monumental elements of these examples needs to be highlighted. However, it is critical to first note the cultural position and influence in Canadian identity construction that these three examples of Hybrid Monumentalism hold.

${ }^{50}$ CTV News. "Veterans Honoured on New \$20 Bank Note," CTV News, May 2, 2012. http://www.ctvnews.ca/veterans-honoured-on-new-20-polymer-bank-note1.804451

51 Bank of Canada. "Polymer Series," Bank Of Canada Website. Accessed May 12, 2014. http://www.bankofcanada.ca/banknotes/bank-note-series/polymer/ ${ }^{52}$ Department of Veterans Affairs. "Canadian National Vimy Memorial" Veterans Affairs Website," February 2, 2014. http://www.veterans.gc.ca/eng/remembrance/memorials/overseas/first-worldwar/france/vimy/vimymap 


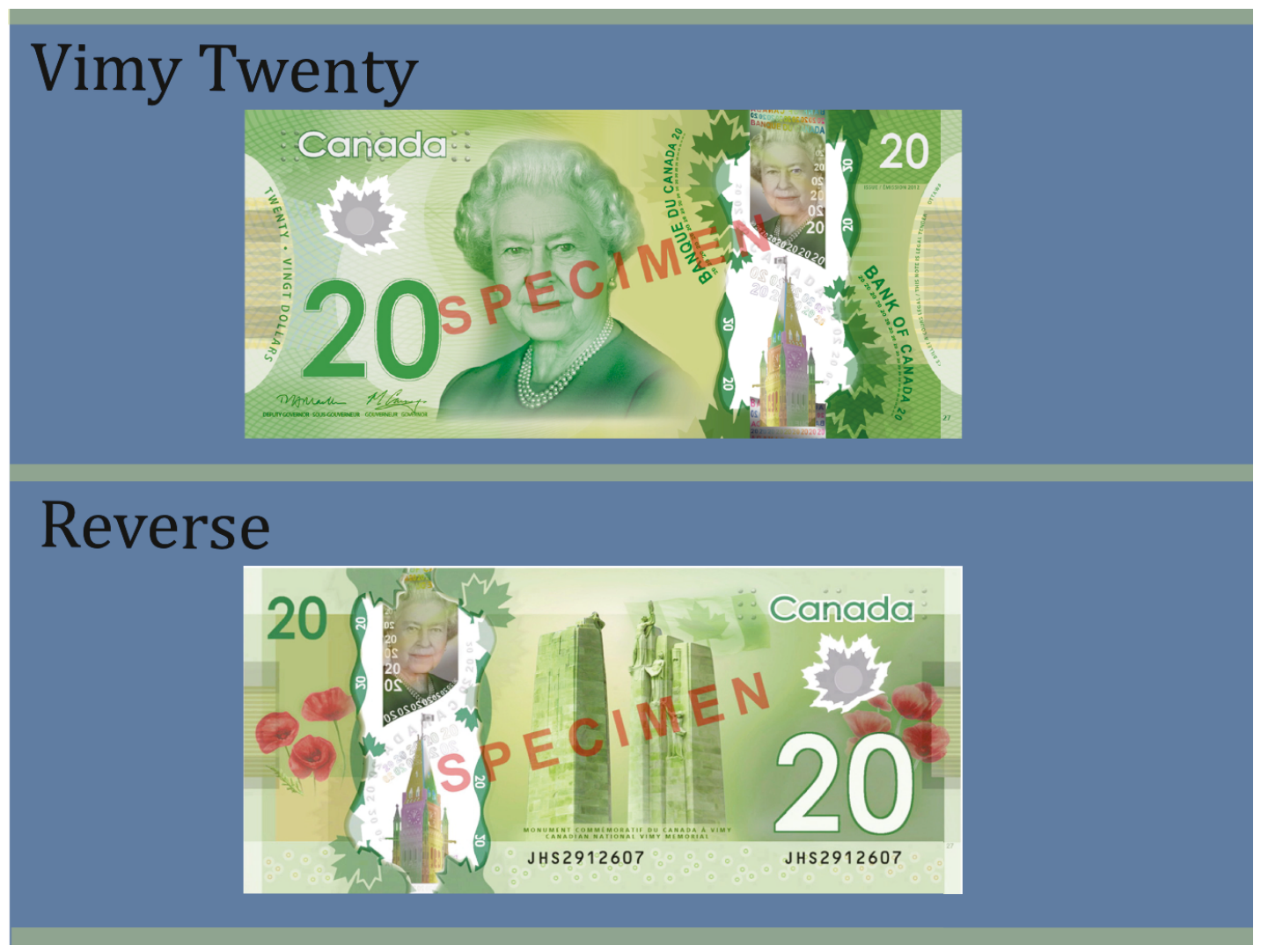

Figure 3 - Vimy Ridge Twenty Dollar Bill

Soure: Royal Canadian Mint Web Site http://www.bank of Canada.ca/banknotes/bank-note-series/polymer

Of the three examples briefly outlined above, the Canadian Fallen Firefighters memorial is the most orthodox nationalistic representation; it is also the most natural to categorize as being monumental, as it physically takes the form of a traditional monument. Its construction of rock and stone, its physical placement in the heart of the nation's capital, as well as its central figure of a gigantic masculine figure fits it into the exceedingly traditional form of monumental architecture of heroic statuary. As Claudette Lauzon has argued, “[p]ublic monuments represent and contribute to the construction of national identity by imposing on public spaces a colossal presence with inculcating 
narratives rendered timeless," in an effort to "monumentalize a preferred version of national history." ${ }^{53}$ The Canadian Fallen Firefighters Memorial literally imposes a colossal figure into the visual articulation of Canadian identity in the nation's capital. The connection to the national imaging in the case of the Canadian Fallen Firefighters Memorial is explicit, with the memorial granted official status at its dedication by the Governor General in $2011 .{ }^{54}$ Its location, scale, singularity, sacred status and permanence force the viewer to understand it as a significant cultural space in the negotiation of Canadian identity.

The Winnipeg Jets logo and the Vimy Ridge twenty-dollar bill are in some ways the opposite of the Canadian Fallen Firefighters Memorial in their form of representation. They are anything but singular, with the twenty dollar bill being re-printed millions of times and passed throughout the country in monetary circulation, and the Jets logo appearing on countless pieces of merchandise, as well as showing up daily as part of television, internet and newspaper coverage of the team. The ubiquitous, mundane, day-to-day representation that these symbols make, mean that they take a different approach to promoting a certain identity of the imagined nation and its characteristics. Though these types of banal representation take a less physically monumental form, their powerful position as identity representations in the day-to-day visual landscape of the nation is

53 Lauzon, Claudette. "Monumental Interventions: Jeff Thomas Seizes Commemorative Space," Imagining Resistance: Visual Culture and Activism in Canada Editors: J. Keri Cronin and Kristy Robertson (Waterloo: Wilfred Laurier Press, 2011) ${ }^{54}$ Hempstead, Doug. "Monument Dedicated to Fallen Firefighters," The Ottawa Sun September 9, 2011. http://www.ottawasun.com/2012/09/09/monumentdedicated-to-fallen-firefighters 
significant. This type of national representation has been well described by Michael Billig in his text, Banal Nationalism. Billig contends that in established nations such as Canada, "there is a constant 'flagging', or reminding of nationhood [...]. This reminding is so familiar, so continual, that it is not constantly registered as reminding." 55 Though more subtle, and ubiquitous in its repetition, banal flagging of the nation shares the same motivation as the physical, orthodox monument in its attempt to provide a visual articulation of a certain narrative of the nation. In Banal Nationalism, Billig specifically notes that, "[c]oins and bank notes typically bear national emblems." ${ }^{16}$ Currency has long been a site of national representation. To be widely accepted as being of value, currency itself requires legitimization that these kinds of symbols can communicate. The symbols on currency then become markers of the legitimacy of the currency itself as a unit of trade. Yet they also become a daily symbolic reminder of the legitimacy of the nation as the issuer of the currency, and the authority over the citizens who use it in their daily lives. The symbols on Canadian currency have followed this tradition most obviously by featuring representations of the Queen as the personification of the state on all coins and on the twenty-dollar bill. They have also featured other popular and accepted symbols of the nation - the maple leaf on the now defunct penny, the beaver on the nickel, the loon on the dollar coin, and a young hockey player on the five-dollar bill. Though not permanent, physically daunting and officially designated like the Canadian Fallen Firefighters Memorial, the banal

${ }_{55}$ Billig, Micheal. Banal Nationalism. (London: Sage, 1995) p.7 ${ }^{56}$ Ibid. p. 41 
representation that the Vimy Twenty makes is certainly an equally important text, which operates from a powerful position of national representation on the bank notes flowing through the Canadian economy every day.

The Winnipeg Jets logo, reproduced on clothing and countless pieces of merchandise, is at its core a commercial product. Professional sports franchises rely on the sale of merchandise featuring their team's logos and colours as an important part of there revenue generation. The jerseys and logos of Canada's National Hockey League teams in this way, on hats and t-shirts, bumper stickers and pencil cases, replica jerseys and beer bottle coolers, enter into the day-to-day visual landscape of the country. These official branded items are popular in Canada, with the relatively small markets of Canadian teams out-selling their American counterparts. ${ }^{57}$ The merchandise put on the market with the Winnipeg Jets' new logo proved especially popular during the new franchise's first year, with the team ranking number one in the entire league in sales. ${ }^{58}$ Fans surely purchase these items to show affiliation with their newly returned team, but hockey enthusiasts across the country also proudly display their Jets t-shirt, Montreal Canadiens license plate holder or Vancouver Canucks hat to mark themselves as fans of the sport of hockey in general.

It is not surprising that many Canadians feel drawn to these hockey-focused products. In discussions of cultural practices that can be identified as being

57 Kirbyson, Geoff. "Jets Merchandise Scores Top Dollar in League Sales," The Winnipeg Free Press, September 7, 2011. http://www.winnipegfreepress.com/breakingnews/jets-merchandise-scores-topdollar-in-league-sales-157729825.html ${ }^{58}$ Ibid. 
distinctly Canadian, hockey is always part of the conversation. Ken Dryden, former star goaltender of the Montreal Canadiens, and Roy MacGregor, hockey author and journalist, famously articulated this placing of hockey as central to Canadian popular identity, in their monograph Home Game: Hockey and Life in Canada. In this book they declare that, "hockey has become part of the Canadian imagination, an instinct, a need, an expectation passed from generation to generation, an obligation of one to the next." 59 This centrality of hockey in the Canadian national imagination has been evidenced recently by the nation-wide euphoria that ensued after the overtime victory of the Canadian men's hockey team at the Vancouver Olympic Games in $2010^{60}$, as well as the collective concern for Canadian superstar Sidney Crosby's concussions. ${ }^{61}$ It is also evident in the blanket of coverage that is given year-round to professional hockey in newspapers and on cable television channels. The prominence of the sport of hockey in Canadian popular culture is analyzed by Richard Gruneau and David Whitson in their book, Hockey Night in Canada: Sport, Identities and Cultural Politics. Gruneau and Whitson do not reject the place of hockey as central to the collective national experience. They reiterate that:

${ }^{59}$ Dryden, Ken and Roy MacGregor. Home Game: Hockey and Life in Canada (Toronto: McClelland and Stewart, Toronto. 1989) p.22

${ }^{60}$ Branch, John. 'For Canada's Faithful, A Gold That Means Most," The New York Times, February 28, 2010.

http://www.nytimes.com/2010/03/01/sports/olympics/01obsession.html?page wanted=all

${ }^{61}$ Cathal, Kelly. "Crosby's Comeback a Cause for Celebration - and Conversation," The Toronto Star, November 20, 2011. http://www.thestar.com/sports/hockey/2011/11/20/kelly_crosbys_comeback_c ause_for_celebration_and_conversation.html 
Canadians have experienced the game both as a community practice and as a commercial product - variously connected to the local community, to broader 'communities' of loyal fans who follow professional teams, and, finally, to an imagined national community. ${ }^{62}$

However, Gruneau and Whitson challenge this positioning of hockey as being 'naturally' a part of the Canadian cultural experience. They specifically point out that the attachment to and representational character of professional hockey teams as identity-markers for Canadians is something that has been fabricated through successful promotion by those who run NHL hockey clubs. They argue, "Popular identifications with NHL hockey teams have never simply arisen on their own. These identifications have been greatly influenced by the shared interests of NHL promoters and myth-makers in the media." ${ }^{33}$ Hockey jerseys and the logos they feature are a focus of this marketing success. However, the centrality of hockey as a cultural practice, not in small part as a result of this successful marketing, has led the wearing of a hockey sweater to be understood beyond simply a marker of support for a certain commercial enterprise. Because hockey has remained so popular and is accepted as a central part of personal, regional and national identity for many Canadians, hockey sweaters' and logos have proven to be powerful regional and national cultural identifiers.

The most striking example of this is surely the cultural identity associated with the jerseys of Canada's two professional hockey teams from the 'original six'

62 Gruneau, Richard and David Whitson. Hockey Night in Canada: Sport, Identities and Cultural Politics. (Toronto, University of Toronto Press, 1992) p. 200 ${ }^{63}$ Ibid. 
era, the Montreal Canadiens and the Toronto Maple Leafs. Through the turbulent years of the Quiet Revolution in Quebec, support for the Canadiens' on-ice struggles against the Maple Leafs, became symbolic of the wider struggle for recognition and political power on the part of French Canadians. The support of the hockey club extended to a reverence for the jersey of the Canadiens to the extent that some supporters of the team still colloquially referred to the jersey as 'La Sainte-Flannelle', which translates roughly to the Holy Flannel. ${ }^{64}$ The short story by Roch Carrier, The Hockey Sweater, which focuses on the distress of a young Québécois boy who accidentally receives a Toronto Maple Leaf jersey from his mother's Eaton's catalogue order, perhaps best illustrates the centrality of the sweaters of these respective teams, as cultural and identity markers. ${ }^{65}$ Based on an interview that Mark Chipman gave the day following the new Jets logo release on The Sports Network (TSN), it would seem that it is this type of cultural and regional symbol that the Jets' ownership was looking to forge in its new logo and jersey. "We wanted to do something that represented what we are all about," Chipman reiterated, "we wanted to authenticate the logo and tie it to something meaningful." ${ }^{\prime 6}$ From this assertion we can understand that the Jets' ownership looked to create a logo and jersey that would resonate in the same way that the

${ }^{64}$ Curran, Peggy. "Religious fervour for the $\mathrm{CH}$ looks like the real thing, theologian says." The Montreal Gazette, January 9, 2009.

http://www.montrealgazette.com/life/Religious+fervour+looks+like+real+thing+the ologian+says/1156384/story.html

${ }^{65}$ Carrier, Roch. the Hockey Sweater and other Stories Translated by Sheila Fischman (Toronto: Anasi, 1979). P.75

${ }^{66}$ TSN. "TSN interviews Mark Chipman regarding new Jets logo: 07/23/11," Video on YouTube, accessed May 12, 2014. http://www.youtube.com/watch?v=y9Shh6cJIEw 
blue and white Toronto Maple Leaf or the Montreal ' $\mathrm{CH}^{\prime}$ logo do. Simply put, the new Jets logo was intentionally designed to be a culturally significant symbol, not just regionally and with this fan base, but nationally in its articulation and reinforcement of the strong association between professional hockey and national imagining.

From their respective positions of cultural influence and national representation, banal and ubiquitous in the case of the Jets logo and the Vimy Ridge twenty-dollar bill, and physically imposing and officially designated in the case of the Canadian Fallen Firefighters Memorial, all three of these examples express an earnest, monumental narrative of Canada as a militarized, warrior nation. The Winnipeg Jets logo, described in the preface as the inspiration for this project, makes the most direct visual representation of this conception, with its striking layering of the silhouette of a Canadian Forces CF-18 onto the most recognizable of national symbols, the red maple leaf. The jet's silhouette is required to complete the figure of the maple leaf (See Figure 4).

This military jet at the center of the new logo presents a visual definition of the franchises nickname 'Jets'. In making this connection, the team's ownership is not fabricating a link between the city and the RCAF. It is important to point out 


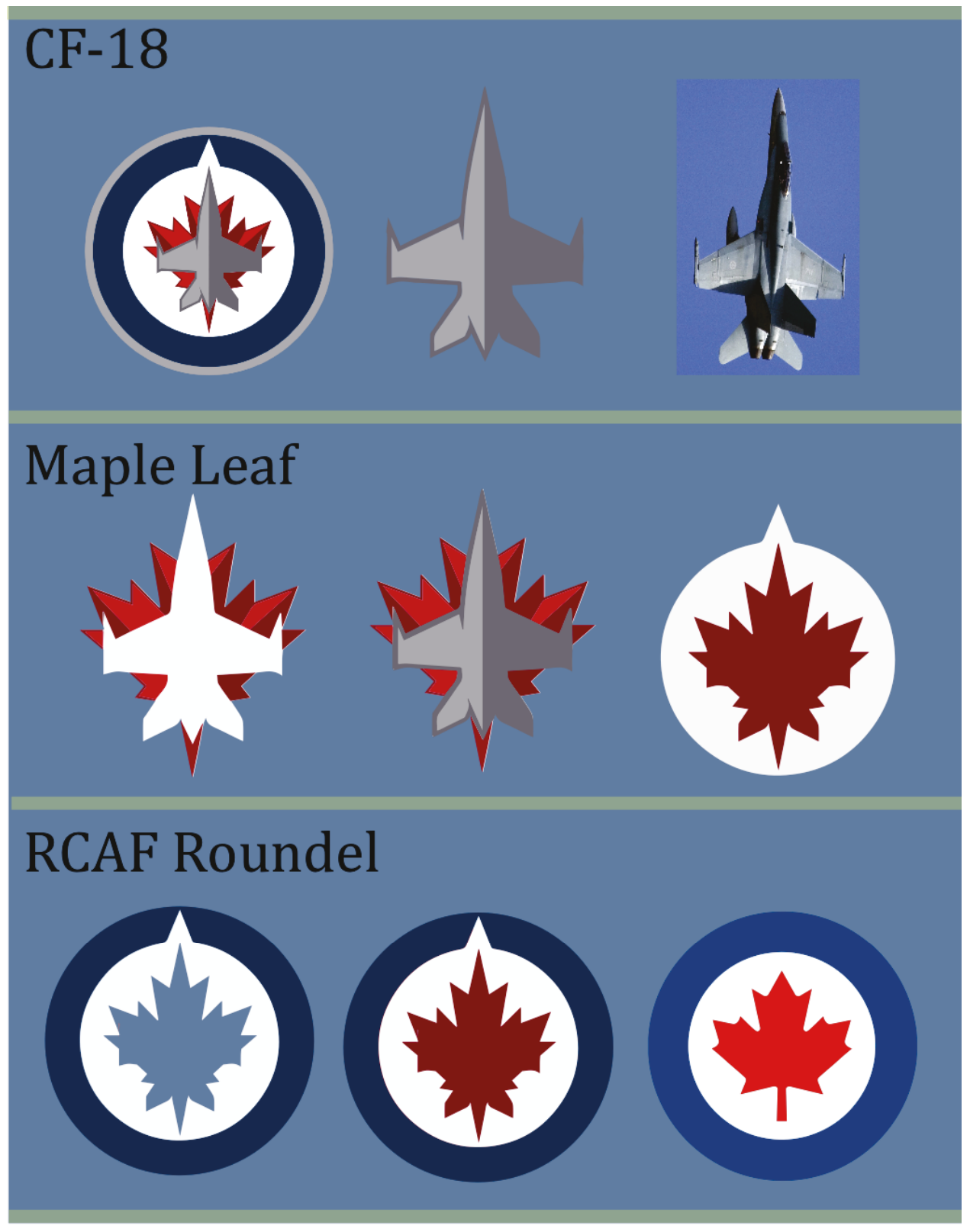

Figure 4 - Jets Logo Breakdown Sources: Jets Logo http://jets.nhl.com/club/page.htm?id=70211 CF18 http://en.wikipedia.org/wiki/File:CF-188A_BANKING.jpg RCAF Roundel http://rcaf-arc.forces.gc.ca/en/logos-insignia.page

that Winnipeg does indeed have a long history of association with the Royal Canadian Air Force (RCAF). The connection to the city began in 1922 with the opening of a small base, which was greatly expanded during the Second World War 
when RCAF Station Winnipeg became a major center in the British Commonwealth Air Training Program. ${ }^{67}$ Following the war the base became home to 17 Wing Winnipeg, one of Canada's major air force units which conducts flying operations as well as a number of training and command functions. ${ }^{68}$ The RCAF Winnipeg base is a significant employer in the city with 3,600 personnel, and supporting industries and services benefit from its presence. ${ }^{69}$ Though this connection makes the nickname and new logo seem a natural fit, the logo is actually breaking new symbolic ground in its strictly military definition of the Jets moniker. A look at previous Winnipeg Jets logos shows that a specifically military-type aircraft was never used previously in their design. The older incarnations of the Jets in Winnipeg have featured other jet silhouettes in their logos, but these have all resembled passenger jet aircraft or, in the case of the logo used by the team from 1990-1996, a simple chevron shape. Two of the historical Jets logos incorporated jet streams trailing off of the aircraft they depicted, implying the verb jets or even the collective adjective describing the speedy players of the team who jet up and down the ice, as sharing similar traits as jet aircraft, rather than the literal imagining of actual jet aircraft serving as the teams mascot. However, the new Jets logo clearly makes a military connection with its specifically fighter jet shaped aircraft. The visual metaphor of the jet completing the maple leaf is blunt; it communicates the message plainly that the military is a fundamental, essential

${ }^{67}$ Royal Canadian Airforce. "The RCAF: 17 Wing Winnipeg," RCAF Website, February 13, 2014. http://www.rcaf-arc.forces.gc.ca/en/17-wing/index.page 68 Ibid.

${ }^{69}$ Ibid. 
part of Canada. The logo also features a 'fuselage ring' around the outside of the dark blue roundel. This 'fuselage ring' is designed to match the paint colour of Canadian fighter aircrafts, turning the jerseys, and the players and

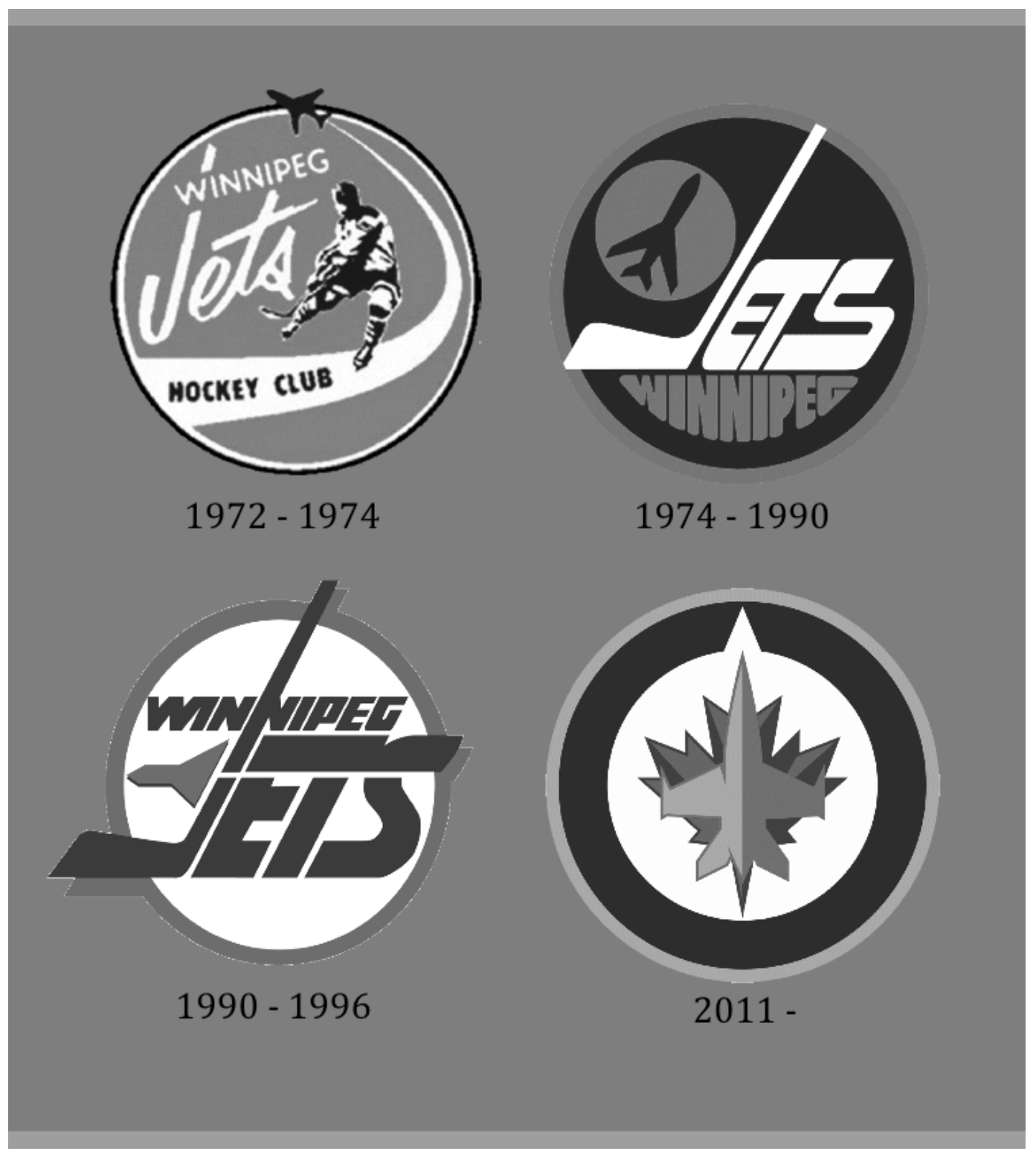

Figure 5- Jets Logo's Past and Present

Soure: Sportslogos.net -

http://www.sportslogos.net/logos/list_by_team/37/Winnipeg_Jets/ 


\section{Brand Identity Slide Show}
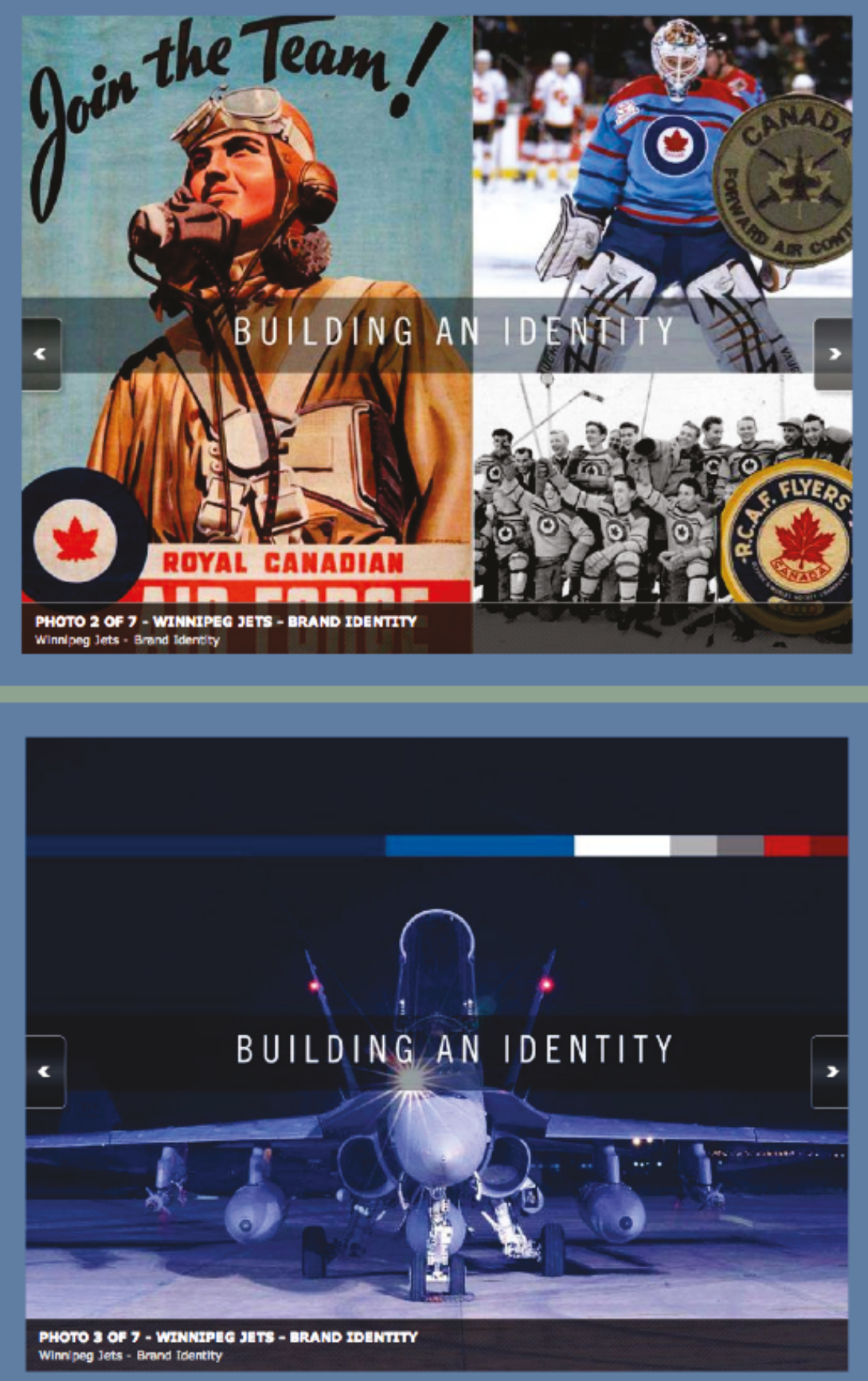

Figure 6 - Winnipeg Jets Brand Identity Slide Show, Slides 2 and 3

Source: http://jets.nhl.com/club/gallery.htm?id=23491 
fans that wear them into a sort of proxy for the fighter jets themselves. The close recreation of the RCAF logo on the Winnipeg Jets' jerseys also makes the entire jersey very similar to the jerseys worn by the RCAF Flyers, the hockey team fielded by the air force which competed for Canada in the 1948 Winter Olympics, wining the gold medal. This direct use of the historic military insignia draws a connection between the military past, and the contemporary military represented by the modern jet. The fact that this connection was intended and carefully crafted is reinforced by the Winnipeg Jets Brand Identity slide show which was posted on the hockey club's website on the day of the logo's release. ${ }^{70}$ The two slides, which precede the actual logo being unveiled, visually represent the inspiration for the logo's design under the earnest headline of, Building an Identity (See Figure 5). The first of these two slides features a reproduction of a World War II RCAF recruitment poster depicting a steely-eyed young pilot, staring to the heavens, captioned with the sport-themed phrase "Join the Team!". On the same slide an image of the RCAF Flyers team celebrating their Olympic victory is featured, as well as an image of a goaltender of the Manitoba Moose franchise of the American Hockey League, wearing a special tribute jersey to the 1948 team, worn in a game held on March 1, 2008.71 This slide offers the tying together of Canada's hockey and military history as the foundation that the new Jets franchise is being built on.

70 The Winnipeg Jets. "Winnipeg Jets Brand Identity", Winnipeg Jets Website, 22 July, 2011. Shared Credits in slide show to: Reebok, True North Sports and Entertainment, The National Hockey League. http://jets.nhl.com/club/gallery.htm?id=23491 ${ }^{71}$ Our Sports Central. "Moose, Military honour the 1948 RCAF Flyers," Our Sports Central, March 1st, 2008. http://www.oursportscentral.com/services/releases/?id=3599440 
The next slide features a dramatic night photo of a contemporary CF-18 fighter jet on the tarmac, its lights on, cockpit open waiting for a pilot to jump in and take off. The historically focused tying of hockey and the military of the previous slide is brought to the contemporary context in this slide, with the CF-18 Jet presented as the focal point of the new Jets franchise identity. These two slides taken as a whole resemble a recruiting pamphlet for the RCAF, as much as a hockey team's brand identity, constructing a narrative of Canadian identity that presents hockey and the military as equally defining features of the national experience. The Winnipeg Jet Brand Identity slide show visually summarizes the clear message of the logo itself, which builds its meaning by placing the military, past and present, at the heart of Canadian national identity.

The Canadian Fallen Firefighters Memorial physically, through its massively scaled firefighter and the surrounding memorial landscape, re-appropriates tropes from Canadian War Memorialization, to mark out firefighters as peers with armed forces members. In its scale, design, and its official designation, the Canadian Fire Fighters Memorial is akin to other orthodox memorials in downtown Ottawa, particularly the National War. Its central sanctuary space is the site of an annual ceremony to mark the deaths of firefighters across Canada, held on the Sunday closest to September 11 th. $^{72}$ The ceremony is a re-creation of Remembrance Day ritual, with firefighters marching into the memorial's sanctuary behind a colour guard, joined by members of the Canadian Armed Forces, to stand guard as

${ }^{72}$ Roche, Kelly. "Fallen firefighters honoured at Ottawa memorial," Ottawa Sun, September 8, 2013. http://www.ottawasun.com/2013/09/08/fallen-firefightershonoured-at-ottawa-memorial 
government, religious and firefighter dignitaries solemnly mark the deaths of firefighters who have died in the line of duty(See Figure 6) ${ }^{73}$ The focus of this ceremony is an altar table placed in front of the granite wall of the White Pine Tree Rock, with its inscription: Always Remember/Grave Dans Nous Memories. This inscription is very similar to the most common phrase used in Canadian War-Dead remembrance 'Lest We Forget'. Many Canadian war memorials bear this inscription in the same way the Fallen Firefighters Memorial is inscribed with this imperative to Always Remember. The phrase, "Lest we forget" originally appeared in Rudyard Kipling's poem Recessional, ${ }^{74}$ and was adopted as a popular call to remembrance after the First World War. The phrase still appears as part of the official Remembrance Day liturgy in the Royal Canadian Legion's Ritual and Insignia manual. ${ }^{75}$

The name of the monument itself in employing the term 'fallen' for those who have died is referencing another popular war-remembrance poem, For The Fallen. The official Royal Canadian Legion act of remembrance, with its own iconic refrain of "We Will Remember Them", is a stanza from this longer poem, written by

73 Ibid.

74 Kipling, Rudyard. "Recessional," The Kipling Society. Accessed March 21, 2014. http://www.kipling.org.uk/poems_recess.htm 75 Royal Canadian Legion, Royal Canadian Legion Ritual and Insignia Manual, Royal Canadina Legion Website. Accesed March 9, 2014.

http://legion.ca/_PDF/Manuals/RitualandInsignia2011_e.pdf 
Laurence Binyon, about the mounting human cost of the First World War. ${ }^{76}$ The use of the term 'fallen' as a synonym for the dead, references this First World War

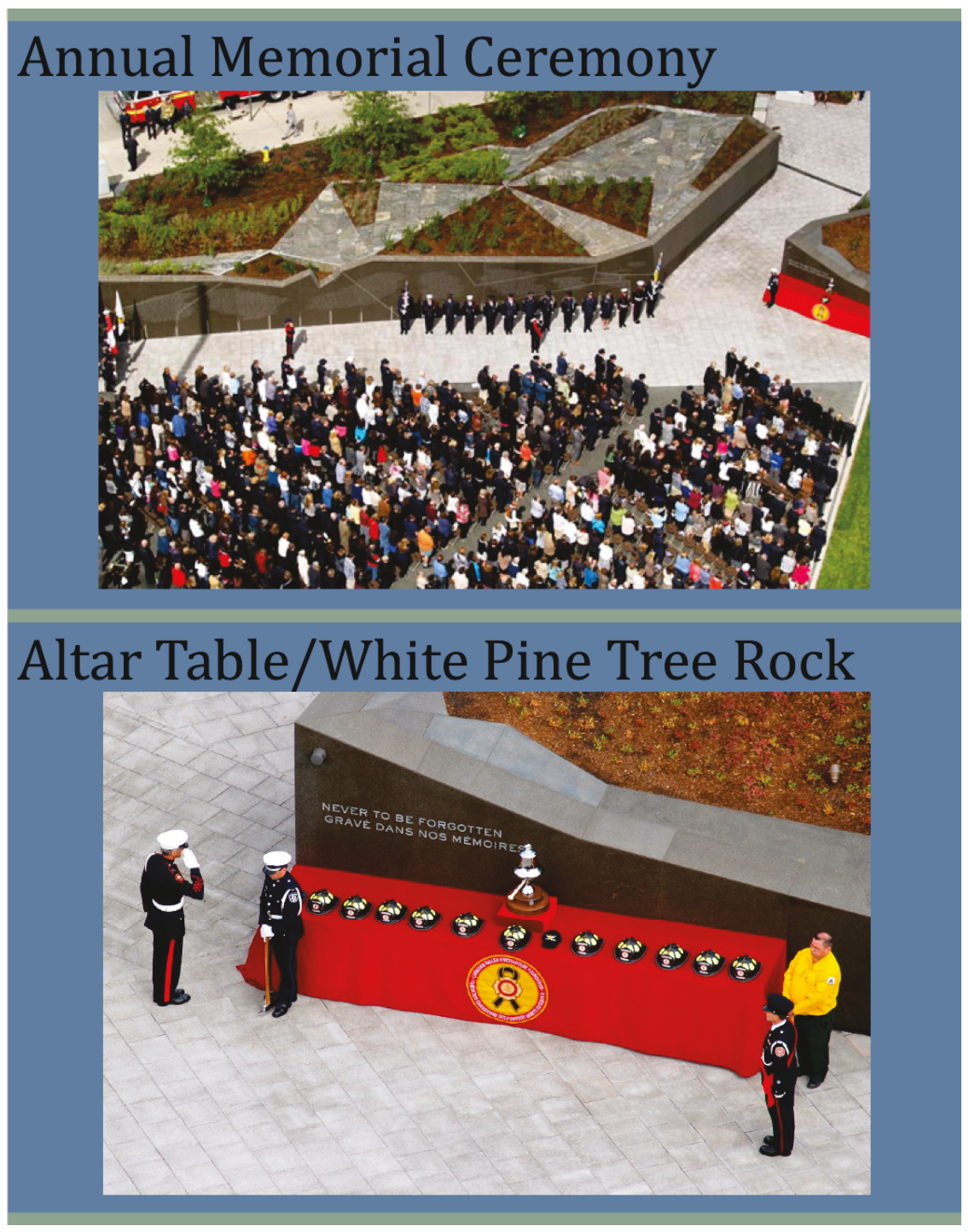

Figure 7 - Annual Remembrance Ceremony

Source: Bottom Image: http://cfff.ca/media/files/upload/ceremonyad1_mp2.jpg Top Image:

http://worldlandscapearchitect.com/image/2012/plant/CanadianFirefighters-Memorial_12.jpg

${ }^{76}$ Binyon, Laurence. For the Fallen. Accessed March 9, 2014. http://en.wikisource.org/wiki/A_treasury_of_war_poetry,_British_and_American_poe ms_of_the_world_war,_1914-1919/The_Fallen\#For_the_Fallen 
connotation and underlines the linkage being made in the memorial with war dead through re-appropriation of familiar ritual and language of remembrance. The association between the military and firefighters is further reinforced by an inscription high on the memorial's Name Wall which reads; "Unknown Firefighter/Pompiers Incognu". The inclusion of a memorialization of those firefighters 'unknown' in their deaths, adopts the powerful symbolism of the Tomb of the Unknown Soldier. Through this trope of the Unknown Dead the story of sacrifice for the nation becomes universal, timeless; the Unknown Dead represent all past unknown firefighting-related deaths for the nation, but also all the future deaths yet unknown. As Benedict Anderson notes in his seminal text on Nationalism, Imagined Communities, "No more arresting emblems of the modern culture of nationalism exist than cenotaphs and tombs of Unknown Soldiers."77 For Anderson, the imagined nation gains legitimacy through the sacrifice of human lives, specifically those who die defending the nation at war. These military deaths are given significance as sacrifices for the nation, a process that legitimizes both ways. The soldier's death is legitimized in the name of the nation, and the nation and its actions in war are legitimized because the soldier died for it. By including a dedication to the Unknown Firefighter the memorial employs this powerful symbolism.

The linkage with the military is also made through the placement of the Canadian Fallen Firefighters Memorial across the street from the Canadian War

${ }^{77}$ Anderson, Benedict. Imagined Communities: Reflections on the Origin and Spread of Nationalism (London: Verso, 1983). p.9 
Museum, with the gaze of the giant firefighter leveled directly at the building, imploring with his stare and outstretched arm for the public to recognize firefighters as peers to military members in the national imagination. Where the Jets logo and the Vimy twenty-dollar bill bring a militarized representation of Canadian identity into the visual landscape through the ubiquity, the singular and monumental Canadian Fallen Firefighters Memorial encourages the viewer to imagine firefighters themselves as thoroughly militarized. The gigantic figure of the firefighter earnestly and bluntly raises the firefighting profession, and specifically those who have died pursuing this profession, out of the fabric of the general society, elevating them to the sacred militarized status of those who are called upon to defend and die for the nation.

The art work on the Vimy Ridge twenty-dollar bill also makes a direct, monumental statement of military-focused Canadian identity. By focusing its representation on the Canadian National Vimy Memorial, the new twenty-dollar bill evokes some of the most powerful and prominent mythologizing of war and the military in Canadian identity production. The Battle of Vimy Ridge, fought on April 9th, 1917 on a stretch of the Western front in Vimy, France, has become the focus of the defining Canadian military myth. Recent revisions to the Canadian citizenship guide Discover Canada, the text given to prospective Canadians to prepare for citizenship examinations, have highlighted Vimy and promoted an understanding of the battle as being of foundational importance to the nation, listing Vimy Day, April 9th , on a chart of National Public Holidays and Other 


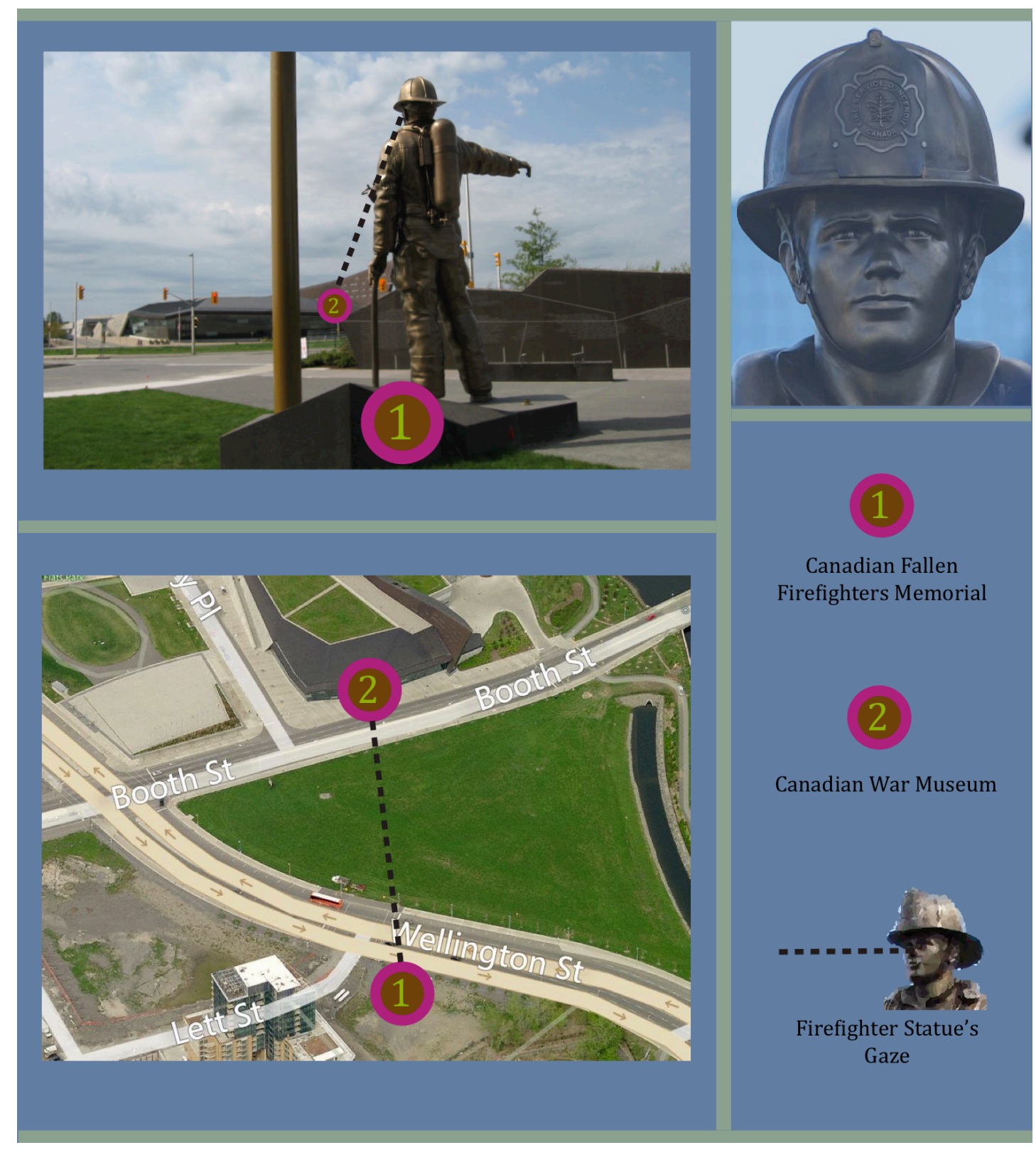

Figure 8 - Fire Fighter's Gaze -

Source: CFFF Blog -

http://fallenfirefightermemorials.blogspot.ca/2012/12/the-canadianfirefighters-memorial.html Arial Photo: bing.com/map 
Important Dates. ${ }^{78}$ The citizenship guide directly quotes Brigadier General Alexander Ross, whose personal recollection of the battle has been seized upon as a foundational text of the Vimy mythic narrative. The excerpt of his description of the battle used in the guide focuses on the soldiers who fought in the battle, and their different geographical origins. "It was Canada from Atlantic to the Pacific on Parade [...] In those few moments I witnessed the birth of a nation." ${ }^{79}$ In his book, What We Talk About When We Talk About War, Noah Richler described the Vimy Myth, which has its early origins in the quote from Ross and his phrase, "birth of a nation." Richler says the Vimy Myth can be understood today as:

The story that Canada, the modern nation, was forged in the trenches of the First World War, when as the Canadian Corps, all four division of the Canadian Expeditionary Force, fought together for the first time [in the battle of Vimy Ridge], is a story that acts as both a creation myth and cautionary tale. As a creation myth, the story offers an explanation of the country and presents mores, as well as the possibility that a population so absurdly dispersed might actually behave as a unified whole. As a cautionary tale it suggests how best we conduct ourselves in order to navigate our way through the, 'global war on terror' and that a better country will arise out of the ashes of our current turbulent times. ${ }^{80}$

The new Vimy twenty articulates the Vimy myth by depicting a view of the Canadian National Vimy Memorial, itself a key historical representation of the battle. The memorial, designed by the Canadian sculpture Walter Seymour

${ }^{78}$ Department of Citizenship and Immigration. Discover Canada: The Rights and Responsibilities of Citizenship. Canadian Department of Citizenship and Immigration, 2013. http://www.cic.gc.ca/english/pdf/pub/discover.pdf 79 Ibid.

${ }^{80}$ Richler, Noah. What We Talk About When We Talk About War. (Fredericton, Gooselane, 2012).p. 56 


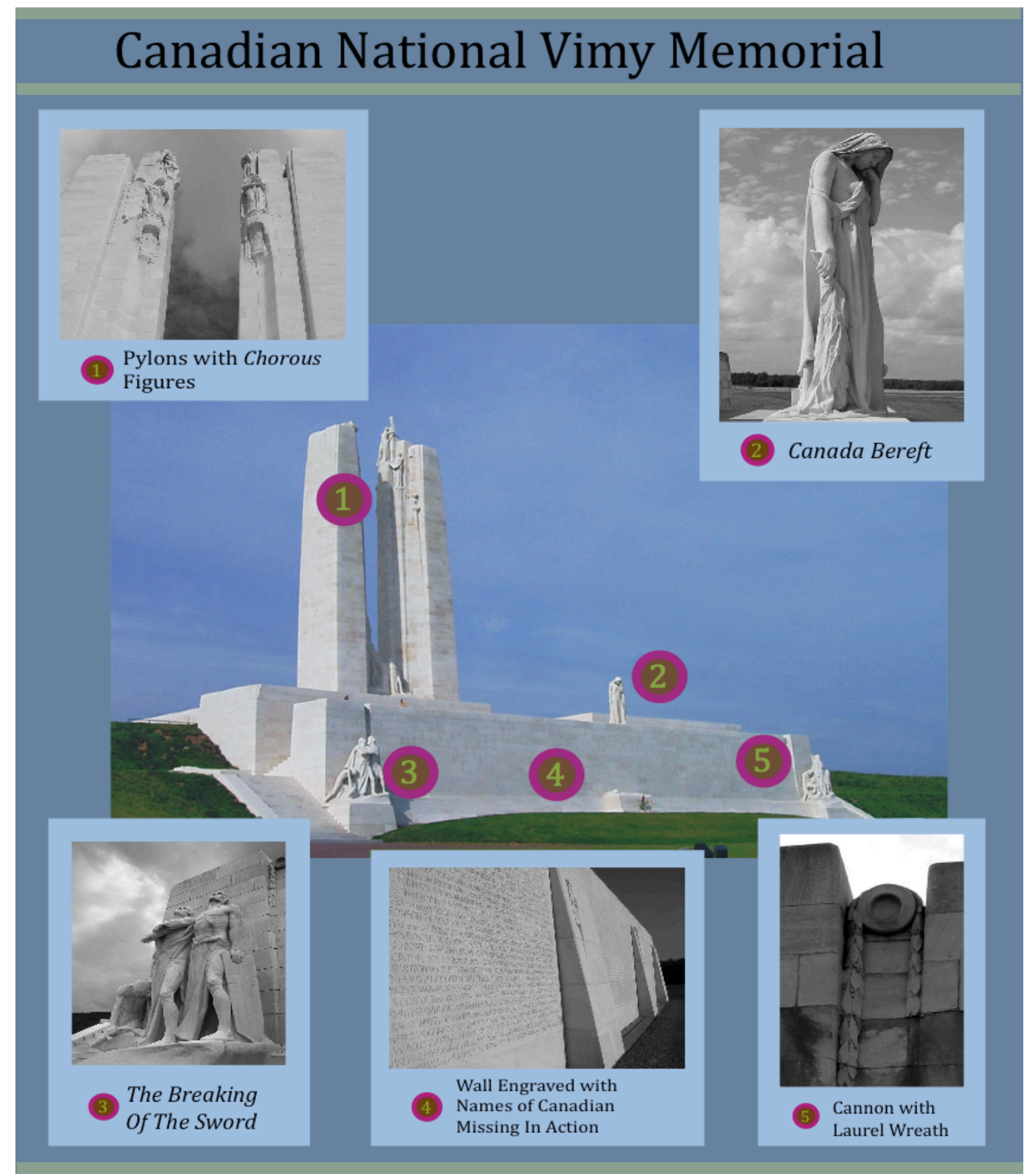

Figure 9 -Canadian National Vimy Memorial Details -

Source: Wikiommons -

http://en.wikipedia.org/wiki/Vimy_memorial\#mediaviewer/File:Vimy_Mem orial_-_Breaking_of_the_Swords.jpg

http://en.wikipedia.org/wiki/Vimy_memorial\#mediaviewer/File:Vimy_Mem orial_Canon.JPGhttp://en.wikipedia.org/wiki/Vimy_memorial\#mediaviewe r/File:Canadian_National_Vimy_Memorial_-_Mother_Canada.jpg 
Allward, was unveiled in July 1936, by King Edward VI, ${ }^{81}$ on the physical site of battle. The memorial is detailed with 20 statues, some of which powerfully create a mournful, sorrow-filled, even anti-war message. ${ }^{82}$ This theme of the monument is most prominently represented by the figure of Canada Bereft (See Figure 8). In this statue the mourning of the nation is symbolized through a veiled female figure with her head cast down in grief. The laurel wreath in her hand, signifying victory, hangs limp, a side note next to the obviously overwhelming grief she is experiencing. ${ }^{83}$ Some of the monuments other statuary details take this symbolism further, most notably with a striking group dubbed by Allward The Breaking of the Sword, which depict a young soldier bent down shattering his sword. The memorial is also accented around its base with carvings of cannons hung with laurels, signifying their silencing in the name of peace. ${ }^{84}$ Perhaps most poignantly, the walls of the memorial are inscribed with the 11,286 names of all the Canadians who were killed in action during the First World War, but whose graves are unknown. 85

81 Department of Veteran Affairs. "The Monument- 1936 Dedication," The Canadian National Vimy Memorial, Veterans Affiars Canada website. Accesed March 12, 2014. http://www.veterans.gc.ca/eng/memorials/ww1mem/vimy/sg/04_monument/0 5_dedicate

82 Ibid.

${ }^{83}$ Hucker, Jacqueline. "The Meaning and Significance of the Vimy Monument" Vimy Ridge: A Canadian Reassesment Editors: Hayes, Geoffrey, Andrew Jarocci, Mike Bechthold. (Waterloo, Wilfrid Laurier Press, 2007). p. 282

${ }^{84}$ Ibid. p.282

${ }^{85}$ Ibid. p.286 
These features make the Canadian National Vimy Memorial a complex and contemplative piece of public art. However, the depiction of the memorial on the twenty-dollar bill does not include any of these features. The landscape of the ridge itself, the site of the battle, the memorial's figures of mourning and de-armament are not included. The representation is a closely cropped, enlarged view of the top of the memorials two pylons (See Figure 9). The figures carved into these pylons envisaged by Allward as a Chorus, comprised of "the figures of Truth, Faith, Justice, Charity, Knowledge and Peace sing(ing) the hymn of Peace," are barely discernable. Instead, the massive pylons are depicted quite simply, with dark shadows throwing their form into a simple silhouette. This silhouette depiction of the memorial, the distinctive shape of the memorial's twin pylons being made its defining feature, fits with other contemporary representations of the memorial. Recent years have seen the appearance of a number of representations of the memorial in this simplified silhouette form.

In 2009 Vimy Ridge Public School was opened in Ajax, Ontario, with the new school's logo featuring a white outline of the Vimy Memorial against the background of a red maple leaf. ${ }^{86}$ In 2012, educational tour company, Education First, produced a special Vimy Ridge hockey jersey to be worn by the youth

\footnotetext{
86 The Vimy Foundation . "Vimy Ridge Public School Under Construction," Vimy Foundation Website. Accessed May 17, 2014. https://www.vimyfoundation.ca/gallery/5
} 


\section{Reverse of Twenty Dollar Bill}

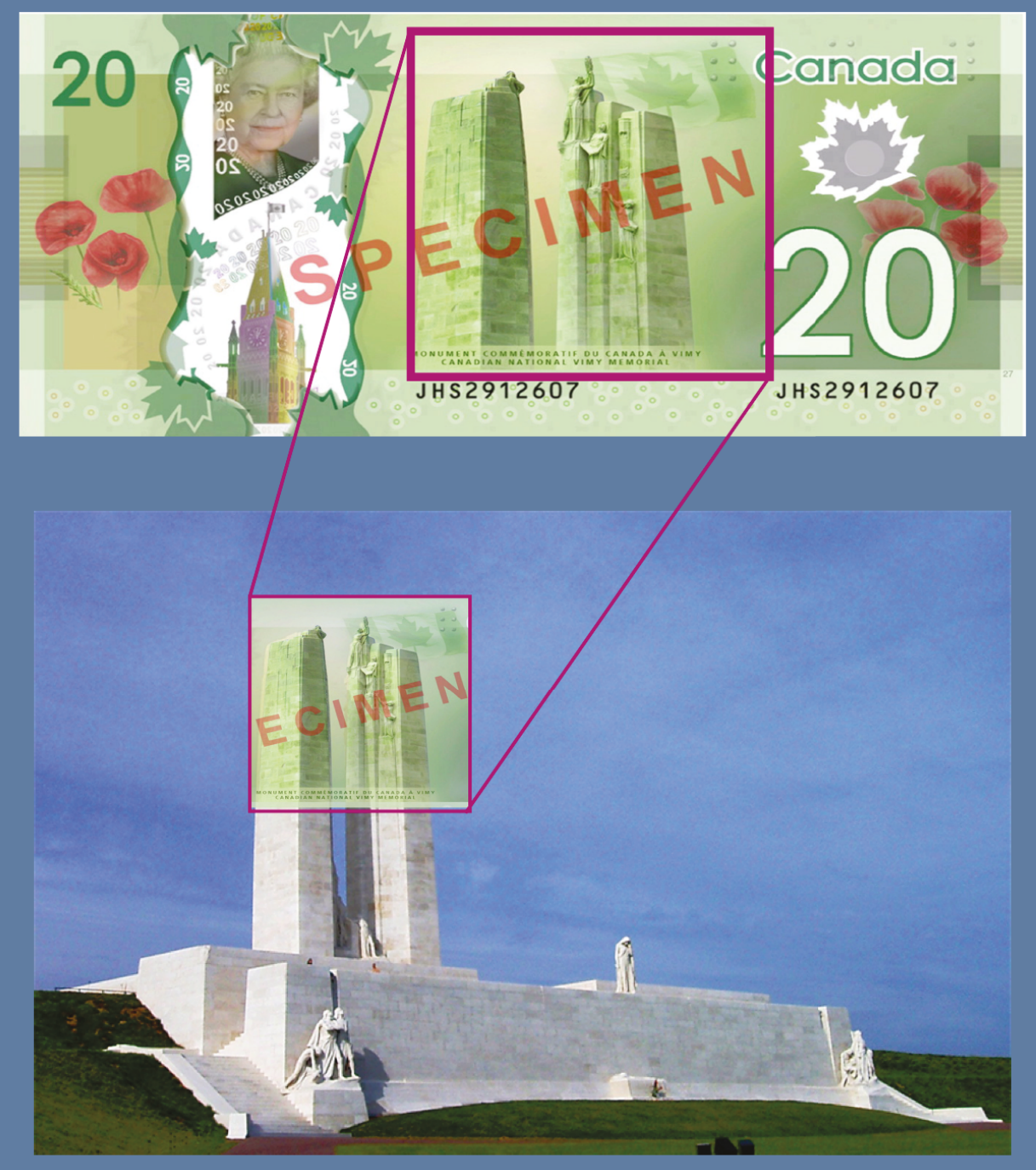

\section{Canadian National Vimy Memorial}

Figure 10 - The Crop Twenty Dollar Bill

Source: Bank of Canada:

http://www.bankofcanada.ca/wpcontent/uploads/2013/05/design_20.pdfV imy Memorial Wikicommons:

http://en.wikipedia.org/wiki/File:Vimy_Memorial_(September_2010)_14_cr opped.jpg 
members of its Vimy: Canada's Coming of Age program, which is based around a trip to France to visit the Canadian National Vimy Ridge Memorial on the anniversary of the battle (See Figure 10) ${ }^{87}$. The jersey features a dark silhouette of the Vimy Memorial with a red maple leaf emerging from behind it. Also in 2009, the Vimy Foundation, a non-profit organization, launched the Vimy Pin, a small pin in the style of a military medal. According to the Vimy Foundation's website, the pin features a ribbon across its bottom that "symbolizes the four divisions that fought together for the first time at Vimy Ridge." 88 The top half of the pin features a maple leaf background, setting off a simple representation of the "iconic two towers of the magnificent Vimy Memorial." ${ }^{89}$ The foundation promotes the pin as "April's Poppy", stating it is their goal that people "wear the pin every Vimy Ridge Day, in remembrance of the outstanding victory on April 9, 1917."90 This pin and promotional program are part of the larger mission of the Vimy Foundation, whose own logo by no coincidence is a simple white silhouette of the memorial, "to preserve and promote Canada's First World War legacy as symbolized with the victory at Vimy Ridge in April 1917, a milestone where Canada came of age and was then recognized on the world stage." 91

${ }^{87}$ EF Tours. "Dave Robinson Presents The Vimy Flag and Jerseys," EF Tours Youtube Channel, April 20, 2012. http://www.youtube.com/watch?v=ko6_MCCl8EI 88 The Vimy Foundation. "The Vimy Pin," Vimy Foundation Website. Accessed May 17, 2014. https://www.vimyfoundation.ca/pin ${ }^{89}$ Ibid. 90 Ibid.

91 The Vimy Foundation. "Mission," The Vimy Foundation Website. Accessed May 17, 2014. https://www.vimyfoundation.ca/mission 
Promotion of the the Vimy Ridge 'birth of a nation' mythology is the central component of the foundations mission. These visual representations of this mythology play an important part of this promotion. Specifically, the foundation has focused on encouraging the use of the trope of the maple leaf emerging from behind a simplified outline of the memoial. Beyond its own logo and the Vimy pin, The Vimy Foundation had a hand in the creation of these other examples of the birth of the nation visual trope. The foundation supported the naming of the new public school in Ajax and the new logo of the school featured on their website. ${ }^{92}$ The company that produced the Vimy hockey sweater, EF Educational Tours, is related to the Vimy Ridge Foundation., through David Robinson, the National Student Tour Coordinator for the company who organizes the annual trips for school children to Vimy Ridge, while also a being a board member of the Vimy Foundation. ${ }^{93}$ Robinson was himself present at Vimy Ridge Public School on November 10, 2012 as a representative of the Vimy Foundation when the Bank of Canada chose the school as the site of the official launch of the bill into circulation. ${ }^{94}$ The foundation played a role in the development of the Vimy Ridge twenty-dollar bill itself, which also features the maple leaf rising from the memorial trope, with a press release on their website

92 The Vimy Foundation. "Vimy Ridge Public School Under Construction," Vimy Foundation Website. Accessed May 17, 2014. https://www.vimyfoundation.ca/gallery/5 93 The Vimy Foundation. "Dave Robinson Bio," The Vimy Foundation Website. Accessed May 17, 2014. https://www.vimyfoundation.ca/node/178 94 Ingino, Joe. "Vimy Ridge Public School Honoured as new \$20 moves into Circulation," The Oshawa/Durham Central, November 12, 2012. 


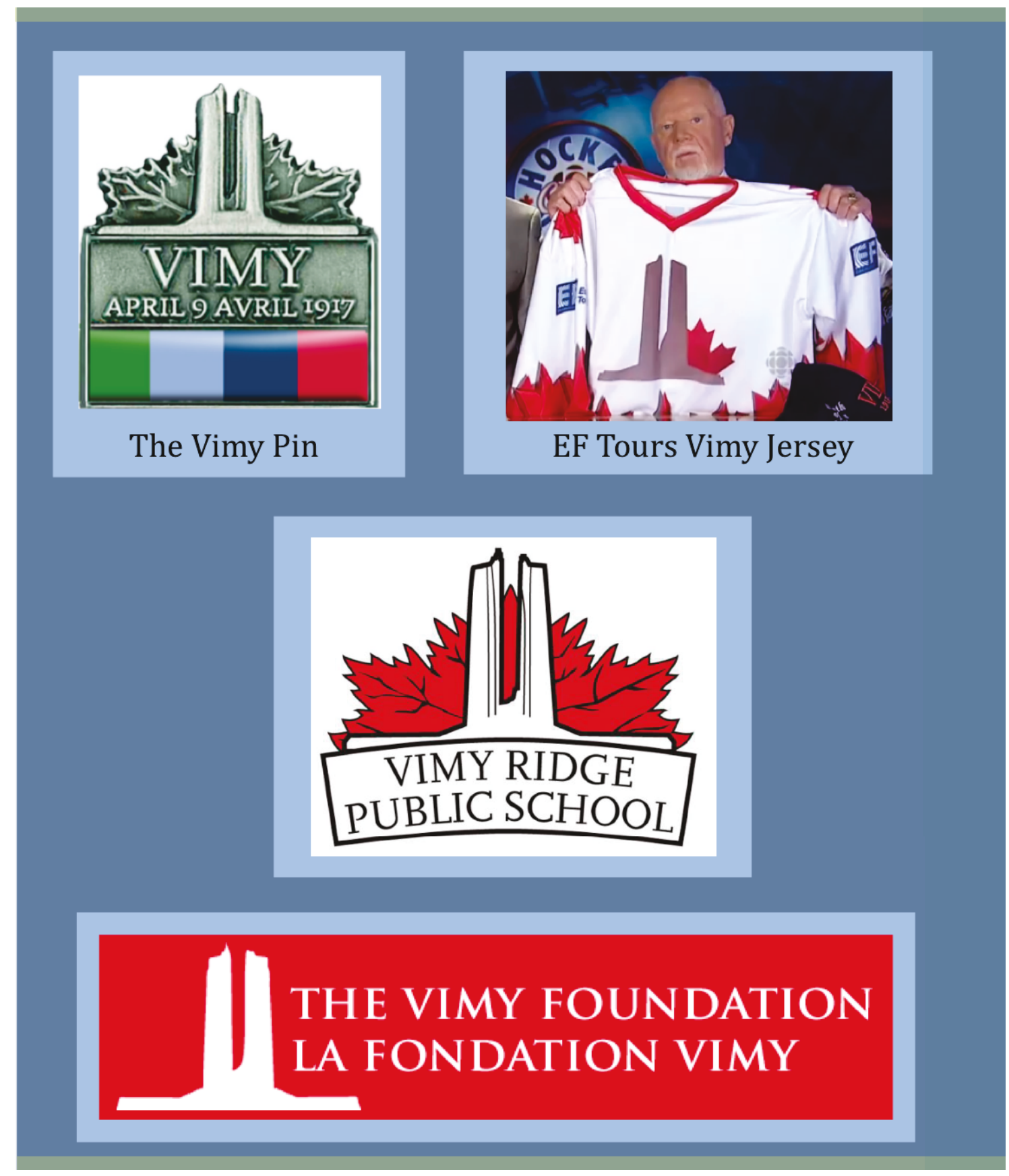

Figure 11 -0ther Vimy Representations

Sources: https://www.vimyfoundation.ca/ cbc.ca coaches Corner, April 7, 2012 -

http://www.cbc.ca/player/Sports/CBC's+Hockey+Night+in+Canada/ID/222 0528646/

http://www.ocentral.ca/vimy-ridge-public-school-honoured-as-new-20-movesinto-circulation/ 
boasting that the foundation was, "proud to have been consulted on this initiative and have given support with regards to the theme and design of the new bill."95

David Houghton, the president of the Vimy Foundation, offered an American comparison in promoting the narrative of the 'birth of a nation' at Vimy, calling it "our Bunker Hill, our Alamo."96 Both of these battles, which have been mythologized from American history, were, in fact, defeats. Similarly, the wider Battle of Arras, of which the Battle of Vimy Ridge was a part, was in the end not a smashing victory, but a prolonged return to a stalemate on the western front. ${ }^{97}$ Reference of the terrible horrors of war, the futility of individual impact on a conflict waged on such a massive scale, and in this case the actual failure to 'win' the wider battle of which Vimy was a part, is ignored in all of the contemporary representations of the memorial promoted by the Vimy Foundation. Criticism which challenges the accuracy of the Birth of the Nation myth, such as that of Jean Martin, who flatly stated in his article in the Canadian Military Journal that, "The battle of Vimy Ridge has nothing to do with the birth of the Canadian nation,"98 does not rattle those who insist on perpetuating the narrative of this particular battle being essential to Canada's existence. As Richler notes, "the purpose of these

95 The Vimy Foundation. "Bank Of Canada Launches New Vimy-Themed \$20 Bill," The Vimy Foundation Website. Accessed May 17, 2014. https://www.vimyfoundation.ca/node/212

${ }^{96}$ Richler, Noah. What We Talk About When We Talk About War. p. 89

97 Martin, Jean. "Vimy April 1917: The Birth of Which Nation," Canadian Military Journal Vol. 18, No.2 (2011). http://www.journal.forces.gc.ca/vo11/no2/06-martineng.asp\#_edn13

98 Ibid. 
mythic stories is inspiration rather than the discomforting truth."99 $0 \mathrm{r}$ as Ian McKay even more succinctly put it, "Warrior Nation promoters do not let the facts stand in the way of a good story."100

The visual trope of the emerging Canadian Flag/Maple Leaf from behind the monument, championed by the Vimy Foundation, is a literal, visual articulation of the "Birth of a Nation" myth. The layering of the memorial, the Canadian flag, and the image itself on the brand new, state-of-the-art polymer bills creates a chronological retelling of the Vimy myth. This visual articulation matches Richler's description of the myth's usefulness in providing a creation myth of Canada's origins in the past, as well as offering a narrative that can inform Canada's military present, casting the contemporary conflicts and the military personnel who fight in the same heroic narrative. The twenty-dollar bill's depiction of the "iconic two towers of the magnificent Vimy Memorial"101 extending into the sky above the ridge transform the memorial into a simplified, ambiguous sign. The Canadian National Vimy Ridge Memorial has been reduced in these examples to a brand mark of the 'birth of a nation' narrative. This simplified Vimy brand can then be used on the twenty-dollar bill and in the other examples seen above by those who want to recast the memorial as solely summoning a monumental, victorious myth of the battle. The mournful and peace-oriented imagery that the actual memorial in France includes have been removed on the twenty-dollar bill, not welcome in the

${ }^{99}$ Richler, Noah. What We Talk About When We Talk About War. p.89 100 McKay, Ian and Jamie Swift. Warrior Nation: Rebranding Canada In An Age of Anxiety (Toront, Between the Lines, 2012) p. 11 101 The Vimy Foundation. "The Vimy Pin," Vimy Foundation Website. Accessed May 17, 2014. https://www.vimyfoundation.ca/pin 
contemporary heroic Warrior Nation paradigm. A simplified, monumental representation of the memorial is what appears on the twenty-dollar bill, and has been given a space among the established symbols of Canadian identity appearing on national currency. "While the image on the notes looks to the past by honouring Vimy Ridge, every other aspect looks to the future," stated Manuel Parreira, senior regional representative for the Bank of Canada at the launching of the bills at Vimy Ridge Public School. ${ }^{102}$ What is brought forward from this 'look to the past' is not a complex articulation of the sorrow, loss, pain, and the ultimate limited success of Vimy Ridge in the larger war effort. As the Vimy Foundation's press release at the time of the bill's unveiling states, "the victory of Vimy Ridge will be depicted on the new bill allowing Canadians to carry a piece of history in their wallets." 103 The simple concept of a heroic victory is what is being brought forward as the foundation of the Vimy myth; the memorial has been transformed into a contemporary, monumental expression of Canada as a warrior nation.

All three of the examples outlined in this chapter articulate their own earnest, monumental narratives of Canada as a nation defined by war. The messaging communicated through these texts, is an understanding of Canada as a nation that has long been a valiant warrior, comfortable in a militant role. These symbols contribute to an overall increased militarization of the everyday

102 Durham Region News. "Bank Of Canada Celebrates New Vimy Ridge Bank Note in Ajax," Durhamregion.com, November 12, 2012.

http://www.durhamregion.com/news-story/3509355-bank-of-canada-celebratesnew-vimy-ridge-banknote-in-ajax/ 103 The Vimy Foundation. "Bank Of Canada Launches New Vimy-Themed \$20 Bill," The Vimy Foundation Website. Accessed May 17, 2014. https://www.vimyfoundation.ca/node/212 
experience of Canadians. The Jets logo boldly brings its military symbolism into the visual experience of hockey fandom in the country, and militarizes one of the more prominent symbols of Winnipeg and Manitoba identity. The twenty-dollar bill will reproduce the Canadian National Vimy Memorial millions of times and ensures that a certain simplified and mythologized representation of the memorial will be recognizable to Canadians after it circulates in their visual lives for decades to come. Finally, the Canadian Fallen Firefighter Memorial brings a contemporary military theme to the national monuments of Canada's capital, by encouraging a strongly militarized understanding of the profession as being a close peer of the military. The memorial challenges Canadians to understand the deaths of firefighters as significant to the nation as a whole, and presents their sacrifice as being made as part of the nation's defense apparatus. New narratives are being articulated in these texts, which define and explain how Canadians should imagine the nation, with soldiers who are ready to 'make the ultimate sacrifice' as the ultimate hero of the nation. As Ian McKay notes, "To an extent that would have seemed mind boggling in 1990, the new warriors have shifted the very meaning of "heroism."104

Visual texts, including the three under discussion here, are playing an important role in articulating and promoting these narratives in Canadian culture. As Hybrid Monumental texts, these symbols communicate the monumental narrative of nationalism of Canada as a Warrior Nation, yet they have not been

104 McKay, Ian and Jamie Swift. Warrior Nation: Rebranding Canada In An Age of Anxiety (Toronto: Between the Lines, 2012) p.283 
noticeable in the cultural landscape of Canada as being particularly disruptive. This is because the messaging of monumental militarism of these texts has been hybridized, in the next chapter they way these texts are defined as much by their hybridity as their, core monumental messaging, will be explored. 


\section{Chapter 2-Hybrid}

Considering the core, monumental messaging of the symbols looked at in Chapter 1, what is most striking is that these symbols articulate the Warrior Nation messaging so brashly, in clear opposition to previous popular narratives, which depict Canada as a country uncomfortable with war and militarism. They do this in an unobtrusive and subtle manner, through their characteristic hybridity. The core expressions of monumental militarism of these symbols have been hybridized through their references to other established narratives of Canadian identity. The hybridization of these other narratives allows those viewers who are well versed with them to feel at home and secure with these representations. However, once these narratives and stylistic elements have been hybridized in a new monumental context, these symbols become disassociated from their previous, oftencontradictory meanings. This chapter looks again at the three examples of Warrior Nation symbols to understand how these texts are defined by this structural hybridization.

The notion of Canada as a nation defined by its role as a global peacekeeper was, as recently as the late 1990 's, the dominant narrative of Canadian identity related to war and conflict. From the time of Lester B. Pearson receiving the Nobel Peace Prize in 1957 for his leadership of the United Nations Suez military force, Canada's conception of its military role in the world has been closely tied to U.N. 
Peacekeeping missions. ${ }^{105}$ Peacekeeping was so firmly rooted in the popular imagining of Canada's military operations by 1991, that the Mulroney Government saw it fit to permanently recognize Canada's peacekeeping efforts with a Canadian Peace Keeping Monument on Sussex Drive. ${ }^{107}$ The words Reconciliation/At the Service of Peace are carved into the stone of the monument; underscoring the theme of a non-aggressive, non-confrontational role that Canada's military was cast within the peacekeeping paradigm. ${ }^{108}$ This conceiving of Canada as a peacekeeping nation extended into popular culture, as evidenced by a line in the extremely popular Molson Canadian advertisement that aired during the NHL playoffs in $2000 .{ }^{110}$ The ad featured "Joe Canada" embarking on a rant of all the great things that made Canada distinct (especially from the United States). ${ }^{111}$ One of the ad's lines played on the 'Canada as peacekeeper' narrative of identity, with Joe proclaiming, "I believe in peacekeeping, not policing", to the rising cheers of an unseen audience. ${ }^{112}$ The War Amps of Canada educational campaign around

105 Bothwell, Robert. “Lester Bowles Pearson," The Canadian Encyclopedia. Last modified August 1, 2014. http://www.thecanadianencyclopedia.com/en/article/lester-bowles-pearson/ 107 Department of Veteran Affairs. "Reconiciliation: The Peacekeeping Monument," Veterans Affairs Canada Website. Last modified February 20, 2014. http://www.veterans.gc.ca/eng/remembrance/memorials/canada/reconciliation 108 Gough, Paul. "Invicta Pax," International Journal of Heritage Studies. Volume 8, Issue 3 (2002). p.210

110 Moslon Canadian Advertisement. "I Am Canadian: The Rant," YouTube Accessed February 20, 2014. http://www.youtube.com/watch?v=WMxGVfk09lU 111 War Amps of Canada. "Never Again!” War Amps Website Accessed March 20, 2014. http://www.waramps.ca/uploadedFiles/English_Site/Military_Heritage/Media/PDF /resource_never_again.pdf

112 Moir, Robin and Joseph Turner. "Never Again Song Lyrics", War Amps Website Accessed March 20, 2014. 
Remembrance Day first released in 1990, centered on the slogan "Never Again", was another example of the peacekeeping myth in popular culture in Canada. ${ }^{113}$ The program was highlighted by a specially composed song, sung by school children across Canada with the repeating refrain;

"NEVER AGAIN! take arms against a brother NEVER AGAIN! take a life without knowing why NEVER AGAIN! stand by to see another baby lose a father Where's the glory? NEVER AGAIN!"114

The Warrior Nation paradigm turns this anti-war message on its head, offering the path to become a hero as sacrificing your life for the nation, fighting an evil enemy. The message of the visual texts focused on in the first chapter suggest the opposite of the 1990's War Amps program; that the glory is in war and that Canada as a nation should be prepared to engage in this glorious undertaking, as it did in the past, again and again. Ian McKay described the Warrior Nation project as being specifically aimed at overturning this previous narrative of peacekeeping. McKay asserts that, "Canada's new myth-symbol complex entails an aggressive campaign to substitute the Warrior Nation for the peaceable kingdom - including a no-holds barred attack on the "myth" of peacekeeping as a key component of the Canadian Identity." 115 A.L McCready also points out the contradiction that the

http://www.waramps.ca/uploadedFiles/English_Site/Military_Heritage/Media/P DF/resource_never_again.pdf 113 Ibid. 114 Ibid. 115 McKay, Ian and Jamie Swift. Warrior Nation :Rebranding Canada in an Age of Anxiety" (Toronto: Between The Lines Publishing, 2013) p.270 
narratives and symbols offered up in the warrior nation paradigm offer because they, "run counter to the predominant Canadian mythologies of peacekeeping and multiculturalism."116

It could be expected that the appearance of this wave of heroic and militaristic representations of Canadian identity as part of the Warrior Nation project, so counter to the peacekeeping paradigm, would lead to a public contestation and debate. Néstor García Canclini describes such a contestation between competing symbols of identity in his text Hybrid Cultures: Strategies for Leaving and Entering Modernity, as a "struggle for a new visual culture in the midst of the stubborn persistence of signs of the old order."117 Yet a struggle over these representations of Canadian identity has not shaken Canadian public life. These symbols have, to a large extent, quietly entered into the national visual landscape. As McKay asserts, "military metaphors and military ways are so much a part of our lives that we can hardly spot them any more."118 This leads to a central question of this research; what is it about the form of these representations of Canada as a militarized society, which allows them to enter into the discourse of national identity construction without major disruption, even when their messaging is in some cases a dramatic reversal from past narratives of Canadian identity as it

\footnotetext{
116 McCready, A.L. Yellow Ribbons: The Militarization of National Identity in Canada, (Halifax: Fenwood Publishing, 2013) P. 40

${ }^{117}$ Canclini, Nestor Garcia. "Hybrid Cultures, Oblique Powers," Media and Cultural Studies Keyworks. Edited: Meenakshi Gigi Durham and Douglas M. Kellner. (Malden: Blackwell Publishing, 2002) p.488 118 McKay, Ian and Jamie Swift. Warrior Nation :Rebranding Canada in an Age of Anxiety" (Toronto: Between The Lines Publishing, 2013).

p. 283
} 
related to war? As has been outlined above, these examples are all fundamentally, militaristic and Monumental, however it is the hybrid nature of this new genre of symbols which allows multiple codes of Canadian identity representation to be employed, facilitating a smooth introduction of conservative, hawkish messaging about Canada's popular relationship with war into the contemporary visual landscape. McCready also points out this hybridity, stating that "the transformation of Canadian culture and society in the post-9/11 moment does not simply break with the tradition of previous legitimating myths of peacekeeping and multiculturalism, but rather actively inhabits and transforms these myths into justifications for increased militarization." ${ }^{119}$ McKay also noted this drawing of past conceptions of Canadian identity in the process of hybridizing and masking the actually sharply different conception of Canada offered in these symbols. For McKay, "Canadians have witnessed an effort to conscript both the distant past and more recent times in reshaping of their country's future."120 These symbols seem familiar, recognizable by nature of this co-opting hybridity, but upon closer inspection the remarkably new definition of Canada and its relationship with war is clearly being established.

Hans-Georg Gadamer, in his landmark text Truth and Method, provides a theoretical explanation as to why symbols that use familiar structures to make sense of a current source of anxiety, such as living in a nation at war, are so

${ }^{119} \mathrm{McCready}$, A.L. Yellow Ribbons: The Militarization of National Identity in Canada, (Halifax: Fenwood Publishing, 2013). p,8 120 McKay, Ian and Jamie Swift. Warrior Nation : Rebranding Canada in an Age of Anxiety" (Toronto: Between The Lines Publishing, 2013). p. 11 
powerful. For Gadamer, “[W]e are always affected, in hope and fear, by what is nearest to us, and hence we approach the testimony of the past under its influence."121 To make sense of the present, to understand how Canada's previous identity as a peaceful nation can reconcile with the decade long war in Afghanistan with hundreds of Canadian casualties, and the prospect of continued conflict in the future, we naturally look to other representations of the nation with which we are comfortable. Following Gadamer's argument, for these new symbols of the Warrior Nation to be effective, they have to overcome the hermeneutic challenge by a process in which, "something distant has to be brought close, a certain strangeness overcome, a bridge built between the once and the now."122 These examples of Hybrid Monumentalism are successful in overcoming this hermeneutic challenge, collapsing the distance and difference between past narratives of Canadian Nationalism as well as narratives of militaristic nationalism, especially from the 'war on terror' paradigm popular in the United States. These narratives are symbolically drawn on to articulate a new narrative of Canada as a Warrior Nation. To illustrate this hybridity, the same three examples from the previous chapter will be examined to see how they each visually summon competing narratives of Canadian identity and nationalistic militarism to overcome this challenge described by Gadamer. All of these bring the viewer, who is familiar with these other conceptions of Canada, or with popular narratives and symbols of militarism

${ }^{121}$ Gadamer, Hans-Georg. Truth and Method (Second Edition) Trans: Joel Weinsheimer and Donald G. Marshall (New York: Continuum, 1989) p. 305 122 Gadamer, Hans-Georg. Philosophical Hermeneutics (Berkley: Universtiy of California Press, 1976) P.22 
from other countries, closer and makes them more comfortable and less concerned with the strikingly militaristic messaging of Canada that is being constructed.

Looking again at the Jets' new logo, the fact that the entire logo is a remake of the RCAF roundel allows it to draw a powerful association with the military. The history of the RCAF in Canada, and military past in general, is fully incorporated into the logo, making it a focus of nostalgia for those with a close association and connection with Canada's military. The RCAF roundel itself is a modified version of the United Kingdom's Royal Air Force Roundel, ${ }^{123}$ meaning that the symbol also articulates a connection with that country and its history of colonial connection with Canada. The compass shape that the logo makes is a nod to the name of the parent company of the Jets franchise, True North Sports and Entertainment. This name is in itself a riff off the line in the Canadian national anthem, which reads, "With glowing hearts we see thee rise/The True North strong and free."124 Both of these references to the north, draw on the narrative of Canadian identity, which places great importance in the exceptionality of Canada as a northern nation, with vast tracts of northern wilderness and harsh winters being the defining element of the nation's culture. This Land Nationalism, though not always easy to notice, is a common theme in Canadian cultural production of national identity. Fundamentally, it is a type of primordialist nationalism, which

123 Royal Canadian Air Force. "The RCAF: 17 Wing Winnipeg," RCAF Website. Last modified February 13, 2014. http://www.rcaf-arc.forces.gc.ca/en/17wing/index.page ${ }^{124}$ Government of Canada. "O Canada," Government of Canada Website. Last modified February 5, 2014 http://www.pch.gc.ca/eng/1359402373291/1359402467746\#a1.1 
links a distinct Canadian character and national traits to characteristics of the particular piece of land that is agreed upon as Canada. This concept comes through in numerous tropes; being tougher because we experience the cold of Canadian winter, being patient and self-reliant because communities big and small are relatively far apart, even the placing of hockey as being so symbolic of Canada is tied to this narrative with the requisite frozen ponds of the hockey in Canadian mythology being a positive outcome of the nations climate. The wildly varying dayto-day experiences of Canadians in different geographic and climactic regions, and rural versus urban settings across the country, are mostly pushed out of the discussion by this Land Nationalism which ties and sells the 'Canadian Experience' as a unifying experience with an imagined national, northern landscape.

By virtue of its location on an NHL hockey jersey, the logo also draws on the extremely powerful narrative of Canadian identity as closely related to the sport of hockey. As soon as the logo was unveiled it became a symbol of hockey in Canada, the Winnipeg franchise in particular, and a regional marker for the city and province as a whole. Regardless of its design, by being sanctioned as the logo of the Winnipeg NHL franchise, it articulates an association with the narrative of the Canadian cultural experience described above by Macgregor and Dryden which places the sport of hockey as, "an instinct, a need, an expectation," within Canadian national imagining. ${ }^{125}$

125 Dryden, Ken and Roy MacGregor. Home Game: Hockey and Life in Canada (Toronto: McClelland and Stewart, 1989). p. 22 
The Canadian Fallen Firefighters Memorial is also notable in its hybridization of different narratives of identity through both its design and its function. PLANT architect, the firm that co-designed the memorial, describes its function as "both to memorialize fallen firefighters and provide a place for their annual Ceremony Service on Ottawa's Lebreton Flats."126 Ritual and ceremony shape the way we understand space, and the clear influence for the annual ceremony at the memorial is Christian religious worship. ${ }^{127}$ The ceremonial space in the center of the memorial is arranged for this annual ritual in the style of a Christian church (See Figure 8), with chairs ordered in rows, all facing an altar table draped in red cloth. The helmets of firefighters killed in the line of duty the previous year are placed in honour on this altar table. The Christian designation of the memorial service is completed and sanctified by the presence of a fire department chaplain. ${ }^{128}$ The physical memorial also features a brass plaque on the north corner of the granite Name Wall, inscribed with The Fire Fighters Prayer, a Christian prayer written by American firefighter A.W. Smokey Linn. ${ }^{129}$ This prayer opens with the line, "When I am called to duty, God", suggesting that the choice to pursue the profession of firefighting is a calling from God. The Land Nationalism

126 Plant Architect. Canadian Firefighters Memorial, PLANT Architect Website. Accessed May 12, 2014. http://www.branchplant.com/landscape/cfm.html 127 Roche, Kelly. "Fallen firefighters honoured at Ottawa memorial," Ottawa Sun, September 8, 2013. http://www.ottawasun.com/2013/09/08/fallen-firefightershonoured-at-ottawa-memorial ${ }^{128}$ Matta, Linda. “Canadian Fallen Firefgihters Memorial Photo Gallery,” PBase Galleries Website. Accessed February 10, 2014. http://www.pbase.com/wakenphotography/image/145993483 129 Lin, A.W. Smokey. "The Fire Fighters Prayer," Firefighters Memorial Website. Accessed March 2, 2014. http://www.firememorials.com/prayer.html 
narrative of Canadian identity is also being referenced through the memorials granite 'Name Wall'. The wall itself is an abstracted version of the Canadian landmass, with the political borders of the provinces appearing as lines approximating how they would appear on a map. ${ }^{130}$ The top of the wall undulates, with its dips and points matching the shoreline of the northern coast of Canada. The back of the Name Wall slopes away in a mound of earth and rock towards the north and the Ottawa River. A close look at this slope reveals that the rocky formations placed on it line up with where the Canadian Shield and the mountain ranges of Western Canada would appear on the abstracted map of the Name Wall. The Name Wall, with its roll of deceased firefighters names, plays on this as well through its abstraction of the political map of Canada, By organizing the names of the deceased firefighters by the province on this map where they died, the tragedy of these deaths becomes a national phenomenon. Like the experience of the weather across the nation, or the national landscape and its wildlife, which we claim as our own, the tragedy of firefighters dying has, through this representation, become a national characteristic. Apart from the Name Wall, another Land Nationalism symbolic device is utilized atop the memorials, "White Pine Tree Rock."131 This 'rock', a sort of island off of the Name Wall, is separated by the opening in the granite wall that allows entrance from the north, off the Ottawa River Parkway (See Fig. 3). This rock is filled with soil and planted with a lone white pine, which will grow above the inscription, "Never To Be Forgotten/Grave

130 Ibid.

131 PLANT Architect. Canadian Firefighters Memorial, PLANT Architect Website. Accessed May 12, 2014. http://www.branchplant.com/landscape/cfm.html 
Dans Nos Memoires". The pine, as it grows, will tower over the opposite end of the sanctuary space from the fireman statue and his pole. The choice of a solitary pine plays on a well-versed trope from the Canadian national art vernacular. Iconic paintings, such as Tom Thomson's West Wind and Fredrick Varley's Stormy Weather Georgian Bay, are centered on the lone pine standing against the elements of the Canadian landscape. Jonathan Bordo has described this practice as signifying the "human presence in the Group[s work] manifested only as a symbolic deposit, most characteristically as the figure of the tree."132 The tree, in this symbolic system, represents the human presence of the white settler society stubbornly claiming and thriving in a hostile landscape. The lone pine on the 'White Pine Tree Rock' adopts this anthropomorphic role in representing the human presence of the deceased firefighters that the memorial was built to honour, by referencing this Land Nationalism device from the Canadian nationalist art tradition. Finally, the re-appropriation of war remembrance traditions and design that the Canadian Fallen Fire Fighter Memorial makes, which has been discussed in Chapter 1, is itself hybridization. The familiarity that many visitors to the memorial have with the traditions around Remembrance Day and war memorials make the entire memorial landscape recognizable, and making it easier to accept the strong assertion that Canadians are to understand Firefighters as similarly heroic warriors in service of the nation.

132 Bordo, Jonothan. "Jack Pine - Wilderness Sublime or the erasure of the aboriginal presence from the landscape," Journal of Canadian Studies, 27. (Winter 1992-93). P.51 
The Vimy Ridge Twenty-Dollar Bill also incorporates multiple narratives of Canadian identity into its design with its simplified depiction of the Canadian National Vimy Memorial discussed at length in the previous chapter. The opposing side of the bill features a portrait of Queen Elizabeth II. Though all coins feature the Queen's likeness, this is the only paper bill that featuring Her Majesty. The monarch's representation on the bill allows the Queen to personify the state of Canada that has issued this bill. Though the Queen is officially the head of state in

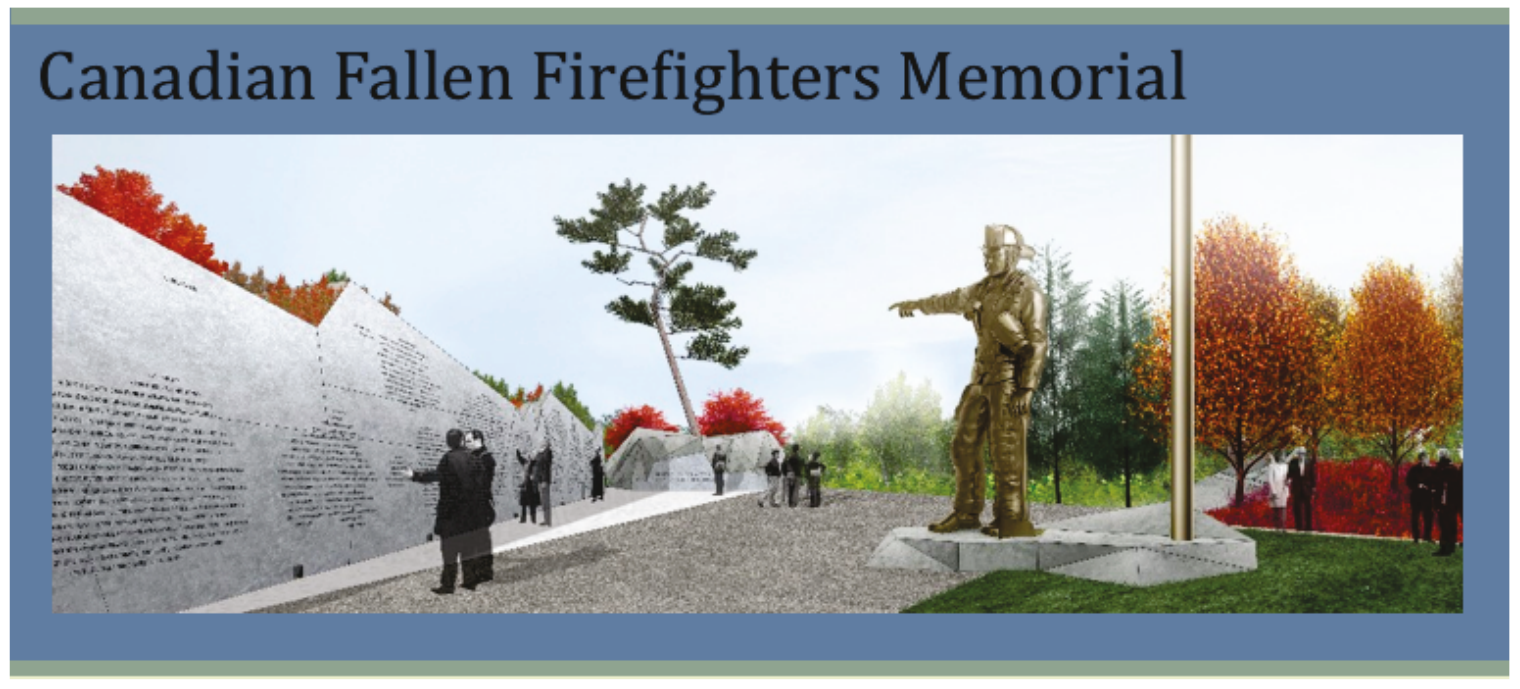

Figure 12 - Design of Canadian Fallen Firefighters Memorial -

Source: PLANT Architects Website http://www.branchplant.com/landscape/cfm.html

Canada, the British-based monarch's role in Canadian public life has declined through Canada's history. This is reflected in the fact that all bank notes formerly featured the sitting the monarch in the same fashion as coins, but today only the twenty-dollar bill feature's the Queen's likeness. The retention of the Queen's 
representation on the twenty-dollar bill makes it a text that visually articulates a connection with Canada's British colonial political and cultural origins, and summons the history of loyalty and devotion to the crown that was a much more prominent part of Canadian national imagining in the past. ${ }^{133}$

Maple leaves and two groupings of red poppies frame the representation of the Canadian National Vimy Ridge Memorial on the bill. The maple leaf is the most prominent of all Canadian symbols, so prominent in fact that it is often not considered as referencing anything beyond the nation itself. However, the maple leaf, a physical product of the flora of the landmass of Canada, is a part of the Land National narrative of Canadian identity production. The acceptance of the maple leaf as the symbol of Canada continually reinforces the connection between the nation and its natural landscape as a fundamental element of Canada's identity. The poppy's inclusion in the bill's design summons the tradition of war remembrance in Canada. The association of the poppy with war remembrance has its origins with the Canadian poet John McCrea whose iconic poem In Flanders Fields first created the association between the soldiers who were being killed on the western front of the First World War, and the red flowers which were the first to grow on the freshly turned soil of their hastily dug graves. ${ }^{134}$ The poppy is a ubiquitous element of Canadian visual culture leading up to Remembrance Day,

133 Bank of Canada. "Polymer Series," Bank Of Canada Website. Accessed April 17, 2014. http://www.bankofcanada.ca/banknotes/bank-note-series/polymer/ ${ }^{134}$ McCrae, John. "In Flanders Fields," Canadian War Museum Web Site. Accessed May 7, 2014. http://www.warmuseum.ca/cwm/exhibitions/remember/flandersfields_e.shtml 
with the wearing of artificial lapel poppies, sold by the Royal Canadian Legion being one of the most widely accepted annual, national rituals. The inclusion of the poppies around the Vimy memorial's image on the twenty-dollar bill signals the Vimy memorial as a war memorial for those not familiar with its silhouette. It also creates an association with established practices of war remembrance in Canada, of which children are educated as they come through the school system, and that are part of annual public ritual each November $11^{\text {th }}$.

The core messaging of monumental militarism of these three examples is in part hybridized through their ability to reference other established narratives of Canadian identity which focus on Canada's landmass and its wildlife, the sport of hockey, as well as military and British Colonial history. The hybridization of these other narratives allow those viewers who are well versed with these narratives feel at home and secure with these representations. However, once these narratives and stylistic elements have been hybridized in a new monumental context, these symbols become disassociated from their previous, oftencontradictory meanings. Here we see an illustration of Barthes conception of mythology. The process of hybridization pushes away the previous meanings associated with the familiar symbols, and in their new context they become examples of Barthes, ideal servants, brining the viewer close and retaining their emotive power, even when the original meaning has through this hybridization in a new contradictory context, "silently disappeared."135 Collapsed into ideal

135 Barthes, Roland. Mythologies (London: J Cape, 1972) p. 117 
servants, these hybridized symbols are effectively dominated by the wider cultural myth of Canada as a natural war-faring, militarized nation.

As was discussed in Chapter 1, this monumental tradition of orthodox warbased Nationalism in Canada, centered on the sacred nature of violent sacrifice for the Nation, is referenced in all three of these examples, fitting them into a long history of monumental representation of war. W.J.T. Mitchell described this history in his text, Art and The Public Sphere where he posited that,

Much of the world's public art - memorials, monuments, triumphal arches, obelisks, columns, and statues - has a rather direct reference to violence in the form of war of conquest. From Ozymandias to Caesar to Napoleon to Hitler, public art has served as a kind of monumentalizing of violence. ${ }^{136}$

Since the 1960's, representations of war in public art have been marked in a number of examples by a genre, which looks to undermine and challenge this monumental form. These Counter-Monumentalist representations are typified by approachability, and a generally more ambiguous expression of national military experience. These representations seek to express a sense of the horror and loss of war without looking to push a consensus view on the value and centrality of war to national identity construction. The prototypical example of this type of CounterMonumentalism approach to war remembrance is the Vietnam Veterans Memorial

136 W.J.T. Mitchell. Art And The Public Sphere (Chicago: The University of Chicago Press, 1990). p. 35 
in Washington D.C., designed by Maya Lin. ${ }^{137}$ Lin's design for the memorial was astoundingly simple, being composed primarily of two intersecting walls of polished black stone, set into the surrounding lawn. ${ }^{138}$ As visitors walk along these walls which gradually slope up to a height of $10^{\prime}$ at their apex they can read the thousands of names of Killed in Action and Missing in Action service members which are inscribed on the rock. ${ }^{139}$ The walls are intentionally finished with a high polish, allowing the visitors own reflection to merge with the names of the killed and missing. ${ }^{140}$ Mitchell describes an inherit duality in Lin's design for the Vietnam memorial as its main strength, saying "[it] can be experienced both as an object of national mourning and reconciliation that is absolutely inclusive, embracing and democratic, and as a critical parody and inversion of the traditional war monument."141 Despite serious opposition to Lin's design when it was selected, it has, according to Cher Krause Knight, been "embraced by an unusually diverse public, and remains enormously popular [...] with the universality of its language confirmed by the proliferation of memorials that adopted its style."142 Mitchell identifies the challenge that orthodox monumental representations face in the contemporary context in which counter-monuments, such as Lin's memorial, have become a part of the visual language of nationalism in North America. For

137 Knight, Cher. Krause Public Art: Theory, Practice and Populism (Malden: Blackwell Publishing, 2008). p. 27

138 W.J.T. Mitchell. Art And The Public Sphere (Chicago: The University of Chicago Press, 1990). p. 35

139 Ibid.

140 Ibid.

${ }^{141}$ Knight, Cher. Krause Public Art: Theory, Practice and Populism (Malden: Blackwell Publishing, 2008).p. 27 142 Ibid. 
Mitchell, "Public sculpture that is too frank or explicit about this monumentalizing of violence [...] is likely to offend the sensibilities of a public committed to the repression of its own complicity in violence."143 The examples of public art being focused on here do not cross the unwritten line in their form described by Mitchell. They do not resemble too closely the genre of Orthodox Monumentalism, yet their message is still best understood as strongly militaristic, and as promoting a consensus view of war as fundamental to the national imagining of Canada. This is accomplished in part through the ability of these Hybrid Monumental representations to retain a fluidity in adopting and absorbing certain elements of Counter-Monumentalism in order to temper their essentially orthodox messaging and, as Mitchell put it, "not offend the sensibilities" of the Canadian public.

Again the three examples of this study illustrate this fluidity in appropriating Counter-Monumental elements into their design. The Canadian Fallen Firefighters Memorial is built around a classically monumental figure of a golden firefighter. This figure evokes the tradition outlined by Mitchel of public art used to monumentalize power and violence in its massive scale and veneration of 'great men'. The visitor standing in front of this massive sculpture is left feeling small and humbled by this anonymous 'great man' statue of a young firefighter, elevated to the status of a timeless hero, dedicated to violent defense of the nation. The dismayed reaction of Cassius to Brutus after the latest glory was, "heap'd on Caesar," in Act 1, Scene 2 of Shakespeare's Julius Caesar, is equally fitting as the

143 W.J.T. Mitchell. Art And The Public Sphere (Chicago: The University of Chicago Press, 1990). p. 35 
imagined reaction of a visitor to the Canadian Fallen Firefighters Memorial, confronted with the enormous golden firefighter:

"Why man, he doth bestride the narrow world Like a Collosus, and we petty men Walk under his huge legs and peep about To find ourselves disnourable graves." ${ }^{144}$

The trope of the physically gigantic, exemplified by Shakespeare figuratively in describing Julius Caesar, and by Coupland physically in the golden firefighter statue, share the powerful code of gigantic representation which Susan Stewart accounts for in her text On Longing: The Miniature, The Gigantic, The Souvenir and The Collection. For Stewart, "The gigantic, occurring in a transcendental space, a space above, analogously mirrors, the abstractions of the institutions - either those of religion, the state, or as is increasingly the case abstractions of technology and corporate power."145 The gigantic nature of the firefighter sculpture reminds the viewer of the abstract concept of the state as a whole, its authority and legitimacy underlined by the heroic sacrifice these largerthan-life defenders make with their deaths for this transcendental concept of the nation. Like walking into a cathedral or standing at the foot of a mountain, the scale of gigantic sculpture orchestrates a confrontation in the viewer with the sublime and provides a physical analogy for the temporal process of

144 Shakespeare, William. Julius Ceasar, Act 1, Scene 2: Line 141. (London: The Folger Library, 1958)

145 Stewart, Susan. On Longing: The Miniature, The Gigantic, The Souvenir and The Collection (Baltimore: John Hopkins University Press, 1984) p. 102 
understanding the concepts of state and nationhood. The concepts for which soldiers, and now in this text firefighters, die is given a physical form fitting its imagined transcendental nature.

The colossal firefighter statue's powerful message, and the other tropes of war remembrance and ritual that are appropriated in the memorial's design, are tempered through adoption of tropes from the Counter-Monumental genre. Maya Lin's Vietnam Veterans Memorial is a close inspiration for some of the memorial's elements, especially the polished black granite Name Wall, engraved with deceased firefighter's names, as well as the sloping entrance from the north into the memorial. The Vietnam Veterans Memorial is well known in popular culture, and for some visitors this similarity acts as a reference point to understand the memorial landscape in Ottawa. The Name Wall brings a very personal focus for the memorial, and like the Vietnam Veterans Memorial, it invites visitors to walk into the memorial, touch the wall and have a more intimate experience with the landscape. Also like Lin's memorial in Washington, the polished granite of the Name Wall reflects the viewers, making their own likeness part of the memorial landscape. This sort of invitation in and involvement of the viewer is typical of Counter-Monumental representation and sits at odds with the sort of monumental messaging that the colossal firefighter brings. The Name Wall's design hybridizes the monumental expression of the colossal firefighter.

The Canadian National Vimy Memorial, uses the engraving of the names of Canadians missing and presumed dead in the First World War to make its memorialization very personal. This design element can be understood as a 
precursor to Lin's work, with this element of the memorial in France making it a nuanced, challenging and notable example among First World War monuments. Yet this element has been erased from the representation of the memorial on the twenty-dollar bill, erasing with it any challenge to the monumental reading of the memorial's silhouette that the bill's representation makes possible. However, both the Vimy Twenty and the Jets logo do adopt and utilize a broader CounterMonumental theme through their ability to straddle the traditional dichotomy of the sacred versus the profane. The division of spaces and objects between those understood as sacred, revered and reserved for society's elite, and those which belong within the profane space of the masses, is fundamental to constructing and encouraging reverence for the nation within the orthodox structure of nationalism. Borrowing from religious conceptions of the sacred, orthodox nationalism invests objects, spaces, certain individuals and professions as being sacred to the imagining of the nation. This sacred designation incorporates national flags, monuments of the nation and the celebration of the choice to serve in the military of a nation as a calling above all others. That this sacred designation is accepted and entrenched in national imagining shows itself in the rules binding the display and treatment of the flag, the public outcry at a desecration of a national monument and the now regular standing ovation given to military members in uniform at sporting events. The genre of Hybrid Monumentalism described here bridges this dichotomy, blurring this orthodox distinction between monuments and symbols of the sacred nation and the profane, everyday space of the people of the nation. The representation of the Canadian National Vimy Ridge memorial on 
the twenty-dollar bill evokes the sacred nature of the physical space of the battle site in Vimy, declared by Prime Minister Mackenzie King as "one of earth's altars". ${ }^{146}$ However, this reproduction on the twenty-dollar bill will quickly become a ubiquitous symbol in Canadians' visual landscape, reproduced millions of times and entering the profane space of their wallets, cash registers and sock-drawers.

The Jets logo is lent a sacred association by its use of the RCAF Roundel, a revered historical symbol of Canada's military. However, the logo is designed to represent a hockey team, and articulate the support of the team and regional and cultural identity of Manitobans. Though the logo is now an important and cherished identity marker in this role, it is not a sacred symbol. This is shown to be particularly true through team merchandising, with the logo now appearing on countless Winnipeg Jets themed commercial items, disseminated out in the profane space of the lives of millions of Canadians. Indeed the very concept of putting a monetary value on something, of selling an RCAF logo for anyone to wear and of putting a representation of the "sacred altar" of Vimy Ridge on the arbitrarily valued twenty-dollar bill, is a contradiction of the priceless and sublime valuation of these symbols as sacred markers of the nation. The effectiveness of the representation of the Canadian National Vimy Memorial and the Jets logo in communicating a notion of sacredness of their inspiration is also immediately diminished by the knowledge of the viewer that what they are looking at, is but

\footnotetext{
146 Martin, Jean. "Vimy April 1917: The Birth of Which Nation," Canadian Military Journal. Vol. 18, No.2 http://www.journal.forces.gc.ca/vo11/no2/06-martineng.asp\#_edn13
} 
one of many, many reproductions. Walter Benjamin noted this sort of process in his essay, The Work of Art in the Age of Mechanical Reproduction, where he observed that "technical reproduction can put the copy of the original into situations which would be out of reach for the original itself."147 For Benjamin, "Even the most perfect reproduction of a work of art is lacking in one element: its presence in time and space, its unique existence at the place where it happens to be."148 Benjamin sums up this unique place in space and the historical testimony of a given representation as its 'aura'. Benjamin argues that what "withers in the age of mechanical reproduction is the aura of the work of art."149 Applying Benjamin's definition, the 'aura' of the Canadian National Vimy Memorial, its unique place and history as a physical marker of where Canadians died in the battle, is precisely what the banknote representation is not capable of recreating. The reproduction of the Jets logo means that is will similarly be incapable of communicating the sacred 'aura' of the RCAF Roundel as a marker of individuals who have chosen the sacred profession of the military.

The elements of the genre of Counter-Monumentalism, with its focus on humanizing, personalizing and making approachable representations of war and violence are hybridized in the three examples of this chapter, however this process does not mean that at their core these examples are fundamentally CounterMonumental. The hybridizing of the sacred/profane dichotomy and the inclusion

\footnotetext{
147 Benjamin, Walter. "The Work of Art in the Age of Mechanical Reproduction," Media and Cultural Studies. Editors: Meenaksji Gigi Durham and Douglas M. Kellner (Oxford: Blackwell, 2001.) P. 50

148 Ibid.

${ }^{149}$ Ibid. p.51
} 
of Counter-Monumental elements does not thwart the core monumental messaging of Canada as a thoroughly militarized nation. Instead, this process creates another route in for viewers to be comfortable with these representations, and to allow these symbols to not as Mitchel put it, "offend the sensibilities of a public committed to the repression of its own complicity in violence, carried out in the public's name by the state's military."150

A final hybridization that these symbols make, is the layering of symbols and tropes of the post-9/11 "War on Terror" paradigm of national militarization that has appeared in the United States, into a Canadian context. As was mentioned in the introduction to the thesis, the terrorist attacks of September 11, 2001 were a culturally seminal moment for all of North America. Although the attacks did not strike Canadian territory, the collective shock and trauma of these violent deaths taking place in North America was felt deeply north of the border. As the Canadian military subsequently joined the United States and other allies in a decade long war in Afghanistan, triggered directly as a result of the $9 / 11$ attacks, the paradigm of the new realities of the "post 9/11 world" became a new normal in the cultural landscape of North America. The three examples of this chapter show how elements of the post 9/11 paradigm have been layered in these Canadian symbols, creating symbols which non-confrontationally hybridize this $9 / 11$ defender heroic narrative into a Canadian context.

150 W.J.T. Mitchell. Art And The Public Sphere. (Chicago: The University of Chicago Press, 1990). p. 35 
The September $11^{\text {th }}$ terrorist attacks in New York City, Pennsylvania and Washington killed 2,753 people. ${ }^{151}$ Three hundred and forty-three of these were firefighters and other first responders who headed into a horrific scene to try and save others. ${ }^{152}$ The majority of people killed on 9/11 however, died in the midst of the normal day-to-day rhythm of their lives, in a wide variety of occupations. That is the nature of violent attacks against civilians; they strike the civil fabric of a community, not just those individuals designated to defend it. The devastating statistic of 658 employees of one financial firm, Cantor Fitzgerald, being killed on 9/11 in One World Trade Centre, painfully illustrates this point. ${ }^{153}$ It is difficult to process the randomness and meaninglessness of a death of a mail clerk or stock analyst just starting work at Cantor Fitzgerald on September 11 $1^{\text {th }}$, but that is the reality of the majority of the victims of terrorism; they were in the wrong place, at the wrong moment. Yet this narrative of terorism will not sell war to the citizens of North American nations, who's own day-to-day lives are astoundingly safe. War necessitates justification to the public when it is fought in distant lands at the cost of Canadian or American lives. War narratives need simple dichotomies of us vs them, enemies vs heroes. The enemy 'other' throughout the post-9/11 epoch has been the 'terrorists'; the heroes have been those who would confront and defend against this difficult-to-define group of threatening enemies. Importantly for this research, it has not been the armed forces alone that have been elevated to this

${ }^{151}$ New York Magazine."9/11 By The Numbers," NY Magazine, September 2012. http://nymag.com/news/articles/wtc/1year/numbers.htm 152 Ibid.

153 Ibid. 
exalted status; firefighters have emerged as peers in this heroic classification. Stemming from the presence of firefighters on the scene in $9 / 11$, and especially because of the deaths of 323 of these firefighters on that tragic day, the profession in general has been re-understood in the post- 9/11 paradigm as part of the heroic defense apparatus. In the introduction to her text, Hero's of Film, Comics and American Culture: Essays on Real and Fictional Defenders of Home, Lisa Detora describes this positioning as being reinforced by "rhetoric that identifies service men and women fighting abroad and police and firefighters as among the most 'real' of American heroes to date." 154 If terrorism threatens the entire fabric of civic life, firefighters have been singled out and elevated out of the general weave of roles and responsibilities into a different class of 'real heroes', responsible for defense, and poised for the possibility of the supreme sacrifice for the nation. The Canadian Fallen Firefighters Memorial can be understood as a massive, physical articulation of this elevation of firefighters to this heroic status. As has been noted above, the memorial unifies the 1,100 firefighters whose names appear on the Name Wall into a narrative that emphasizes their deaths as sacrifices, not simply for the people or property that they specifically were working to save or the city or municipality that employed them, but for the entire imagined community of the Canadian nation. As Peter Hodgins has noted in his study of narratives of the Halifax Explosion, Why Must Halifax Keep Exploding, "Sacrifice has always played an important role in forging communal and national unity and in eliminating any

154 Detora, Lisa. M. Hero's of Film, Comics and American Culture: Essays on Real and Fictional Defenders of Home. (London, McFarlane and Company, 2009). P. 2 
lingering sense that nations and communities are artificial constructions." ${ }^{155}$ The placing of the names of firefighters on the map of the name wall has given the deaths of these men symbolic significance to the nation as a whole. At the same time, the listing of the names by province, not in chronological order, pulls these deaths out of the context of the passage of time, and unites the deaths symbolically as a single collective act of sacrifice for the nation. This removal of a chronological context to the deaths is significant because of the long period from which the names were collected; the earliest death having occurred in 1848.156 The memorial does not provide any notice of this long time period. What it does communicate is that the first chronological death on the memorial, which occurred 19 years before Canadian Confederation to the most recent loss of life are connected by being deeply significant to the nation of Canada today. The collection of 1,100 names on the Name Wall create a sense of awe and anguish when viewed as a whole; it creates the fantasy of a Canadian 9/11-style tragedy and provides the justification for the golden fireman's epic proportion. The Canadian Fallen Firefighter Foundation (CFFF), the organization of firefighter's which co-sponsored the memorial's creation with the Federal Government, is eager to utilize the 9/11 narrative of firefighters as heroic defenders in a Canadian context. The CFFF's emblem is a direct riff off of the 'Yellow Ribbon', ubiquitous in post 9/11 'war on

155 Hodgins, Peter. "Why Must Halifax Keep Exploding?: English-Canadian Nationalism and the Search for a Usable Disaster," Settling and Unsettling Memories. Edited by Nicole Neatby and Peter Hodgins (Toronto: University of Toronto Press, 2012). P. 574

156 Canadian Fallen Firefighters Foundation. "The Memorial," Canadian Fallen Firefighters Foundation Website. Accessed June 2, 2014. http://www.cfff.ca/EN/thememorial/memorial-contract-awarded.html 


\section{Canadian Fallen Firefighters Foundation Logo}

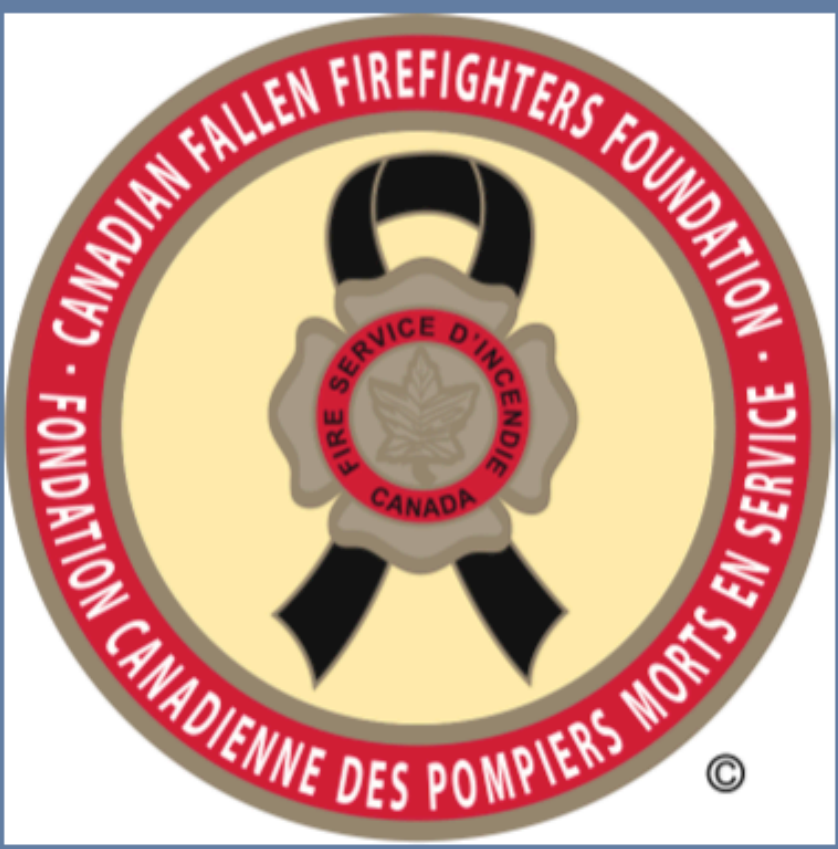

Figure 13 - Canadian Fallen Firefighters Foundation Logo

Source: CFFF Website: http://www.cfff.ca/EN/index.html

terror' North America. (See Figure 7) The effort to create an association between the memorial, firefighter's deaths in Canada, and 9/11 is most clearly underscored 
by the timing of the annual ceremony at the memorial organized by the CFF, which is held annually, on the Sunday closest to September $11^{\text {th }} .157$

The relationship between war-related nationalism and professional sports has also been an important focus of militaristic symbolism in post 9/11 United States. It is important to note that a connection between sport, at the highest competitive levels, and war is not a new phenomenon. George Orwell commented on this relationship in his essay The Sporting Spirit, which was first published in 1945 in the Tribune. For Orwell, "serious sport has nothing to do with fair play. It is bound up with hatred, jealousy, boastfulness, disregard of all rules and sadistic pleasure in witnessing violence: in other words it is war minus the shooting."158 The post-9/11 push to link war with the popular heroism found in the realm of professional sport is not a surprise to David Altheide who posits that "sports are a sure fire source of fan identification."159 These identifications are then played upon in a way that "joins sport and nationalism within popular culture through narratives, metaphors, and emotions." ${ }^{160}$ In the United States, the singing of Take Me Out To Ball Game has been largely replaced in the seventh inning stretch of baseball games with singing of God Bless America, usually coinciding with an

157 Roche, Kelly. "Fallen firefighters honoured at Ottawa memorial," Ottawa Sun, September 8, 2013. http://www.ottawasun.com/2013/09/08/fallen-firefightershonoured-at-ottawa-memorial 158 Orwell, George. The Sporting Spirit. First published: Tribune. London December 1945. Accessed at http://orwell.ru/library/articles/spirit/english/e_spirit 159 Altheide, Davide. Terrorism and the Politics of Fear. (New york, Altamira Press, 2006) p. 185 160 Ibid. p. 186 
acknowledgment of the military members in attendance at the game. ${ }^{161}$ In the realm of professional football, in a tradition that started in the weeks after 9/11, games regularly feature a massive American flag being held by military members, or police and firefighting personal during the national anthem. ${ }^{162}$ In college football, teams such as the Northwestern University Wildcats, have begun to annually wear special uniforms around Veterans Day, which honour the military. ${ }^{163}$ Canadian sports teams have joined this trend, with most NHL teams playing games or warming up in specially designed military tribute uniforms. ${ }^{164}$ The Jets' new logo is a more permanent anchoring of this trend; with the logo on the team's jerseys continually articulating this joining of sport and military nationalism. Bartley Kives argued in the July $31^{\text {st }}$ edition of the Winnipeg Free Press that he finds people's discomfort with the new Jets logo as misplaced "because professional sport has always served as a proxy for the warfare that used to be a more commonplace aspect of Western society."165 Paraphrasing Orwell, Kives says

161 Rumberg, Howie. "God Bless America and Baseball 10 years later," Yahoo News, August 11, 2011. http://news.yahoo.com/god-bless-america-baseball-10-yearslater-043645293.html 162 Golub, Eric. "9/11/11: Why Football Matters," Washington Times Communities, September 8, 2011. http://communities.washingtontimes.com/neighborhood/tygrrrrexpress/2011/sep/8/91111-why-football-matters/ 163 Rovell, Darren. "Northwestern to honor military," ESPN Chicago, November 6, 2013. http://espn.go.com/chicago/collegefootball/story/_/id/9925831/northwestern-wildcats-wear-red-white-blueuniforms

${ }^{164}$ Ferda, Tom. "The Unbreakable Bonds Between The NHL and U.S. Military," USA Hockey Magazine, Issue 11 - 2011. http://www.usahockeymagazine.com/article/2011-11/unbreakable-bondsbetween-nhl-and-us-military 165 Kives, Bartley. “I Salute you, Jets logo,” Winnipeg Free Press, July 31, 2011. 
that, "in the modern context, organized sport serves as a relatively bloodless surrogate for actual war."166 Kives argues that, "all the owners of the Winnipeg Jets have done is make the relationship between pro-sport and the military more obvious than it tends to be." 167 Kives has it half right, the team's logo makes the relationship with the military more obvious, but his notion that it helps people understand pro-sport as a useful 'surrogate' for more dangerous militaristic and nationalist identifications is naïve at best. The logo's symbolism works to quite the opposite effect. The logo, and the message the ownership of the Jets have attached to it in their attempt to provide authenticity to the Jets' brand, creates a symbol which encourages comfort and attachment to militarism. This comfort and attachment in turn make it less likely that fans will question the role of war and violence as an acceptable way of dealing with other nations and individuals, instead internalizing the assertion that Canada is at its core a military, Warrior Nation. The era of war on, and defense, against international terrorism is centered on the 9/11 terrorist attacks in the United States. They represent the anxiety that the specter of terrorism has brought to North America and the underlying justification for both the United States and Canada engaging in the long and bloody armed conflict in Afghanistan. However, for Canadian Identity imagining, the 9/11 paradigm presents a double problem in that it contradicts both the narrative of Canada as a peacekeeping nation, while the adoption of such an American cultural

166 Ibid.

167 Ibid. 
narrative contradicts the deep tradition of defining Canadian culture in contrast to the United States.

McCready has analyzed the ubiquitous Yellow Ribbon, mentioned above, in his text Yellow Ribbons: The Militarization of National Identity in Canada. As an articulator of the Warrior Nation narrative of identity, he points out that this, originally American, symbol's non-specific nature makes it particularly powerful. McCready argues that, "in spurring the growth of popular identification of national belonging and virtue with soldiers and forms of militarized engagement, the Yellow Ribbon's ambiguity is devastatingly effective." ${ }^{168}$ Again, Barthes conception of myth proves valuable in understanding McCready's argument. As an open and ambiguous symbol, the history and the context of the specifically American Yellow Ribbon, "silently disappears: all that is left for," a viewer of the Ribbon is, "to enjoy this beautiful object without wondering where it comes from."169 Any gap or question of its meaning is filled with the mythology that it is the focus and articulator of, the myth of the glory of death and sacrifice for the Warrior Nation.

The Vimy Twenty-Dollar bill's representation of the Canadian National Vimy Memorial, and the other very similar examples of the memorial's representation looked at above, transform the memorial's silhouette into this sort of ambiguous sign, leaving it free to be used in the Warrior Nation narrative. Though it would be too much to suppose that it was an intentional design element, the two pylons represented as they are on the twenty-dollar bill resemble the

168 McCready, A.L. Yellow Ribbons: The Militarization of National Identity in Canada, (Halifax: Fenwood Publishing, 2013) P. 41 ${ }^{169}$ Barthes, Roland. Mythologies. (London: J Cape, 1972) p. 117 
iconic towers of the World Trade Centre. Members of the Canadian public who were used to review the bill's design through a focus group process pointed out this comparison. ${ }^{170}$ One focus group member commented, "My first thought when I looked at the back of this bill was the Twin Towers because I've never seen this monument, ever." 171 This comment is obviously anecdotal and cannot be generalized, however it illustrates how the sort of ambiguous representation the bill makes of the memorial can be used to build a new meaning and focus of mythology for those who do not recognize or know what Vimy Ridge is and what the monument there looks like. The hybridity of the Vimy twenty relies on this ambiguity to act as a bridge between the historically based narrative of the Vimy myth and the contemporary Warrior Nation narrative of Canadian identity.

The ambiguity of these symbols of the Warrior Nation of Canada fit with A.L. McCready's perceptive argument that militarization in the 2010's, "is not simply a particular set of values or bombastic glorification of militarism, but a dense cultural fog that has descended over the national imagination, one that seeps into the cultural production in complicated ways that blur the lines between structure and agency, jingoism and ambivalence, power and autonomy and state, market and citizenry."172 The hybridity of these symbols fit this description of militarism in North America through their layering of different narratives and

170 Madan, Richard. "Canadian's see Two Towers, Pornography in $\$ 20$ design," CTV News, May 6, 2012. http://www.ctvnews.ca/canadians-see-twin-towerspornography-in-20-bill-design-1.806190 ${ }^{171}$ Ibid. 172 McCready, A.L. Yellow Ribbons: The Militarization of National Identity in Canada. (Halifax: Fenwood Publishing, 2013) P. 107 
tropes to create polysemic signs, which rely on individuals' given saliency with different elements of these texts, to draw different meanings and messages out of the 'dense cultural fog'. In this context what is meant by salience, is the relative importance a viewer attributes to a given part of a sign. What each viewer of these Warrior Nation texts sees, what message they take away from these intentionally hybridized and complex symbols relates directly to their personal experience, knowledge of Canadian and North American culture, history and their individual emotional attachment to other symbols and myths of Canadian national identity. All of these factors condition the viewer, making them predisposed to view certain elements of these symbols as more prominent and important than others. If a viewer is particularly knowledgeable about Canadian history or if their own family has a personal connection to the military, the Vimy Memorial or the RCAF Roundel are more likely to jump forward as important elements to them, making this historical connection appear as the symbols' most important element. Canadians with a family history in the country in its second, third or more generation are likely to have a higher degree of saliency with the historical context of these symbols. These are the Canadians who are more likely to have had a father, or grandfather who fought in a World War. For these groups, the connections are more likely to be deeply personal. Another viewer, uninitiated with this historical context, and with no experience or personal connection to the military and its history, might simply see a generic monument on the twenty-dollar bill. For example, the ubiquitous symbol of the poppy, which is included with the Vimy Memorial's representation, is certainly more recognizable to a wider group of 
viewers as related to Canadian War dead remembrance. Yet, the comment from one focus group tester of the new twenty-dollar bill that it "looks like the Two Towers of the World Trade Centre" shows how widely ambiguous, polysemic signs can be read by different individuals. Similarly, the Jets logo to someone unaware of the history of the RCAF Roundel, would be wholly dominated by the CF-18 silhouette and its layering on a maple leaf. Its employment of the Jet creates a connection to American inspired militarism, particularly the sort of heroization of Jet pilots; most famously characterized by the Tom Cruise film Top Gun. Without the historical context that knowledge of the RCAF roundel brings, it can be read as a blunt, cotemporary statement of militarism in Canada as being similar to popular conceptions of militarism in the United States. Finally, the CFF Memorial offers to a passerby, or a new viewer approaching the landscape, a simple monumental message of the heroism of firefighters through its massive statue. The hybridization of this message occurs with the other elements, which pull on different genres of memorialization and nationalism. These temper the brash statement of the golden firefighter and his fire pole to the sky, but viewers first need to walk into the landscape to appreciate them, and must have a knowledge of the symbols and codes of these forms in order for a more rounded understanding of the landscape to be appreciated. What a viewer takes away from these texts depends on the individual's salience with the codes of representation employed in these symbols. They are open enough to offer a simple explanation of Canada's present militarized moment in different ways to different people, offering up at their core and most obvious through their monumental elements, easy to decipher 
messages of heroism and militarism. These different elements can act as a way in for viewers, uneasy or unsure of the messages these symbols are making, or act as a part of the 'cultural fog' described by McCready, obscuring the core militaristic nationalism of these symbols to those unaware of the symbolic devices being used.

The three examples of this chapter pull on the cultural practices from the United States that have emerged as part of the 9/11 paradigm. The tropes of firefighters as defense heroes, the layering of national sports and the military, as well as the use of intentionally ambiguous signs, are all hybridized into these symbols. This hybridization makes them recognizable as part of the general 9/11 "defender" paradigm of which the Warrior Nation narrative of Canada is a part, yet allows them to remain recognizably Canadian and not over-stepping the bounds of being too overtly militarized. The hybridity of these symbols, their ability to draw on different established narratives of Canadian identity, the counter-monumental genre of design and 9/11 defender paradigm tropes, allow them to overcome the hermeneutic challenge presented by Gadamer. These other narratives and tropes bring viewers with the desired and required saliency, closer to these symbols and their core monumental, militaristic message. The hybridity of these symbols is what allows them to form Gadamer's, "bridge built between the once and the now." ${ }^{174}$ The strangeness, of the monumental Warrior Nation narrative that these symbols articulate, "has been overcome". The hybrid nature of these symbols of Canada as a Warrior Nation does make them more familiar, tempering their core

${ }^{174}$ Gadamer, Hans-Georg. Philosophical Hermeneutics. (Berkeley: Universtiy of California Press, 1976). P.22 
message. However, their hybridity, their layering of theme upon theme, also makes them perfectly fit into McCready's description of militarism in the contemporary moment as, "a dense cultural fog." These are foggy symbols; their jingoistic messaging is obscured by their own design, which intentionally blurs the lines between competing narratives and genres to build non-obtrusive yet powerfully effective pro-war symbols. These symbols in their hybrid monumentalism visually articulate the process pointed out by Mackay through which, "both the distant past and more recent times," get conscripted in overt attempts to rebrand Canada as a Warrior Nation. Through unconscious naivety or uncaring indifference, the notion of a sacred aura of the origins of the symbolic elements of these texts in relation to their historical context has been disregarded in the process of hybridizing them into Warrior Nation symbols. 


\section{Chapter 3 - Just another Brand}

Through the first two chapters of this discussion, the examples of Hybrid Monumentalism under examination have been treated as visual texts from the general perspective of art history; breaking down their elements, pulling out their tropes and codes of representation. Yet these symbols are hybrids because they cannot best be understood as being definable in any single category. To continue understanding these symbols as agents on their own, and understand what they themselves $d o$, it is vital to understand them not singly as artistic representations, but also as brand markers. Understanding these symbols as also being hybrids between art and branding, allows a different language and perspective based on brand identity production to be brought into the discussion, which can provide the best explanation of the process by which these symbols were created.

Alina Wheeler, in her textbook, Designing Brand Identity, defines a brand as, "the promise, the big idea, and the expectations that reside in each customer's mind about a product, service or company." 175 The desire of each producer of these symbols is to define and authenticate the, 'big idea' of their product, in a way that is specifically appealing to their target market. When a company or individual is looking to evaluate their brand they will engage in a brand audit. This process, takes stake of the current brand identity of an entity and leads to recommendations on how further branding should take shape. An early stage in the brand audit process described by Wheeler, is a survey of the range of

175 Wheeler, Alina. Designing Brand Identity. (Hoboken: John Wiley and Sons, 2006). p. 4 
stakeholder's invested in a given brand. ${ }^{176}$ She argues this is critical because, "each organization needs to identify and prioritize the constituencies that affect its success." 177 Wheeler describes this process as, "Identifying key stakeholders and gaining insight into their characteristics, behavior, needs, and perceptions as a critical success factor."178 Taking this approach to the three texts looked at in this study, key stakeholders involved in these symbols creation can be identified.

In the case of the design of the Jets logo, the Brand Identity Slideshow that was used by TNSE as part of the logo's release, is a useful resource. It credits the design of the logo to collaboration between the sports wear company Reebok, the National Hockey League and the ownership company of the team, True North Sports and Entertainment. ${ }^{179}$ Reebok has an important stake in the logo's design and the larger brand of the Jets because they will be looking to share the profits of the merchandise they exclusively produce, marked with the Jets logo. While the NHL has an interest in seeing the brand of the team fitting into the larger brand of the entire league, and also share in merchandizing profits with the team. The Canadian Forces and the Department of National Defence (DND) are also thanked, a hint at the collaboration between the team and DND, based on the formal agreement signed between the two over the roundel's use. Through this agreement between the team and, "Her Majesty the Queen in Right of Canada as represented by the Minister of National Defence," the Federal Government also became a key

\footnotetext{
176 Ibid. p. 90

177 Ibid.

178 Ibid. p. 90

179 The Winnipeg Jets. "Winnipeg Jets Brand Identity", Winnipeg Jets Website, 22 July, 2011. http://jets.nhl.com/club/gallery.htm?id=23491,
} 
stakeholder in the Jets. ${ }^{180}$ The fans of the team in Winnipeg, across the province and country are also important stakeholders in the team's brand identity. They are the customers, they represent the market that needs to engage and accept the brand, because they are the ones that will fork over their own money for Jet's jerseys and tickets. Finally, the general public is an important stakeholder in the new teams brand. Those not inclined to be fans of the team or hockey at all, need to be considered as stakeholders because as has been noted earlier, the brand will be reproduced and circulated widely in the visual landscape of the public. If the new Jets brand were to come through as offensive or even simply unattractive, the public discussion and backlash would hurt the brand, and dissuade future costumers, and certainly reduce the chance, of the brand will being accepted as a wider identity marker. The graphic designer or artist who specifically designed the Winnipeg Jets logo, and what their individual artistic vision was, is unknown. Instead the logo has to be understood as the result of a collaborative design process that looked to satisfy the different needs and perceptions of all of these stakeholders, to create a credible and marketable brand.

The Vimy Ridge twenty-dollar bill's designer is also unknown, the design being made inhouse at the Bank of Canada. What is clear is one of the most important stakeholders in the bills design was the Vimy Foundation. In a press release published on the day of the design's unveiling the foundation boasted that

180 Rennie, Steve. "Canadian military has final say on Jets logo," The Globe and Mail, November 19, 2011. http://www.theglobeandmail.com/sports/hockey/canadianmilitary-has-final-say-on-jets-logo/article4183945/\#dashboard/follows/ 
they were, "consulted on this initiative, and have given support with regards to the theme and design of the new bill."181 A look at the foundation's leadership and supporters reveals some of Canada's most prominent Warrior Nation promoters. The honourary chair of the foundation is retired General Rick Hillier, who put a great deal of energy during his tenure as Chief of Defense Staff into promoting and rebranding of the Canadian Forces as a world class, military and not a peacekeeping oriented force. ${ }^{182}$ Hillier was unequivocal in his vision of the military as aggressive and offensive declaring sharply, "We are not just another department. We are the Canadian Forces, and our job is to be able to kill people."183 Joinning Hiller at the Vimy Foundation, as chair of the foundation's advisory board is prominent military historian, J. L. Granatstein, who Ian MacKay described as, "the doyen of the new warrior historians." 184 In the Afghanistan War era Granatstien has become a fixture of public commentary on the war, publishing a book titled, Whose War Is It? How Canada Can Survive in the Post 9/11 World ${ }^{185}$, as well as contributing to the Discover Canada citizenship guide discussed earlier, and

181 The Vimy Foundation." The Bank of Canada Launches New Vimy-Themed \$20 Bill The Bank of Canada Launches New Vimy-Themed \$20 Bill," Vimy Foundation Website. Accessed May 17, 2014 https://www.vimyfoundation.ca/node/212

${ }^{182}$ Saracino, Peter. "Rick Hillier," The Encyclopedia Britanica. Last modified October 22, 2013. http://www.britannica.com/EBchecked/topic/1490553/RickHillier 183 Ibid. ${ }^{184}$ McKay, Ian and Jamie Swift. Warrior Nation :Rebranding Canada in an Age of Anxiety" (Toronto: Between The Lines Publishing, 2013) p. 8 185 Ibid. 
serving as CEO of the Canadian War Museum. ${ }^{186}$ Strong and vocal views of Canadian identity as fundamentally defined by the military make both Hillier and Granatstein perfect fits as leaders of the Vimy Foundation, in its mission is to promote the Warrior Nation paradigm of Canada's past and present by focusing on the narrative of Vimy as the critical moment in Canadian history. The Vimy Foundation has found a perfect champion of its products and message in Don Cherry. During his wildly popular Coaches Corner segment during CBC's Hockey Night In Canada broadcast every Saturday night, Cherry has continually promoted and supported the military in the post 9/11 era. On the segment closest to April 9th, he has specifically encouraged Canadians to celebrate the day as "Vimy Day", showing off both the Vimy Ridge Jersey and Pin discussed in chapter one. ${ }^{187}$ In the opening of the April $7^{\text {th }} 2012$ segment Cherry proved his usefulness as a mouth piece for the Vimy Foundation's mission declaring, “On the $9^{\text {th }}$ coming up it is Vimy Day, it is very important in Canada, and I know the lefties don't like that, but it made us a nation as they say...birth of a nation...all the troops say 'this was the first team Canada."188 With this caliber of prominent leadership and supporters, getting behind the singular goal of promoting a heroic narrative of Vimy as a essential, formative battle in Canadian history and identity, the role of the Vimy Foundation

186 Canadian Department of Citizenship and Immigration. Discover Canada: The Rights and Responsibilities of Citizenship. Canadian Department of Citizenship and Immigration, 2013. http://www.cic.gc.ca/english/pdf/pub/discover.pdf

187 CBC Sports. “Coaches Corner,” CBC Sports, April 7, 2012. http://www.cbc.ca/player/Sports/CBC's+Hockey+Night+in+Canada/ID/2220528 646/?page $=16 \&$ sort=MostPopular 188 Ibid. 
as a "consultant and supporter" of the twenty dollar bill during its design makes them an important stakeholder and partner in the design and promotion of the Vimy twenty as part of their mission

The Harper Government is a key stakeholder in the branding of Canada through the design of all the national currency. As was described in Chapter 1, physical currency is a prominent and ubiquitous space where national representation is expected to appear. Because of this the Federal Government has an interest in ensuring these representation fits with their own branding and political messaging. When there was a public backlash over the revelation that the design of the one hundred dollar bill, released in 2011, had been revised after focus groups reported one of the scientists depicted on the bills reverse appeared "too Asian", the Governor of the Bank of Canada was forced to apologize. ${ }^{189}$ In the subsequent reporting it was revealed that the Minister of Finance's signature was required on the final design of any new bill, shedding light on the supposed arms length distancing between the Federal Cabinet and the Bank of Canada. Through this concrete connection, the Harper Government maintains control as a key stakeholder in national currency design. ${ }^{190}$ The general public of Canada is the target market and an important stakeholder in the messaging made on the nation's currency. Though the public did not have a choice to 'buy' this product when the

189 Beeby, Dean. "Canada \$100 Bill Controversy: Mark Carney, Bank Of Canada Governor, Issues Apology," The Huffington Post, August 20, 2012. http://www.huffingtonpost.ca/2012/08/20/asian-100-billcarney_n_1810925.html 190 Madan, Richard. "Canadian's see Two Towers, Pornography in $\$ 20$ design," CTV News, May 6, 2012. http://www.ctvnews.ca/canadians-see-twin-towerspornography-in-20-bill-design-1.806190 
bill entered circulation, it immediately became a fixture of the visual landscape of Canadians as they use it in their daily lives. The public perception of the representations on currency requires the same sort of consideration of not offending the wider pool of customers, as when a company puts a new product on the market. As established markers of national identity, the images on Canada's currency do change over time, but to avoid controversy, they must stay within the bounds of the generally accepted symbols and attached narratives of Canadian identity of the Canadian public.

The Canadian Fallen Fire Fighters Memorial is a different case in terms of authorship, because its design is credited to a collaboration between Douglas Coupland, and PLANT Architect a Toronto based firm. ${ }^{191}$ The design was picked through a competition from a final list of five entries, picked by jury made up of Canadian Fallen Firefighter Foundation representatives and 'design professionals'.192 Douglas Coupland's artistic vision for the memorial landscape, which he described as a desire for the, "monument to convey deep emotion and simple dignity," 193 needs to be respected. However, it is significant that as an artistic work, this memorial needed to jump through a number of hoops, held by powerful players, to become a reality. The five artists picked as finalists were

${ }^{191}$ CBC News. "Douglas Coupland designs firefighters monument," CBC News, September 9, 2010. http://www.cbc.ca/news/canada/ottawa/douglas-couplanddesigns-firefighters-monument-1.933910 192 Ibid.

${ }^{193}$ Canadian Fallen Firefighters Foundation. "The Memorial," Canadian Fallen Firefighters Foundation Website. Accessed June 2, 2014. http://www.cfff.ca/EN/thememorial/memorial-contract-awarded.html 
paired with architectural firms also picked by a CFFF and NCC panel. ${ }^{194}$ On April 7, 2010 the short listed artist/architect teams visited the site with the NCC and CFFF representatives and, "received detailed requirements and instructions for the design competition." 195 Then on August $5^{\text {th }}$ the finalists were invited to Ottawa to present their designs to the jury, who then deliberated and picked a winner. The CFFF itself as patron and driving force behind this project is clearly a central key stakeholder in the branding of the memorial. The CFFF is a not-for-profit organization made up mainly of firefighting professionals and leaders from across the country, which was formed explicitly to, "construct a national memorial to Canada's fallen firefighters, conduct an annual national memorial service, and support their families." ${ }^{196}$ Because the memorial itself is this foundations primary purpose, the messaging it would communicate was obviously a central concern of the organization. Along with the CFFF, two powerful entities in the domain of public art in the nations capital also had significant influence over the project and its final design. To begin with the National Capital Commission was an integral part of the project, Marie Lemay, CEO of the NCC at the time described this relationship in 2010 saying, "the NCC has collaborated closely with the CFFF on this unique monument."197 This collaboration was important because the NCC's approval for the use of its land for the memorial on Lebreton Flats, adjacent to the Canadian

194 Ibid.

195 Canadian Fallen Firefighters Foundation. "The Journey To Build The Canadian Fallen Firefighters Memorial," Courage: The Official Publication of The Canadian Fallen Firefighters Memorial. Vol. 6 (2010) http://read.uberflip.com/i/31928/49 p. 46 196 Ibid.

197 Ibid. p.47 
War Museum was required. The NCC also sent members of its Advisory Committee on Planning, Design and Realty to give official input on each proposed design to the jury before they made a final decision on the design. ${ }^{198}$ The other powerful entity that was integral to making the memorial a reality was the Federal Government. In the search to secure funding for the eventual 5 million dollar price tag for the memorial, the Department of Heritage was successfully lobbied to provide 2.4 million in support. ${ }^{199}$ Though there is no record of final approval from the PMO or Cabinet for the memorial's design, their financial commitment to the project, through Heritage Canada, as well as the indirect link through the NCC as an arms length corporation funded directly from the Federal level, makes the Harper Government an exceptionally powerful stakeholder in the memorial. All three of the examples of this study then, when looked at through the lens of a branding audit, were created under the influence and responding to the needs of their respective group's of key stakeholders. The representations, which resulted, the visual branding which the Winnipeg Jets, Bank Of Canada and the Canadian Fallen Fire Fighters Foundation decide upon all fit neatly into the Warrior Nation myth of Canadian identity. This is partly due to the influence of the same key stakeholder being instrumental in all three examples, the Harper Government.

The fact that these relationship between private entities, arms length corporations and the government is difficult to spot, and hard to formally account

\footnotetext{
198 Ibid.

199 Canadian Fallen Firefighters Memorial. "The Memorial” Canadian Fallen Firefighters Foundation Website. Accessed June 2, 2014. http://www.cfff.ca/EN/thememorial/memorial-contract-awarded.html
} 
for is intentional. The appearance of these texts popping up separate from government influence and funding, allows them to serve as further corroborating proof that Canada is indeed a Warrior Nation. A.L. McCready pointed to these difficult to pin down sort of relationships as, "[ke]y to the cultural production of militarization today across distinct texts and genres." He argues they, "blur the lines between cultural and creative independence and autonomy and direct government oversight." 200 The fact that these other stake holders played a role in creating these symbols, serves the Harper government by making the Warrior Nation myth appear as a grassroots, widely held set of narratives and symbols. The murkiness of the Harper government's role in creating these symbols hides the fact that depicting Canada as a nation comfortable with war and defined to a larger degree by its military past and present is a central strategic plank of the Harper Government's own branding. As Richard Nimijean pointed out, "branded states depend on trust and customer satisfaction." ${ }^{201}$ Just like a company selling a product, governments need to establish and maintain the brand of the state it is running, and like a corporate entity needs to ensure its customers, the voters, trust and find resonance with, the brand. In using their influence to encourage and directly assist the creation of these representations of the Warrior Nation myth, the Harper Government are helping build a new visual landscape of Canadian identity, which naturally points back to the Conservative Part of Canada as the

${ }^{200}$ McCready, A.L. Yellow Ribbons: The Militarization of National Identity in Canada, (Halifax: Fenwood Publishing, 2013). P. 17

${ }^{201}$ Nimijean, Richard. "Articulating the 'Canadian Way': Canada(TM) and the Political Manipulation of the Canadian Identity." British Journal of Canadian Studies 18.1 (2005): 26,52,206. ProQuest. Web. 27 Feb. 2014. 
natural guardian's and champions of this, long overlooked but fundamental Canadian militarism. The Prime Minister himself, and his inner circle have proven to be deeply motivated to make the Conservatives as the 'natural governing party' of Canada, replacing the Liberal Party in this role. The Warrior Nation myth has been adopted as an important focus of this branding process on the part of the Harper Government to achieve this goal. Jane Taber noted this very deliberate switching of narratives from, "The Liberals who embraced the Charter, the flag, peacekeeping and multiculturalism," to the Harper Tories who, "are pursuing symbols and areas ignored by the Grits - the Arctic, the military, national sports and especially the monarchy." 202 The three texts focused on in this study are able to strike most viewers as being independent of this government program, as apolitical. This allows them to present themselves as evidence of the identity of the nation shifting to resemble the Harper vision of Canada, not simply part of the program to achieve this goal. McCready also noted this tactic, observing that these sort of representations intentionally create a new national identity out of the, "the well worn tropes of patriotic nationalism, yet present themselves as, not political. ${ }^{203}$ The role of the government, in producing these symbols needs to be kept obscured, so these symbols retain this apolitical status, and build their meaning in a way that appears not as political rhetoric, but as a natural reflection

202 Taber, Jane. 'Harper spins a new brand of patriotism," The Globe and Mail, August 19, 2011. http://www.theglobeandmail.com/news/politics/ottawanotebook/harper-spins-a-new-brand-ofpatriotism/article618385/\#dashboard/follows/ 203 McCready, A.L. Yellow Ribbons: The Militarization of National Identity in Canada, (Halifax: Fenwood Publishing, 2013). p. 54 
of Canadian identity. These new visual texts showing up on bank notes, pro hockey sweaters and national memorials are tough to spot as being a government influenced part of the branding of the national identity, or they are hard to recognized as propaganda at all. Why would anyone tuning in to watch a hockey game assume one of the team's the military themed jerseys were co-designed by the government as part of a political branding campaign? The structure of these visual texts, and the process by which they were created, allows this core message to be communicated, while their hybridity, shields not only their message but helps disguise them as not appearing as propaganda at all.

If the Harper Governement was keen to keep their role in creating these symbols under the radar, they certainly were overt in their promotion of the resulting symbols of Canada as Warrior Nation. This was shown by the PMO's eagerness to included these symbols as part of their own branding strategy, largely through the dispatching of senior cabinet ministers and key Harper loyalists to important launching ceremonies and photo ops. In the case of the CFF Memorial the Harper Government sent Lawrence Cannon, then Minister of Foreign Affairs to the September 2010 unveiling of the winning memorial design. ${ }^{204}$ The next year, Government House Leader John Baird and Conservative MP Pierre Polievre were

204 Canadian Fallen Firefighters Memorial. "The Journey To Build The Canadian Fallen Firefighters Memorial," Courage: The Offical Publication of The Canadian Fallen Firefighters Memorial. Vol. 6 (2010) http://read.uberflip.com/i/31928/49 P.45 
part of the ground-breaking ceremony for the memorial in May. ${ }^{205}$ At the ceremony marking the introduction of the Vimy Twenty dollar bill in circulation on November $7^{\text {th }}$ 2011, the Governor of the Bank of Canada, Mark Carney, was joined by both the Minister of Finance Jim Flaherty and the Minister of Veteran Affairs Steven Blaney, as well as David Houghton, President of the Vimy Foundation (See Figure 15). ${ }^{206}$ As mentioned in the introduction, the Jets logo received its own stirring endorsement from Stephen Harper himself when he arrived in Winnipeg

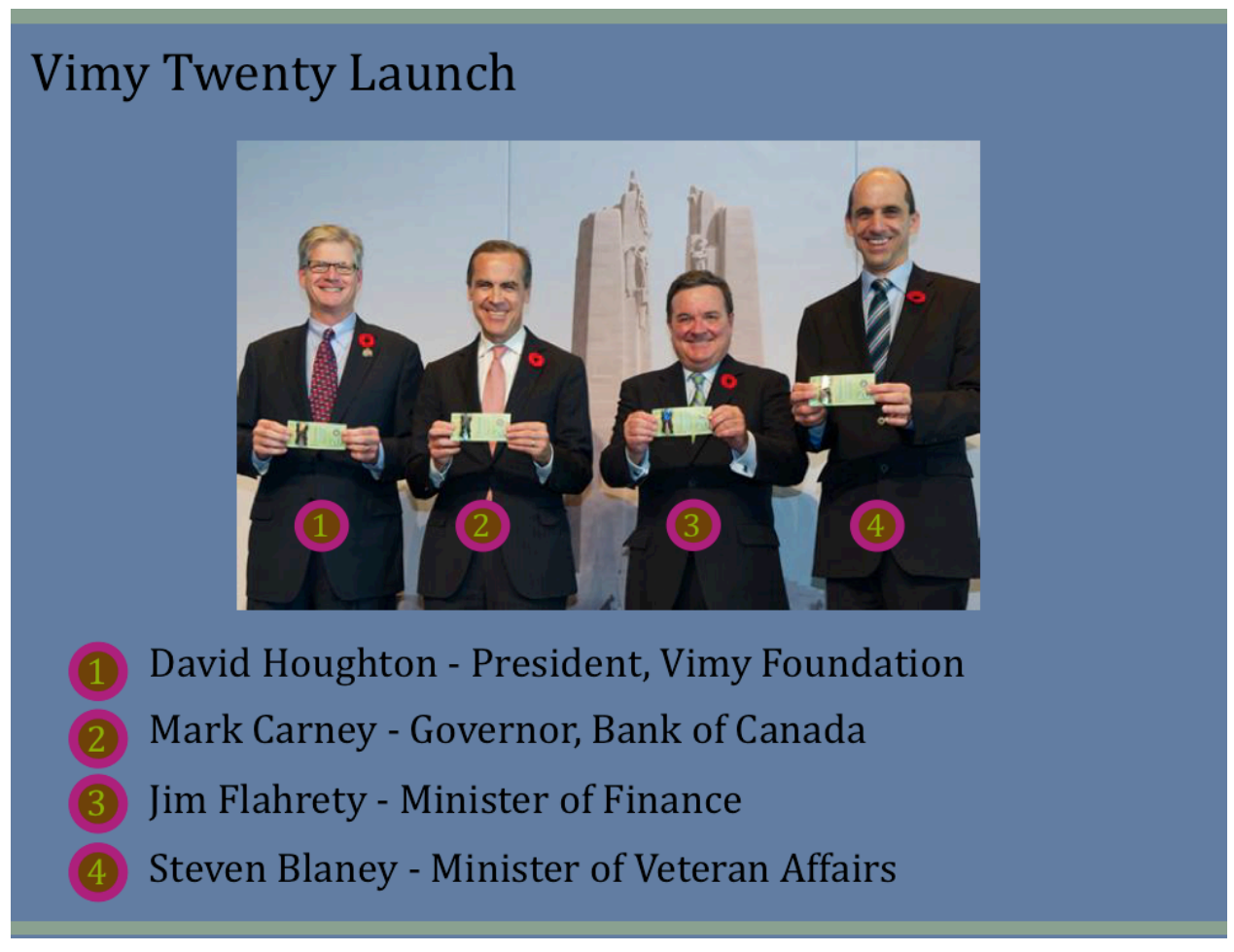

Figure 14 - Vimy Twenty Dollar Bill Launch, Novmber 7, 2011.

205 Canadian Fallen Firefighters Memorial. "The Memorial," Canadian Fallen Firefighters Foundation Website. Accessed June 2, 2014. http://www.cfff.ca/EN/thememorial/memorial-contract-awarded.html ${ }^{206}$ Government of Canada. "Bank of Canada Issues \$20 Polymer Bank Note," Canada's Economic Action Plan Website, November 7, 2012. http://www.actionplan.gc.ca/en/news/bank-canada-issues-20-polymer-banknote\#archived 
Source: http://www.actionplan.gc.ca/en/news/bank-canada-issues-20polymer-bank-note

for the team's first home game on September 9 $9^{\text {th }}, 2011$. The Prime Minister was so chuffed with the new logo's messaging and how well the symbol his government helped create dovetailed with his personal and entire governments brand that during the trip to he posed in a Winnipeg Jersey ${ }^{207}$, unveiled a special edition coin produced by the Royal Canadian Mint in honour of the Jets return to Winnipeg208, and declared on Canada's most watched television program that the logo was, "Good for the Country. ${ }^{209}$ That the Harper Government played the role of key stakeholder, acting as the ultimate approval body or patron for each of these respective texts is an important point. The structure of these designs, their Hybrid Monumentalism, is key to them being so appealing to the government as part of their own branding strategy.

Recognizing the way these symbols have been partially shaped by the government, it is important to understanding that their designs allow them to voice a startlingly pro-war and jingoistic message, along the lines of what W.J.T

207 Kirbyson, Geoff. "Prime Minister falls in love with Jets jersey, signs up for waiting list," The Winnipeg Free Press, October 9, 2011. http://www.winnipegfreepress.com/sports/hockey/jets/prime-minister-falls-inlove-with-jets-jersey-signs-up-for-waiting-list-129578393.html ${ }^{208}$ MacGregor, Roy. "Harper unveils commemorative coin to mark return of Winnipeg Jets," The Globe and Mail, October 09, 2011. http://www.theglobeandmail.com/sports/hockey/globe-on-hockey/harperunveils-commemorative-coin-to-mark-return-of-winnipegjets/article618138/\#dashboard/follows/ ${ }^{209}$ CBC Sports. "Hockey Night in Canada Broadcast, Winnipeg Jets vs. Montreal Canadiens," CBC Sports, October 9th, 2011. 
Mitchel called, "a rather direct reference to violence."210 Taking note of how smoothly this strong monumental message is hidden by the blending of other tropes and codes of national representation with which Canadians are comfortable and well versed as well as important militaristic symbolism and tropes from the Untied States are all important to understanding how subtle yet powerful these examples of propaganda are. This understanding of these symbols as propaganda, leads naturally to an imagining of the Harper government acting as a powerful puppeteers, pulling the strings of key stakeholders in their network and sphere of influence to create propaganda useful to their own aims and branding. Certainly many of these key stakeholders could be described as being part of the Conservative network and noted supporters of the Government. However, these connections are loose, and do not perfectly explain a system of total influence from the center of the Harper government, out to obedient organization and supporters. Though these stakeholders were obviously willing to work with the Harper Government and accept its influence and direction, there is no strong argument that they engaged in this process with a shared desire to specifically create well disguised, but effective propaganda. There is no evidence that all of the stake holders involved in the texts were looking to get on board with a low profile government run program to encourage the appearance of Warrior Nation symbols in the national visual landscape. The upside for the stakeholders to essentially get embroiled in that sort of political operation does not add up. It is ultimately not a

210 W.J.T. Mitchell. Art And The Public Sphere. (Chicago: The University of Chicago Press, 1990). p. 35 
dedication to the Harper Government and a Conservative ideological vision of Canada, as an American inspired warrior society that fundamentally unites these stakeholders.

What unites the Harper Government and all of the key stakeholders involved in the creation of these texts, more than a shared political ideology, is a shared commitment to selling themselves in the manner of a commercial product, towards a shared target audience. The image's themselves, the concept of the brand they articulate and the connection they make with the viewers desires and anxieties is the primary concern. To borrow a classic marketing analogy, the sizzle for all of the stakeholders in these symbols is the the primary concern, not the steak. Each group were committed in the design and marketing process of these texts to build, reinforce and maintain their own brand in a way that is deeply meaningful as identity markers for to these target costumers. Mark Carney reinforced this motivation at the unveiling of the Vimy Ridge Twenty dollar bill, where he described the art on the new bills as, "cultural touchstones that reflect and celebrate our Canadian experience."211 Similarly, at the launch of the CFF memorial's design Douglas Coupland described his vision for the memorial landscape saying he, "wanted the monument to convey deep emotion and simple dignity, and that he hoped visitors would, "reflect on firefighters and what they do

211 The National Post. "Bank of Canada unveils new \$20 Bill," The National Post, May 2, 2012. http://business.financialpost.com/2012/05/02/bank-of-canadaunveils-new-20-bill/ 
every day when they go to work." ${ }^{212}$ While, at the revealing of the Jets new logo Mark Chipmann described the teams motivations in designing the logo as a, "desire to authenticate the name and make it as meaningful as we possibly could."213 All three of these statements reveal that in creating these visual texts, each party was looking to produce not simple symbols, but markers of iconic brands which they each hoped specific consumers would personally find deep attachment with. This deep attachment, based on personal identification with a symbol, is so desired because it forges a strong connection between the consumer, and the brand's of these organizations, in the hope of creating a customer for life.

In his fascinating text, How Brands Become Icon's: The Principles of Cultural Branding, Douglas B. Holt lays out a strategic process by which a brand can be elevated to the iconic status, which Coupland, Carney and Chipman were after. Holt asserts that brand's become iconic when they, "represent a particular kind of story - an identity myth." ${ }^{214}$ These, "identity myths are useful fabrications that stitch back together otherwise damaging tears in the cultural fabric of the nation. In their everyday lives people experience these tears as personal anxieties " $215 \mathrm{He}$ argues that for a brand to become truly iconic it has to, "perform its myth."216 Holt's

212 Canadian Fallen Firefighters Foundation. "The Memorial," Canadian Fallen Firefighters Foundation Website. Accessed June 2, 2014. http://www.cfff.ca/EN/thememorial/memorial-contract-awarded.html

213 TSN. "TSN interviews Mark Chipman regarding new Jets logo: 07/23/11," YouTube, Accessed May 12, 2014. http://www.youtube.com/watch?v=y9Shh6cJIEw ${ }^{214}$ Holt, Douglas B. How Brands Become Icons: The Principles of Cultural Branding. (Boston: Harvard Business School Press, 2004) p.2

215 Ibid. p. 8

216 Ibid. 
definition and explanation of these anxieties and identity myths provide a clear way to understand, the symbols of Warrior Nation myth of this study in an iconic branding context. Holt's framework provides a fruitful explanation of what led all of the stakeholders discussed above to each arrive at a Hybrid Monumental symbol, which preforms this particular identity myth, in their attempts at building an iconic Canadian cultural brand. Holt argues that the most iconic brands focus on the deep personal identity of potential costumers by adopting and using identity myths that negotiate national ideology. Holt defines national ideology as, "a system of ideas that forges link between everyday life - the aspirations of individuals, families, and communities - and those of the nation." ${ }^{217}$ Holt argues that, "contradictions in national ideology create myth markets." 218 To understand which contradiction, and the anxiety that it creates is being focused on and exploited in the process of creating iconic brands of Canada as a Warrior Nation, the images themselves and their core monumental message again needs to be looked at.

In his text Holt argues that, "identity myths are usually set in imagined populist worlds: places separated not only from everyday life but also from the realms of commerce and elite control." 219 These worlds, "are potent cultural sites because the public perceives that populist worlds ideologies," and the people who inhabit them, as "authentic."220 Holt argues that these populist worlds supply the,

${ }^{217}$ Holt, Douglas B. How Brands Become Icons: The Principles of Cultural Branding. (Boston: Harvard Business School Press, 2004) p. 8

218 Ibid. p. 59

219 Ibid. p. 9

${ }^{220}$ Ibid. p. 58 
"raw ingredients that iconic brands draw on to create their myths." 221 The populist worlds of the Warrior Nation myth are those where the heroes, who articulate the core monumental theme of sacrifice for the nation are imagined to dwell. The Vimy Ridge Twenty dollar bill draws on the populist world of the rank and file Canadian infantry of the First World War, the Jet logo also draws on the world of veteran's and past conflict, as well as the world of the Canadian Forces, while the Canadian Fallen Firefighters memorial draws on the world of contemporary firefighters who are part of the post 9/11 defenders of the nation narrative. All of the heroes of these worlds, are perceived to act not for commercial or personal gain, but by the pure motivation of moral conviction and the ultimate virtue of sacrifice for the protection of the nation. All of the heroic characters in these worlds are united in their willingness to sacrifice themselves for the nation. Ian MacKay described this centrality of these mythic characters in these imagined, populist worlds, saying it places these "warriors, as the significant Canadians - no one else is in the running." 222 These hero warriors are also united by the fact that they are drawn from occupations that in reality are comprised of almost all white males. Of the entire 616, 778 person Canadian Expeditionary Force sent overseas to fight in the First World War, only approximately 5000 were visible minorities, representing $0.8 \%$ of

221 Holt, Douglas B. How Brands Become Icons: The Principles of Cultural Branding. (Boston: Harvard Business School Press, 2004) p. 59

222 McKay, Ian and Jamie Swift. Warrior Nation :Rebranding Canada in an Age of Anxiety. (Toronto: Between The Lines Publishing, 2013). p.15 
the entire force. ${ }^{223}$ Women, made up $0.46 \%$ of the force, and none of them were involved in a combat role. ${ }^{224}$ In the contemporary Canadian Forces, these percentages have improved, but they still do not come close to reflecting the general population of Canada. In 2002, only 6\% of the Canadian Forces personnel were members of visible minorities, and only $15 \%$ were women. ${ }^{225}$ The situation in the profession of Firefighting in contemporary Canada is similar. Though national firefighting demographics do no exist, the numbers available tell a story of white male domination. In the Province of Quebec, immigrant populations make up only $1.2 \%$ of the Firefighting work force, and women account for $3.6 \% .{ }^{226}$ While in the famously multicultural city of Toronto, visible minorities make up only $4.2 \%$ of the fire service work force, and of 2, 742 Toronto firefighters working in the city, 67 are women, representing $2.4 \% .227$ The subjects of these symbols are then drawn from one narrow group of Canadians: all the fire fighters honoured in the Canadian Fallen Firefighters Memorial, all of the soldiers who died at Vimy and all

${ }^{223}$ Walker, James. W. St. G. "Race and Recruitment I World War I: Enlistment of Visible Minorities in the Canadian Expeditionary Force," Canadian Historical Review. Volume 70, issue 1 (1989). p.1-26

${ }^{224}$ Duguid, A. Fortescue. "Demographics: Composition of the CEF," The Canadian Great War Project. Accessed June 6, 2014.

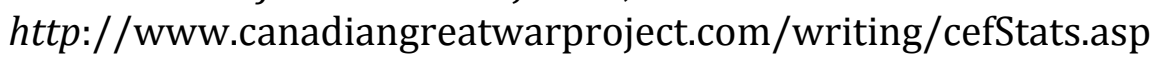
225 Park, Jungwee. "A Profile of The Canadian Forces," Statistics Canada, 2008. Last Modified May 14, 2014. http://www.statcan.gc.ca/pub/75-001-x/75-001x2008107-eng.htm

${ }^{226}$ Service Canada. "Job Futures Quebec: Firefighting," Service Canada. Last Modified September 3, 2013.

http://www.servicecanada.gc.ca/eng/qc/job_futures/statistics/6262.shtml 227 Garvey, Kyla. "As fire department looks to recruit women, sexist tweets suggest some firefighters may not be so welcoming," National Post, August 9, 2013. http://news.nationalpost.com/2013/08/09/as-fire-department-looks-to-recruitwomen-sexist-tweets-suggest-some-firefighters-may-not-be-so-welcoming/ 
of the hockey players past and in the foreseeable future who play for the Winnipeg Jets are men, and almost all of them are white.

It is important to understand which segments of the population are being allowed into the sacred group of defenders of the nation through these symbols. It is notable that these visual articulations of the Warrior Nation myth focus not on heroic generals, or a certain heroic firefighter who died on duty, but on the general members of these occupations. The rank and file members of these populist worlds are the focus of these symbols. This spreading of reverence, away from an elite group or specific individual, out to a wider group gives these symbols a generally populist message. Yet, the reality that the overwhelming majority of people involved in the business of fighting for the Canadian forces, and fighting fires at home are white males narrow this populist focus to a very specific group of individuals. These symbols, with out being implicit about it, are only effectively offering up this certain type of individual, as candidates to become hero's of the nation. This focus of representation on a certain group of the population can be understood through Jonathan Harris's argument in his text Federal Art and National Culture: The Politics of Identity in New Deal America, where he focuses on the nature of the federal state's role in cultural production from the perspective of Gramsci's notion of hegemony. ${ }^{228}$ For Gramsci in this example, hegemony is, "the social process through which a political and ideological consensus is constructed

${ }^{228}$ Harris, Jonathan. Federal Art and National Culture: The Politics of Identity in New Deal America. (Cambridge: Cambridge University Press, 1995). p. 7 
and maintained by an alliance of forces, organized around a particular class. ${ }^{229}$ Central to Gramcsi's notion of hegemony is the idea of the creation and promotion of a certain, "national-popular, which includes the discourses of patriotism and nationalism." 230 Holt has taken the concept of the nation-popular described by Gramsci and offered it up as an effective concept to leverage in building iconic brands. The Warrior Nation branding led by the Harper Government is an effort to reinforce and help produce a certain national-popular rhetoric of patriotism and nationalism, which communicates an imagined consensus of Canadian identity that is focused on a segment of the Canadian population both as subject and audience.

These symbols offer nostalgic connections to historic periods and cultural areas of contemporary society, when and where white men are naturally regarded as the central characters, free to use their power and physical force to their advantage. The national-popular rhetoric, which characterizes the Warrior Nation myth, is then focused on professions and cultural areas, Holt's populist worlds, inhabited by male hero figures. The symbols which articulate this rhetoric provide a bridge with a past, and certain segments of contemporary society which still resemble this past, where the dominance of males, was a given, and not under threat. The three representations of this national-popular rhetoric mapped in the previous two chapters, are offered as a connection over the tension that exists between the real lived experiences of North American's, especially men, and the imagined male hero's living in the mythic realm of these populist worlds. Holt

229 Ibid.

230 Ibid. 
asserts that, "these tensions between ideology and individual experience produce intense desires and anxieties, fueling demand for symbolic resolutions that smooth over these tensions. The distance between the model and everyday life acts as a cultural engine, creating demand for myths that manage these differences." ${ }^{241}$ Holt seems to be taking cultural theory, and spinning it around as effective corporate branding strategy. In this case his framework pulls on the concepts described by Jean Baudrillard in his text, Simulation where he describes, "a collective demand for signs of power [...] which forms around the disappearance of power. "242 The representations of this study, championed by the Harper Government, are targeted to speak to those who find personal identity value with the Warrior Nation myth. But importantly, as Baubrillard describes, these visual expressions of nationalistic identity, amount not to true indications of power, but are simply empty representations, which, "produce nothing but signs of [powers] resemblance." 243 These symbols offer nostalgic signs of previous eras, and specific cultural realms, yet these symbols do not indicate, that the Harper Government or anyone else involved with their creation is particularly committed to improving the economic power of those being targeted. Quite the opposite, the commitment to increased global free trade and hard line policies towards unionized labour on the part of the Harper Government actually perpetuates and even increases the pinch on the rank and file employees of the professions of firefighting and the military in Canada.

\footnotetext{
${ }^{241}$ Holt, Douglas B. How Brands Become Icons: The Principles of Cultural Branding. (Boston: Harvard Business School Press, 2004). p.58

242 Ibid.

${ }^{243}$ Baudrillard, Jean. Simulations. (New York: Semiotext[e], 1983). p. 45
} 
These signs are then offered as a poor substitute in the manner decried by Baudrillard. This reality, that these symbols offer signs of power, but not a real commitment to shaping policy to returning power to this group, underscores how the main uniting factor of the stakeholders who produced these symbols is really a shared branding strategy, more than political ideology. All of the stakeholders who collaborated to create these symbols were targeting the same market; the 'Support the Troops' and 'Tim Horton's Voter's'. This group of mostly males, from Canada's wide spectrum of middle class, are fans of hockey, support the military, and are the target markets for professional hockey in Canada, firefighting as a profession, the Vimy Foundation in its desire to promote militarism through the recounting of heroic narrative of the century-old battle. They are also the key target market for the political brand of the Harper Government itself. The desire to appeal to this group with iconic brands, led the stakeholders to be united in their targeting of the same underling anxieties this group feels. The results are fundamentally monumental symbols, which offer up iconic branding of Canada based on the Warrior Nation myth to this group. The cultural conditions of Canada through the national experience of the War in Afghanistan, and the wider post-9/11 defender of the nation paradigm largely influenced by the Unites States, made the Warrior Nation mythology a perfect fit for these stakeholders to use as the basis of their iconic branding. These symbols effectively offer up the fantasy of power to this target audience, without actually offering up a solution to the decline in power and economic stability this same constituency is continuing to live through. 
In Designing Brand Identity, Alina Wheeler points out that, "a company's reputation and goodwill extend beyond its target customers." ${ }^{44}$ When a brand is pushed out to the public, but the perceptions of the broader public and their reaction has to be weighed and considered. The softening of the militaristic message and hero worship of a certain group at the core of these symbols through there hybridization, allows them not to offend the public, they do not damage the brand of the Harper Government or other key stake holders as being too jingoistic, or too 'un-Canadian' in their militarism to those, beyond the target customer group, who might object.

For those opposed to the Warrior Nation mythology and its militarization of the Canadian identity and looking to publicly criticize their messaging, the hybridity of these symbols proves to be effective in deflecting this criticism. When observers point out these symbols' jingoistic messaging, like John K. Samson did when he argued, "putting such a weapon on a logo that every hockey-loving Winnipegger should feel enthusiastic to wear [...]is a decision we should ask some serious questions about,"245 the hybridity becomes a useful asset in deflecting criticism, collapsing the ability to talk about these symbols mythology in a critical way. Because their hybridity allows them to straddle sacred/profane dichotomies, criticism of these symbols is rebutted by a focus on one side of this pairing or the

${ }^{244}$ Wheeler, Alina. Designing Brand Identity (Hoboken: John Wiley and Sons, 2006). p. 90

${ }^{245}$ Samson, John K. "The New Jets Logo, a Boardroom, and a Bargain," The Winnipeg Review, August 2, 2011. http://www.winnipegreview.com/wp/2011/08/the-new-jets-logo-a-boardroomand-a-bargain/ 
other. The response from defenders of these hybrid monumental symbol falls into two general categories, pointing to these symbols as being either; harmless and profane, garnering responses along the lines of, "it is just a hockey jersey" or, "it is pictures on money, relax." This deflection attempts to point away from the mythological level of signification, which these symbols articulate, and instead encourages the viewer to, as Barthes put it, simply "enjoy this beautiful object without wondering where it comes from." ${ }^{246}$ This tactic of defense works to portray the critic as taking it all too seriously. However, these symbols are also able through their nimble hybridity to be defended with a completely opposite tactic, arguing that these symbols are sacred and holy, with cries of, "they died for you, show some respect!." The critic in this scenario is portrayed as being insensitive and disrespectful to those who died, "to make you free." This built in defend-ability, makes these symbols of Canada as a Warrior Nation difficult to criticize, and allows them to facilitate the curbing of debate over the role of war and the military in Canadian culture.

The main, blunt elements, a maple leaf layered with a fighter Jet, a soaring monument flanked in poppies and a massively scaled firefighter, offer up a quick and easy to decipher message to the uninitiated of national heroism on a monumental scale using scale and the widely recognizable symbols of the poppy and maple leaf to make simple blunt meaning. Viewers reading these symbols with a basic level of saliency with war symbolism, both Canadian and American, can find explanations of Canada as defined by heroic militarism. These texts, when read at

${ }^{246}$ Barthes, Roland. Mythologies (London: J Cape, 1972). p. 117 
this level as more of a whole representation that a sum of its referent parts, make them work as simple symbols for these uninitiated viewers, earnestly representing firefighting's risks, the national history on its currency or an eye catching explanation of a hockey team's nickname, and linking these to a theme of Canada as a war-faring nation. The deeper meanings can be missed, and are not actually necessary for them to act as more literal symbols.

All of the stakeholders involved in creating the visual texts of the Warrior Nation studied here, were looking to build their own iconic brand, by appealing to 'buyers' of this narrative of identity. By going this route in its promotion and branding, the Harper Government has joined with other, often-powerful, stakeholders in addressing important anxieties of the contemporary national moment, for a specific constituency that is their shared target market. These brands route to becoming iconic, of becoming meaningful identity markers for individuals, is certainly propaganda, and is being used by the Harper Government as such, but it is a type of propaganda specially suited to the contemporary political cultural moment in both content and form. Addressing the anxiety of a society just emerging from a decade long war, supplying the monumental justification and historical context that makes Canada as a Warrior okay, and even heroic and admirable. While adopting a hybridity that address the tension this new Warrior Canada presents to the old myths of Canada as benevolent peace keeping nation by appropriating tropes from other narratives of Canadian identity. This hybridism also layers in the powerful war related narratives from the United States of the post 9/11 heroic defenders of the nation, which heroizes firefighters 
and the military as part of a civil defense structure, called upon to defend the nation from largely unknown terrorist enemies. The hybridity that this layering accomplishes brings these different narratives into the symbols and blunting and hiding the reversal in national mythology they are essentially making.

Beyond effective propaganda, encouraged by the Harper Government, these symbols represent the near complete layering of marketing, branding and political messaging that is the norm in Canadian politics in the contemporary moment. They were created through shared commitment to iconic branding practices, more than a shared political agenda. The process of political branding, and in this case war propaganda are so indistinguishable from commercial branding and marketing in the contemporary moment in Canada that minimal steering needed to be done for the desired results. Because the Harper Government and the respective stakeholders of these symbols targeted the same general audience, and had the same goal of building deep and authentic connections through iconic branding, the same mythic narrative was turned to, which would resonate with the audience. This reality means that these symbols reveal the cultural moment in Canada at the end of the Afghanistan War era, and the way that this sort of cultural moment is accounted for and marketed to, by politicians and businesses alike. 


\section{Conclusion}

Disillusioned words like bullets bark

As human gods aim for their mark

Make everything from toy guns that spark

To flesh-colored Christs that glow in the dark

It's easy to see without looking too far

That not much is really sacred.

- Bob Dylan, It's Alright Ma (I'm Only Bleeding) ${ }^{247}$

The symbols focused on in this study entered into the Canadian cultural landscape without much disruption, but have certainly contributed to the success of the Warrior Nation narrative gaining wide exposure. They did so because they all took a Hybrid Monumental form. As Susan Delacourt noted, by the end of the first decade of the $21^{\text {st }}$ century, "So attached were the Conservatives to the military that it began to feel like every day in Ottawa was Remembrance Day."248 The function of these symbols in subtly communicating narratives of Canadian identity not just on the military, but focused on the heroic militaristic-type sacrifices of firefighters, is important to understand. They are visual markers of the project led by the Harper Government of re-imagining Canada as a Warrior Nation. Viewers of these hybridized symbols need to be tuned in not just to the core monumental, messaging they make to understand the role they play as a form of propaganda

247 Dylan, Bob. “It's Alright Ma (I'm Only Bleeding” Bringing It All Back Home, 1965. Accessed July 12, 2014 http://www.bobdylan.com/ca/node/25793 248 Delacourt, Susan. Shopping for Votes (Madeira Park: Douglas andMcIntyre, 2013) p. 246 
that the Harper Government, has encouraged, funded and championed in their effort to militarize the everyday lives of Canadians. All three texts studied above are examples of the symbolic representation of the Warrior Nation narrative of Canada, which has unobtrusively become both powerful and ubiquitous in the visual negotiation of Canadian identity. Canadian author Farley Mowat described these sort of articulations of the Warrior Nation as signs of a "viral infection [that usually] lies dormant, festering in society, nurtured by boys' adventure stories of heroism in service to the nation." Mowat added, "You see it in the monuments we erect to the fallen and carefully scripted remembrances - until it slowly slouches back into respectability." 249

Beyond recognizing the content of these symbols, this thesis argues that it is critical to understand the way that their form has facilitated their presentation of a jingoistic and militarized way of understanding Canada, in a way that has gone largely unnoticed. It is because the symbols of the new narrative of Canada as a Warrior Nation did not take an orthodox monumental form, but instead are marked by a subtle Hybrid Monumental form that they were able to appear without a great amount of notice or disjunction with competing narratives of identity. The Warrior Nation narrative, used by the Harper Government in its project of branding Canada as being characterized by war generally and death in the name of the nation specifically, is perfectly captured in the symbols of this study. The Hybrid Monumental form they take is a result of their creation being driven by a

${ }^{249}$ McKay, Ian and Jamie Swift. Warrior Nation :Rebranding Canada in an Age of Anxiety. (Toronto: Between The Lines Publishing, 2013) p.258 
collaborative process inspired by corporate branding. The representations that resulted are themselves the key to understanding the extent to which the branding mentality is the driver of not just the Warrior Nation texts, but by the Hybrid Monumental genre. To look beyond the image misses the point. The image is the point. All of these symbols were released into the visual landscape of Canada, placed in culturally powerful positions, and heralded as "authentic", "truly authentic", "deeply meaningful." However, what this study fundamentally shows is that these symbols are indeed none of these things. When narratives and ideas of war, death for the nation, and sacrifice are hybridized and collapsed into simplified brands and symbols to produce a deep connection within a target audience or market, they may be effective in gaining customers, yet the entire process shows the deep contradiction of branding. As Douglas Holt pointed out, "consumers flock to brands that embody the ideals they admire, brands that help them express who they want to be."250 But in this process, the idea of a brand, its story and its value as an identity marker, becomes the product, with the real product becoming secondary or even inconsequential. Naomi Klein succinctly captured this shift from product marketing to branding in her seminal text No Logo:

The old paradigm had it that all marketing was selling a product. In the new model, however, the product always takes a back seat to the real product, the brand, and the selling of the brand acquired an extra component that can only be described as spiritual. Advertising is about hawking product. Branding, in its truest most advanced incarnations, is about corporate

${ }^{250}$ Holt, Douglas B. How Brands Become Icons: The Principles of Cultural Branding Harvard Business School Press, Boston. 2004 P.4 
transcendence. It may sound flakey, but that's precisely the point...The brand builders conquered and a new consensus was born: the products that will flourish in the future will be the ones presented not as "commodities" but as concepts: the brand as experience, as lifestyle. ${ }^{251}$

The Harper Government chose to make militarism and heroic sacrifice, a defining focus of its own iconic brand experience. The 'commodities' of a foreign policy necessitating war, the cost and benefit to Canadian society of putting its citizens in harms way, or a fruitful public discourse on the justification for war are not what is being 'sold' to the public. The brand of Canada as a heroic Warrior Nation is what is being branded and marketed to the public. The key weakness of this adoption of iconic branding as a political strategy is that inevitably market conditions change. As Holt describes, "myth markets eventually crumble when cultural disruptions hit. As a result iconic brands remain iconic only if they abandon their old myth and invent a revised version that taps into a new myth market." 252 The challenge in the political realm is that a politician shifting their brand can be suddenly shown as anything but authentic, and the whole iconic branding strategy can collapse. Richard Nimijean notes that, "the challenge for political marketing or branding is to convince consumers/citizens that all is well with the product". ${ }^{253}$ As time passes, this sort of political "branding campaign, like

251 Klein, Naomi. No Logo (London: Flamingo Books, 2000). p.17

252 Holt, Douglas B. How Brands Become Icons: The Principles of Cultural Branding (Boston: Harvard Business School Press, 2004). P.60

253 Nimijean, Richard. "Articulating the 'Canadian Way': Canada(TM) and the Political Manipulation of the Canadian Identity." British Journal of Canadian Studies 18.1 (2005): 26,52,206. ProQuest. Web. 27 Feb. 2014. 
all advertising campaigns, risks running its course if the value of a product/public policy to consumers/citizens is not reinforced."254 By 2014 telltale signs have emerged that the Warrior Nation branding of Canada, championed by the Harper Government has begun to run out of its political value. The 2014 Federal Budget included sharp cuts to military spending. This decision drew a critical response from the Chief of Defense Staff Tom Lawson, publicly exposing a division between the military and its supposed champions in Government. ${ }^{255}$ Even more damaging perhaps to the Warrior Nation brand are rising protests on the part of veterans themselves. In January of 2014, a group of veterans meeting with Julian Fantino to discuss cuts to regional support centers very publicly argued with the minister over their feeling of a lack of respect for themselves and their cause. ${ }^{256}$ In May 2014 the days leading up to a National Day of Honour for the veterans of the Afghanistan War was overshadowed by a public riff between the government and the Royal Canadian Legion over a lack of consultation over the plans for the event, a lack of funding for families of veterans to attend and the plan for the last Canadian flag flown in Afghanistan to be presented to the Prime Minister and not the Governor General, the official Commander-in-Chief of the Canadian Forces. ${ }^{257}$

\footnotetext{
254 Ibid..

255 Everson, Kristina. “Gen. Tom Lawson warns military cuts will hurt readiness.” CBC News, June 26, 2014. http://www.cbc.ca/news/politics/gen-tom-lawsonwarns-military-cuts-will-hurt-readiness-1.2687806 256 CBC News. "Veterans fighting service cuts felt disrespected at Fantino meeting," CBC News, January 28, 2014. http://www.cbc.ca/news/politics/veterans-fightingservice-cuts-felt-disrespected-at-fantino-meeting-1.2513837

257 Geddes, John. "Legion's president voices misgivings about day to honour Afghan vets," Maclean's Magazine, May 8, 2014.
} 
On June 4th, a protest on Parliament Hill in Ottawa by wounded veterans of Afghanistan called for more support from the Government for their physical and psychological wounds dealt another blow to the brand of the Conservative Party and its leader Harper as champions of the military and its heroic warriors. The now obvious gap between the iconic brand of the Harper Government as promoters and supporters of the military and the reality of spending cuts laid them open to sharp criticism. Writing in The Globe and Mail Doug Saunders plainly laid out the growing problem for the Conservative Brand,

Canada has 68,000 full-time soldiers and another 26,000 reservists, the most we've had in 20 years. Few questioned these numbers during the past 13 years, when virtually our entire military was tied up in Afghanistan. Those years turned the Canadian Forces into a much more professional, experienced force - and then those soldiers came home to discover their support services had been cut. It turns out that the Conservative government is not willing to pay for a military of that size after all - but is unwilling to admit it. 258

The growing rift between veterans, the military leadership and the Harper Government in 2014 has exposed the weakness of harmonizing political strategy and policy making with iconic branding and marketing. A Government dedicated to a branding stagey at all cost, has a great deal of trouble remaining consistent. The authenticity sold as part of the iconic brand is nearly impossible to maintain. The project of selling a political brand, developing an image that will help build that

http://www.macleans.ca/politics/ottawa/legions-president-complains-ofsecretive-planning-for-afghanistan-commemoration/ ${ }^{258}$ Saunders, Doug. "Canada's military policy doesn't add up," The Globe and Mail March 1, 2014. http://www.theglobeandmail.com/globe-debate/canadas-militarypolicy-doesnt-add-up/article17160469/\#dashboard/follows/ 
brand into an iconic marker for voters, actually leads to inauthenticity and shallowness in policy that with time comes out. The visual texts of the Warrior Nation studied above held the clues to this reality in their Hybrid Monumental structure. This form allows these symbols to articulate the strong monumental messaging to make a connection, to develop a feeling of authenticity in a core audience, yet are sufficiently hybridized so that when cultural and political realities change, they remain neutral and ambiguous enough to not damage the brand as it is forced to shift to meet the changed markets. It is not surprising that they were the result of a collaborative branding process, and now as the cultural market is shifting, the brand moves on to a new focus and target. This reality means that the most important message that these symbols can communicate and remind viewers, is not there effectiveness as propaganda to sell the Afghanistan War, or their effectiveness in honouring war dead or veterans, or their ability to bring a new level of militaristically inspired respect to firefighting. These symbols are visual reminders of the degree to which political strategy in the contemporary moment in Canada is dominated by an iconic branding mindset. Those who fully accept this approach will adopt any subject matter to make the sale. In the political realm this means that anything is on the table to be used to augment a politicians or party's brand in an attempt to appeal to new voters, while still strongly playing to and activating a party's base. A hundred year old battle in France, firefighters' and soldiers' recent and long ago deaths, and the official insignia of the RCAF, have all proven to be fair game to be turned into brand markers of the project of Warrior Nation branding of Canada. These symbols need to be understood as a 
reminder that no content or subject matter in this approach is off limits, not even the deaths of Canadians past and present, from being collapsed and simplified into a simple brand mark, useful for a while in shoring up political support, then cast aside as the demands of the market of voters shifts and a new branding strategy is required. Beyond being specific examples of the Warrior Nation moment, these Hybrid Monumental symbols offer a clear example of the way that this process of collapse and simplification in fact defines this genre. The monumental core of these symbols, though appearing to be earnest and 'truly authentic' is constantly held in check by these symbols defining hybridity. These symbols structurally exist as hybrids; they live in multiple worlds, straddling the division between the sacred and profane, between art and brand-mark, and between competing, even contradictory, narratives of identity, within their design. This results in polysemic, nimble symbols that can be held up at one moment as having a deep, sacred meaning, and then moved away from in the next, left as visual elements of the profane space of the day-to-day visual cultural landscape. Though they may project an earnestly monumental core statement, these symbols are structurally always hybrids. Bound to neither be as sincere as the truly monumental symbols their core messaging suggests, nor sufficiently self-aware and reflective as their hybridity could lead them to be. 


\section{Bibliography}

Altheide, Davide. Terrorism and the Politics of Fear. (New york, Altamira Press, 2006).

Anderson, Benedict. Imagined Communities: Reflections on the Origin and Spread of Nationalism. (London: Verso, 1983).

Bank of Canada. "Polymer Series," Bank Of Canada Website. Accessed May 12, 2014. http://www.bankofcanada.ca/banknotes/bank-note-series/polymer/

Barthes, Roland. Mythologies (London: J Cape. 1972).

Baudrillard, Jean. Simulations. (New York: Semiotext[e], 1983).

Beeby, Dean. “Canada $\$ 100$ Bill Controversy: Mark Carney, Bank Of Canada Governor, Issues Apology," The Huffington Post, August 20, 2012. http://www.huffingtonpost.ca/2012/08/20/asian-100-billcarney_n_1810925.html

Benjamin, Walter. "The Work of Art in the Age of Mechanical Reproduction," Media and Cultural Studies. Editors: Meenaksji Gigi Durham and Douglas M. Kellner (Oxford: Blackwell, 2001.)

Bercuson, David. "The military is a central actor in Canada's story," The Globe and Mail, July 12, 2014. http://www.theglobeandmail.com/globe-debate/the-militaryis-a-central-actor-in-canadas-story/article586788/\#dashboard/follows/

Billig, Micheal. Banal Nationalism (London: Sage, 1995).

Binyon, Laurence. For the Fallen. Accessed March 9, 2014.

http://en.wikisource.org/wiki/A_treasury_of_war_poetry,_British_and_American_poe ms_of_the_world_war,_1914-1919/The_Fallen\#For_the_Fallen

Bordo, Jonothan. "Jack Pine - Wilderness Sublime or the erasure of the aboriginal presence from the landscape," Journal of Canadian Studies 27. (Winter 1992-93)

Bothwell, Robert. "Lester Bowles Pearson," The Canadian Encyclopedia. Last modified August 1, 2014.

http://www.thecanadianencyclopedia.com/en/article/lester-bowles-pearson/ 
Branch, John. 'For Canada's Faithful, A Gold That Means Most," The New York Times, February 28, 2010.

http://www.nytimes.com/2010/03/01/sports/olympics/01obsession.html?page wanted=all

Campbell, Tim. “Its Official: It's the Jets." Winnipeg Free Press, June 24, 2011. http://www.winnipegfreepress.com/sports/hockey/jets/And-now-here-comeThe-Jets--124498414.html

Canclini, Nestor Garcia. "Hybrid Cultures, Oblique Powers," Media and Cultural Studies Keyworks. Edited: Meenakshi Gigi Durham and Douglas M. Kellner. (Malden: Blackwell Publishing, 2002).

Canadian Department of Citizenship and Immigration. Discover Canada: The Rights and Responsibilities of Citizenship.Canadian Department of Citizenship and Immigration, 2013. http://www.cic.gc.ca/english/pdf/pub/discover.pdf

Canadian Fallen Firefighters Foundation. "The Memorial" Canadian Fallen Firefighters Foundation Website. Accessed June 2, 2014. http://www.cfff.ca/EN/thememorial/memorial-contract-awarded.html

Canadian Fallen Firefighters Foundation. "The Journey To Build The Canadian Fallen Firefighters Memorial," Courage: The Official Publication of The Canadian Fallen Firefighters Memorial. Vol. 6 (2010) http://read.uberflip.com/i/31928/49

The Canadian Press. "Canadian Involvment in Afghanistan Formally End," The Canadian Press, March 12, 2014. http://www.cbc.ca/news/world/canadianmilitary-involvement-in-afghanistan-formally-ends-1.2569162

Cathal, Kelly. "Crosby's Comeback a Cause for Celebration - and Conversation," The Toronto Star, November 20, 2011.

http://www.thestar.com/sports/hockey/2011/11/20/kelly_crosbys_comeback_c ause_for_celebration_and_conversation.html

Carrier, Roch. the Hockey Sweater and other Stories Translated by Sheila Fischman (Toronto: Anasi, 1979).

CBC News. "Douglas Coupland designs firefighters monument," CBC News, September 9, 2010. http://www.cbc.ca/news/canada/ottawa/douglas-couplanddesigns-firefighters-monument-1.933910

CBC News.“Hockey: What should Winnipeg's NHL team be called?” CBC NEWS: Community Blog, June 21, 2011. 
CBC News. "Veterans fighting service cuts felt disrespected at Fantino meeting," CBC News, January 28, 2014. http://www.cbc.ca/news/politics/veterans-fightingservice-cuts-felt-disrespected-at-fantino-meeting-1.2513837

CBC News. “Winnipeg Jets Unveil New Logo” CBC News - CBC.CA, July 22, 2011. http://www.cbc.ca/sports/hockey/winnipeg-jets-unveil-new-logo-1.1041454

CBC News."Winnipeg Jets Unveil New Jerseys" CBC News Manitoba, September 6, 2011. http://www.cbc.ca/news/canada/manitoba/winnipeg-jets-unveil-newjerseys-1.1051695

CBC Sports. "Coaches Corner," CBC Sports, April 7, 2012.

http://www.cbc.ca/player/Sports/CBC's+Hockey+Night+in+Canada/ID/2220528 646/?page=16\&sort=MostPopular

CBC Sports. 'Hockey Night in Canada Broadcast, Winnipeg Jets vs. Montreal Canadiens' CBC Sports, October 9th, 2011.

CBC Sports. 'Winnipeg Cheers Return of Jets.' CBC Sports cbc.ca, May 31, 2011. http://www.cbc.ca/news/canada/manitoba/winnipeg-cheers-return-of-nhl1.1062589

CTV News. "McKay: Renming military corrects 'historical mistake," CTV News, August 16, 2011. http://www.ctvnews.ca/mackay-renaming-military-correctshistorical-mistake-1.684081

CTV News. “Veterans Honoured on New \$20 Bank Note," CTV News, May 2, 2012. http://www.ctvnews.ca/veterans-honoured-on-new-20-polymer-bank-note1.804451

Curran, Peggy. "Religious fervour for the $\mathrm{CH}$ looks like the real thing, theologian says." The Montreal Gazette, January 9, 2009.

http://www.montrealgazette.com/life/Religious+fervour+looks+like+real+thing+the ologian+says/1156384/story.html

Delacourt, Susan. Shopping for Votes (Madeira Park: Douglas and McIntyre, 2013).

Department of Citizenship and Immigration. Discover Canada: The Rights and Responsibilities of Citizenship. Canadian Department of Citizenship and Immigration, 2013. http://www.cic.gc.ca/english/pdf/pub/discover.pdf

Department of Veterans Affairs. "Canadian National Vimy Memorial” Veterans Affairs Website," February 2, 2014. http://www.veterans.gc.ca/eng/remembrance/memorials/overseas/first-worldwar/france/vimy/vimymap 
Department of Veteran Affairs. "The Monument- 1936 Dedication," The Canadian National Vimy Memorial, Veterans Affiars Canada website. Accesed March 12, 2014. http://www.veterans.gc.ca/eng/memorials/ww1mem/vimy/sg/04_monument/0 5_dedicate

Department of Veteran Affairs. "Reconiciliation: The Peacekeeping Monument," Veterans Affairs Canada Website. Last modified February 20, 2014. http://www.veterans.gc.ca/eng/remembrance/memorials/canada/reconciliation

Detora, Lisa. M. Hero's of Film, Comics and American Culture: Essays on Real and Fictional Defenders of Home. (London, McFarlane and Company, 2009).

Dryden, Ken and Roy MacGregor. Home Game: Hockey and Life in Canada (Toronto: McClelland and Stewart, Toronto. 1989).

Duguid, A. Fortescue. "Demographics: Composition of the CEF," The Canadian Great War Project. Accessed June 6, 2014.

http://www.canadiangreatwarproject.com/writing/cefStats.asp

Durham Region News. "Bank Of Canada Celebrates New Vimy Ridge Bank Note in Ajax," Durhamregion.com, November 12, 2012.

http://www.durhamregion.com/news-story/3509355-bank-of-canada-celebratesnew-vimy-ridge-banknote-in-ajax/

Dylan, Bob. “It's Alright Ma (I'm Only Bleeding” Bringing It All Back Home, 1965. Accessed July 12, 2014 http://www.bobdylan.com/ca/node/25793

EF Tours. "Dave Robinson Presents The Vimy Flag and Jerseys," EF Tours Youtube Channel, April 20, 2012. http://www.youtube.com/watch?v=ko6_MCCl8EI

Everson, Kristina. “Gen. Tom Lawson warns military cuts will hurt readiness.” CBC News, June 26, 2014. http://www.cbc.ca/news/politics/gen-tom-lawson-warnsmilitary-cuts-will-hurt-readiness-1.2687806

Ferda, Tom. "The Unbreakable Bonds Between The NHL and U.S. Military," USA Hockey Magazine, Issue 11 - 2011. http://www.usahockeymagazine.com/article/2011-11/unbreakable-bondsbetween-nhl-and-us-military

Fremeth, Howard D. Memory, Militarism and Citizenship: Tracking the Dominion Institute in Canada's Military Cultural Network. PhD. Thesis. (Ottawa: Carleton University, 2011) 
Gadamer, Hans-Georg. Truth and Method (Second Edition) Trans: Joel Weinsheimer and Donald G. Marshall (New York: Continuum, 1989).

Gadamer, Hans-Georg. Philosophical Hermeneutics (Berkley: Universtiy of California Press, 1976).

Garvey, Kyla. "As fire department looks to recruit women, sexist tweets suggest some firefighters may not be so welcoming," National Post, August 9, 2013. http://news.nationalpost.com/2013/08/09/as-fire-department-looks-to-recruitwomen-sexist-tweets-suggest-some-firefighters-may-not-be-so-welcoming/

Geddes, John. “Legion's president voices misgivings about day to honour Afghan vets," Maclean's Magazine, May 8, 2014.

http://www.macleans.ca/politics/ottawa/legions-president-complains-ofsecretive-planning-for-afghanistan-commemoration/

Golub, Eric. “9/11/11: Why Football Matters,” Washington Times Communities, September 8, 2011.

http://communities.washingtontimes.com/neighborhood/tygrrrrexpress/2011/sep/8/91111-why-football-matters/

Gough, Paul. "Invicta Pax," International Journal of Heritage Studies. Volume 8, Issue 3 (2002).

Government of Canada. “O Canada," Government of Canada Website. Last modified February 5, 2014

http://www.pch.gc.ca/eng/1359402373291/1359402467746\#a1.1

Government of Canada. "The Fight For Canada - War of 1812 Advertisement," YouTube Video, July 3, 2012. https://www.youtube.com/watch?v=s4i_qe9W6Dk.

Gruneau, Richard and David Whitson. Hockey Night in Canada: Sport, Identities and Cultural Politics. (Toronto, University of Toronto Press, 1992)

Harris, Jonathan. Federal Art and National Culture: The Politics of Identity in New Deal America (Cambridge: Cambridge University Press, 1995).

Hempstead, Doug. "Monument Dedicated to Fallen Firefighters," The Ottawa Sun September 9, 2011. http://www.ottawasun.com/2012/09/09/monumentdedicated-to-fallen-firefighter

Hodgins, Peter. "Why Must Halifax Keep Exploding?: English-Canadian Nationalism and the Search for a Usable Disaster", Settling and Unsettling Memories Edited by Nicole Neatby and Peter Hodgins (Toronto: University of Toronto Press, 2012). 
Holt, Douglas B. How Brands Become Icons: The Principles of Cultural Branding (Boston: Harvard Business School Press, 2004)

Hooper, Tristan. "Royal returns for Canadian Forces.” The National Post, August 15, 2011. http://news.nationalpost.com/2011/08/15/royal-returns-for-canadasarmed-forces/

Hucker, Jacqueline. "The Meaning and Significance of the Vimy Monument" Vimy Ridge: A Canadian Reassesment Editors: Hayes, Geoffrey, Andrew Jarocci, Mike Bechthold. (Waterloo, Wilfrid Laurier Press, 2007).

Ingino, Joe. "Vimy Ridge Public School Honoured as new \$20 moves into Circulation," The Oshawa/Durham Central, November 12, 2012. http://www.ocentral.ca/vimy-ridge-public-school-honoured-as-new-20-movesinto-circulation/

Kipling, Rudyard. "Recessional," The Kipling Society. Accessed March 21, 2014. http://www.kipling.org.uk/poems_recess.htm

Kirbyson, Geoff. "Jets Merchandise Scores Top Dollar in League Sales," The Winnipeg Free Press, September 7, 2011.

Kirbyson, Geoff. "Prime Minister falls in love with Jets jersey, signs up for waiting list," The Winnipeg Free Press, October 9, 2011.

http://www.winnipegfreepress.com/sports/hockey/jets/prime-minister-falls-inlove-with-jets-jersey-signs-up-for-waiting-list-129578393.html

Kives, Bartley. “I Salute you, Jets logo,” Winnipeg Free Press, July 31, 2011.

Klein, Naomi. No Logo (London: Flamingo Books, 2000).

Knight, Cher. Krause Public Art: Theory, Practice and Populism (Malden: Blackwell Publishing, 2008).

Lauzon, Claudette. "Monumental Interventions: Jeff Thomas Seizes Commemorative Space," Imagining Resistance: Visual Culture and Activism in Canada Editors: J. Keri Cronin and Kristy Robertson (Waterloo: Wilfred Laurier Press, 2011)

Lin, A.W. Smokey. "The Fire Fighters Prayer," Firefighters Memorial Accessed March 2, 2014. Website.http://www.firememorials.com/prayer.html 
MacGregor, Roy. "Harper unveils commemorative coin to mark return of Winnipeg Jets," The Globe and Mail, October 09, 2011.

http://www.theglobeandmail.com/sports/hockey/globe-on-hockey/harperunveils-commemorative-coin-to-mark-return-of-winnipegjets/article618138/\#dashboard/follows/

Madan, Richard. "Canadian's see Two Towers, Pornography in $\$ 20$ design," CTV News, May 6, 2012. http://www.ctvnews.ca/canadians-see-twin-towerspornography-in-20-bill-design-1.806190

Martin, Jean. "Vimy April 1917: The Birth of Which Nation," Canadian Military Journal Vol. 18, No.2 (2011). http://www.journal.forces.gc.ca/vo11/no2/06-martineng.asp\#_edn13

Matta, Linda. "Canadian Fallen Firefgihters Memorial Photo Gallery," PBase Galleries Website. Accessed February 10, 2014.

http://www.pbase.com/wakenphotography/image/145993483

McCrae, John. "In Flanders Fields," Canadian War Museum Web Site. Accessed May 7, 2014.

http://www.warmuseum.ca/cwm/exhibitions/remember/flandersfields_e.shtml

McCready, A.L. Yellow Ribbons: The Militarization of National Identity in Canada. (Halifax: Fenwood Publishing, 2013).

McKay, Ian. "Empire Strikes Back: Militarism, Imperial Nostalgia, and the RightWing Reconceptualization of Canada," Lecture at the New Frontiers Graduate Conference, March 15, 2011. http://activehistory.ca/2011/03/podcast-ian-mckayon-the-right-wing-reconceptualization-of-canada/

McKay, Ian and Jamie Swift. Warrior Nation: Rebranding Canada in an Age of Anxiety. (Toronto: Between The Lines Publishing, 2013).

Moslon Canadian Advertisement. "I Am Canadian: The Rant," YouTube Accessed February 20, 2014. http://www.youtube.com/watch?v=WMxGVfk09lU

Moir, Robin and Joseph Turner. "Never Again Song Lyrics", War Amps Website Accessed March 20, 2014. http://www.waramps.ca/uploadedFiles/English_Site/Military_Heritage/Media/P DF/resource_never_again.pdf

Mirtle, James. “Winnipeg Jets Unveil Logo," The Globe and Mail, July 22, 2001. http://www.theglobeandmail.com/sports/hockey/globe-on-hockey/winnipegjets-unveil-logo/article616579/ 
The National Post. "Bank of Canada unveils new $\$ 20$ Bill," The National Post, May 2, 2012. http://business.financialpost.com/2012/05/02/bank-of-canada-unveilsnew-20-bill/

Nimijean, Richard. "Articulating the 'Canadian Way': Canada(TM) and the Political Manipulation of the Canadian Identity." British Journal of Canadian Studies, 18.1 (2005): 26,52,206. ProQuest. Web. 27 Feb. 2014.

New York Magazine.“9/11 By The Numbers,” NY Magazine, September 2012. http://nymag.com/news/articles/wtc/1year/numbers.htm

Orwell, George. The Sporting Spirit. First published: Tribune. London December 1945. Accessed at - http://orwell.ru/library/articles/spirit/english/e_spirit

Our Sports Central. "Moose, Military honour the 1948 RCAF Flyers,” Our Sports Central, March 1st, 2008.

http://www.oursportscentral.com/services/releases/?id=3599440

Owen, Wilfred. "Dolce and Decorum Est," The War Poetry Website. Written 19171918. Accessed on September 12, 2014 -

http://www.warpoetry.co.uk/owen1.html

Park, Jungwee. "A Profile of The Canadian Forces," Statistics Canada, 2008. Last Modified May 14, 2014. http://www.statcan.gc.ca/pub/75-001-x/75-001x2008107-eng.htm

Prendergast, Chris. "Introduction" The Triangle of Representation (New York: Columbia University Press, 2000)

PLANT Architect. Canadian Firefighters Memorial, PLANT Architect Website. Accessed May 12, 2014. http://www.branchplant.com/landscape/cfm.html

Pearlman, Chaïm and Lucie Olbrechts-Tyteca. The New Rhetoric: A Treatise on Argumentation, Translated by: John Wilkinson and Purcell Weaver. (Notre Dame: University of Notre Dame Press, 1969).

Raj, Althia. "New Canadian Passports: Tories Pushed Design in a Historical Direction," The Huffington Post, October 10, 2012.

http://www.huffingtonpost.ca/2012/10/25/new-canadian-passportsepassports_n_2016055.html\#slide $=1690113$

Rennie, Steve. "Canadian military has final say on Jets logo," The Globe and Mail, November 19, 2011. http://www.theglobeandmail.com/sports/hockey/canadianmilitary-has-final-say-on-jets-logo/article4183945/\#dashboard/follows/ 
Richler, Noah. What We Talk About When We Talk About War. (Fredericton, Gooselane, 2012).

Roche, Kelly. "Fallen firefighters honoured at Ottawa memorial," Ottawa Sun, September 8, 2013. http://www.ottawasun.com/2013/09/08/fallen-firefightershonoured-at-ottawa-memorial

Rovell, Darren. "Northwestern to honor military," ESPN Chicago, November 6, 2013. http://espn.go.com/chicago/collegefootball/story/_/id/9925831/northwestern-wildcats-wear-red-white-blueuniforms

Royal Canadian Airforce. "The RCAF: 17 Wing Winnipeg," RCAF Website, February 13, 2014. http://www.rcaf-arc.forces.gc.ca/en/17-wing/index.page

Royal Canadian Legion. "Memorial Unveiled For Fallen Firefighters," Legion Magazine, November 24, 2012. http://legionmagazine.com/en/index.php/2012/11/memorial-unveiled-forfallen-firefighters/

Royal Canadian Legion, Royal Canadian Legion Ritual and Insignia Manual, Royal Canadina Legion Website. Accesed March 9, 2014. http://legion.ca/_PDF/Manuals/RitualandInsignia2011_e.pdf

Rose, Gillian. Visual Methodologies: An Introduction to the Interpretation of Visual Materials (London: Sage Publishing, 2001)

Rumberg, Howie. "God Bless America and Baseball 10 years later," Yahoo News, August 11, 2011. http://news.yahoo.com/god-bless-america-baseball-10-yearslater-043645293.html

Samson, John K. "The New Jets Logo, a Boardroom, and a Bargain," The Winnipeg Review, August 2, 2011. http://www.winnipegreview.com/wp/2011/08/the-newjets-logo-a-boardroom-and-a-bargain/

Saracino, Peter. "Rick Hillier," The Encyclopedia Britanica. Last modified October 22, 2013. http://www.britannica.com/EBchecked/topic/1490553/Rick-Hillier

Saunders, Doug. "Canada's military policy doesn't add up," The Globe and Mail March 1, 2014. http://www.theglobeandmail.com/globe-debate/canadas-militarypolicy-doesnt-add-up/article17160469/\#dashboard/follows/

Service Canada. "Job Futures Quebec: Firefighting," Service Canada. Last Modified September 3, 2013.

http://www.servicecanada.gc.ca/eng/qc/job_futures/statistics/6262.shtml 
Shakespeare, William. Julius Ceasar, Act 1, Scene 2: Line 141. (London: The Folger Library, 1958)

Stewart, Susan. On Longing: The Miniature, The Gigantic, The Souvenir and The Collection (Baltimore: John Hopkins University Press, 1984)

Taber, Jane. "Harper spins a new brand of patriotism," The Globe and Mail, August 19, 2011. http://www.theglobeandmail.com/news/politics/ottawanotebook/harper-spins-a-new-brand-ofpatriotism/article618385/\#dashboard/follows/

TSN. “TSN interviews Mark Chipman regarding new Jets logo: 07/23/11," Video on YouTube, accessed May 12, 2014. http://www.youtube.com/watch?v=y9Shh6cJIEw

The Vimy Foundation . "Vimy Ridge Public School Under Construction," Vimy Foundation Website. Accessed May 17, 2014. https://www.vimyfoundation.ca/gallery/5

The Vimy Foundation. “The Bank of Canada Launches New Vimy-Themed \$20 Bill,” Vimy Foundation. Accessed May 17, 2014.

https://www.vimyfoundation.ca/node/212

The Vimy Foundation. "The Vimy Pin," Vimy Foundation Website. Accessed May 17, 2014. https://www.vimyfoundation.ca/pin

The Vimy Foundation. "Mission,” The Vimy Foundation Website. Accessed May 17, 2014. https://www.vimyfoundation.ca/mission

The Vimy Foundation. "Dave Robinson Bio," The Vimy Foundation Website. Accessed May 17, 2014. https://www.vimyfoundation.ca/node/178

Walker, James. W. St. G. "Race and Recruitment I World War I: Enlistment of Visible Minorities in the Canadian Expeditionary Force", Canadian Historical Review. Volume 70, issue 1 (1989). p.1-26

War Amps of Canada. "Never Again!” War Amps Website Accessed March 20, 2014. http://www.waramps.ca/uploadedFiles/English_Site/Military_Heritage/Media/PDF /resource_never_again.pdf

Wheeler, Alina. Designing Brand Identity John Wiley and Sons. (Hoboken: New Jersey, 2006) 
The Winnipeg Jets. "Winnipeg Jets Brand Identity", Winnipeg Jets Website, 22 July, 2011. Shared Credits in slide show to: Reebok, True North Sports and Entertainment, The National Hockey League. http://jets.nhl.com/club/gallery.htm?id=23491

W.J.T. Mitchell. Art And The Public Sphere (Chicago: The University of Chicago Press, 1990). 